\title{
Technetium Removal Using Tc-Goethite Coprecipitation
}

W Um

G Wang

HB Jung

RA Peterson

November 2013

\section{Pacific Northwest} NATIONAL LABORATORY

Proudly Operated by Battelle Since 1965 



\title{
DISCLAIMER
}

This report was prepared as an account of work sponsored by an agency of the United States Government. Neither the United States Government nor any agency thereof, nor Battelle Memorial Institute, nor any of their employees, makes any warranty, express or implied, or assumes any legal liability or responsibility for the accuracy, completeness, or usefulness of any information, apparatus, product, or process disclosed, or represents that its use would not infringe privately owned rights. Reference herein to any specific commercial product, process, or service by trade name, trademark, manufacturer, or otherwise does not necessarily constitute or imply its endorsement, recommendation, or favoring by the United States Government or any agency thereof, or Battelle Memorial Institute. The views and opinions of authors expressed herein do not necessarily state or reflect those of the United States Government or any agency thereof.

\author{
PACIFIC NORTHWEST NATIONAL LABORATORY \\ operated by \\ BATTELLE \\ for the \\ UNITED STATES DEPARTMENT OF ENERGY \\ under Contract DE-AC05-76RL01830
}

Printed in the United States of America
Available to DOE and DOE contractors from the Office of Scientific and Technical Information, P.O. Box 62, Oak Ridge, TN 37831-0062; ph: (865) 576-8401 fax: $(865) 576-5728$
email: reports@adonis.osti.gov
Available to the public from the National Technical Information Service 5301 Shawnee Rd., Alexandria, VA 22312 ph: (800) 553-NTIS (6847) email: orders $a$ ntis.gov $<$ http://www.ntis.gov/about/form.aspx> Online ordering: http://www.ntis.gov



PNNL-22967

EMSP-RPT-017

\section{Technetium Removal Using Tc-Goethite Coprecipitation}

W Um

G Wang

HB Jung

RA Peterson

November 2013

Prepared for

the U.S. Department of Energy

under Contract DE-AC05-76RL01830

Pacific Northwest National Laboratory

Richland, Washington 99352 



\section{Executive Summary}

This report describes the results from laboratory tests performed at Pacific Northwest National Laboratory for the U.S. Department of Energy (DOE) EM-31 Support Program (EMSP) subtask, "Low temperature waste forms coupled with technetium removal using an alternative immobilization process such as Fe(II) treated-goethite precipitation" to increase our understanding of ${ }^{99} \mathrm{Tc}$ long-term stability in goethite mineral form and the process that controls the ${ }^{99} \mathrm{Tc}(\mathrm{VII})$ reduction and removal by the final Fe (oxy)hydroxide mineral forms.

The overall objectives of this task were to 1) evaluate the transformation process of $\mathrm{Fe}$ (oxy)hydroxide minerals to more crystalline goethite $(\alpha-\mathrm{FeOOH})$ mineral for ${ }^{99} \mathrm{Tc}$ removal and 2) determine a scientific mechanism for limiting ${ }^{99} \mathrm{Tc}(\mathrm{IV})$ reoxidation in $\mathrm{Fe}(\mathrm{II})$-treated ${ }^{99} \mathrm{Tc}$-goethite mineral and the long-term ${ }^{99} \mathrm{Tc}(\mathrm{IV})$ oxidation state change.

The results of mineral transformation tests using three synthesized $\mathrm{Fe}(\mathrm{oxy})$ hydroxide minerals [ferrihydrite, magnetite, and $\mathrm{Fe}(\mathrm{OH})_{2}(\mathrm{~s})$ ] showed that $\mathrm{Fe}(\mathrm{OH})_{2}(\mathrm{~s})$ transformed easily to a mixture of magnetite, maghemite, and goethite even at room temperature (RT) and circumneutral pH conditions. Even though the most transformation products were found at high $\mathrm{pH}(\sim 12)$ and temperature $\left(75-80^{\circ} \mathrm{C}\right)$ conditions, $\mathrm{Fe}(\mathrm{OH})_{2}(\mathrm{~s})$ can be used as an initial substrate for ${ }^{99} \mathrm{Tc}$ removal due to its high reactivity. Removal of ${ }^{99} \mathrm{Tc}$ from solution by $\mathrm{Fe}(\mathrm{OH})_{2}(\mathrm{~s})$ was fast and more than $95 \%$ of the initial ${ }^{99} \mathrm{Tc}\left(10^{-5} \mathrm{M}\right)$ was removed from solution containing $\mathrm{Fe}(\mathrm{OH})_{2}(\mathrm{~s})$, even without aqueous $\mathrm{Fe}(\mathrm{II})$ addition. Since $\mathrm{Fe}(\mathrm{OH})_{2}(\mathrm{~s})$ can be oxidized to form magnetite $\left(\mathrm{Fe}_{3} \mathrm{O}_{4}\right)$ by reacting with $\mathrm{H}_{2} \mathrm{O}$ even in anaerobic conditions, the presence of $\mathrm{Fe}(\mathrm{OH})_{2}$ (s) can provide aqueous $\mathrm{Fe}$ (II) to reduce ${ }^{99} \mathrm{Tc}(\mathrm{VII})$ to ${ }^{99} \mathrm{Tc}(\mathrm{IV})$. In addition, because the final $\mathrm{pH}$ of a slurry mixed with ${ }^{99} \mathrm{Tc}$ and $\mathrm{Fe}(\mathrm{OH})_{2}(\mathrm{~s})$ was fairly alkaline $(\mathrm{pH}=9-11.5),{ }^{99} \mathrm{Tc}$ removal was not considered to be from surface adsorption, but incorporation into transformed mineral product. Although a further analysis is essential to confirm ${ }^{99} \mathrm{Tc}$ speciation in the final transformed product from $\mathrm{Fe}(\mathrm{OH})_{2}(\mathrm{~s})$, mineral transformation from $\mathrm{Fe}(\mathrm{OH})_{2}(\mathrm{~s})$ can be used to effectively remove ${ }^{99} \mathrm{Tc}(\mathrm{VII})$ in alkaline $\mathrm{pH}$ conditions germane to off-gas scrubber secondary waste and low-activity waste streams. Slightly more transformation products were also found from $\mathrm{Fe}(\mathrm{OH})_{2}(\mathrm{~s})$ with a solution-to-solid ratio of 100 than with a ratio of 1000 . The transformation product from ferrihydrite was similar, and solely goethite mineral was produced in most of the conditions. It is clear that comparison results from both $\mathrm{Fe}(\mathrm{OH})_{2}(\mathrm{~s})$ and ferrihydrite substrates show that high slurry $\mathrm{pH}$ and high temperature conditions favor more goethite formation from the transformation reaction. Unfortunately, we could not conduct ${ }^{99} \mathrm{Tc}$ removal using ferrihydrite as an initial substrate in this task, but based on previous results (Um et al. 2010), ferrihydrite can also be used to remove ${ }^{99} \mathrm{Tc}$ with additional aqueous Fe(II). Transformation product from magnetite was very limited and there were only small amounts of maghemite and goethite formed from magnetite reacted as initial substrate under high $\mathrm{pH}$ and temperature conditions. In addition, negligible ${ }^{99} \mathrm{Tc}$ removal $(<5 \%)$ from solution was also found in magnetite slurry without aqueous Fe(II) addition.

Even after long-term leaching in the Integrated Disposal Facility (IDF) pore water solution for two years, very limited amounts of ${ }^{99} \mathrm{Tc}$ and $\mathrm{Fe}$ (total) were detected in the IDF leachates. The limited

${ }^{99} \mathrm{Tc}$ release was attributed to more stabilized ${ }^{99} \mathrm{Tc}(\mathrm{IV})$ present in ${ }^{99} \mathrm{Tc}$-goethite lattice even after long-term exposure to oxygen, while zero detected Fe(total) concentration in the IDF leachate indicated that the 
structure of the final goethite mineral was stable in a circumneutral $\mathrm{pH}$ condition similar to the IDF pore water. Reduced ${ }^{99} \mathrm{Tc}(\mathrm{IV})$ incorporated in the goethite was unlikely to be reoxidized to ${ }^{99} \mathrm{Tc}(\mathrm{VII})$, even when the final ${ }^{99} \mathrm{Tc}$-goethite product (sample 2-5) was exposed to oxidizing conditions for three years (two years in IDF solution plus one year in air). In addition, the measured reductive capacity of both ${ }^{99}$ Tc-goethite 2-2 sample (prepared without additional armoring process) and 2-5 sample (with additional $\mathrm{Fe}(\mathrm{III})$ armoring) before leaching showed that a higher reductive capacity of $0.744 \mathrm{meq} / \mathrm{g}$ was found in ${ }^{99}$ Tc-goethite 2-2 sample, which was not prepared with an additional armoring process, while a lower reductive capacity of $0.140 \mathrm{meq} / \mathrm{g}$ was found in the ${ }^{99} \mathrm{Tc}$-goethite $2-5$ sample, which was prepared with the additional armoring process. However, more ${ }^{99} \mathrm{Tc}$ leaching was found in sample 2-2 than sample 2-5, which also indicates that a higher chemical reducing factor (e.g., higher reductive capacity in sample 2-2) is not the main controlling process in ${ }^{99} \mathrm{Tc}$ reoxidation and release. The limited reoxidation and release of ${ }^{99} \mathrm{Tc}$ is attributed to ${ }^{99} \mathrm{Tc}(\mathrm{IV})$ coprecipitated within goethite lattices and subsequently armored with additional goethite layers as well as to the chemical and structural stability of goethite in the circumneutral Hanford pore water solution.

Since mineral transformation from $\mathrm{Fe}(\mathrm{OH})_{2}(\mathrm{~s})$ to a more stable $\mathrm{Fe}$ (oxy)hydroxide mineral such as goethite can be used to remove ${ }^{99} \mathrm{Tc}$ from alkaline waste streams, ${ }^{99} \mathrm{Tc}$ reduction and incorporation into a goethite mineral lattice is an effective solidifying method for long-term ${ }^{99} \mathrm{Tc}$ sequestration even after exposure to oxygen, suggesting potential use of goethite as a low-temperature Fe oxide solid waste form.

Although additional analysis of ${ }^{99} \mathrm{Tc}$ speciation in the final transformed product and more detailed $\mathrm{Fe}(\mathrm{II})$ analysis to identify the pathway of transformation are still required to confirm ${ }^{99} \mathrm{Tc}$ incorporation within the mineral structure of the transformed product from $\mathrm{Fe}(\mathrm{OH}) 2(\mathrm{~s})$, the results of this testing are expected to provide more credible indication of the possibility of goethite precipitation as an alternative immobilization process for ${ }^{99} \mathrm{Tc}$ removal from alkaline Hanford waste streams. 


\section{Acknowledgments}

The authors are grateful to U.S. Department of Energy (DOE) Headquarters for DOE EM-21 Office of Tank Waste funding and the DOE Office of River Protection. We also acknowledge Steven Baum, Keith Geiszler, Cristian Iovin, Igor Kutnyakov, and Dennese Smith in the Geosciences group and Environmental Science Laboratory at Pacific Northwest National Laboratory (PNNL) for their analytical and laboratory support. Special thanks to Ravi K. Kukkadapu for Mössbauer spectroscopy analysis and Jeff Serne for the technical reviews. The technetium $x$-ray absorption fine structure data collection and analysis performed by Wayne Lukens at Lawrence Berkeley National Laboratory are greatly appreciated. We would like to acknowledge Maura Zimmerschied and Kathy Neiderhiser for editing and formatting this report, respectively. PNNL is a multi-program national laboratory operated by Battelle for DOE. 



\section{Acronyms and Abbreviations}

DI

DOE

EDS

EMSP

EQL

FESEM

HAW

ICP-MS

ICP-OES

IDF

LAW

RT

PNNL

SEM

WTP

XAFS

XANES

XRD deionized

U.S. Department of Energy

energy dispersive $\mathrm{x}$-ray spectroscopy

DOE EM-21 Support Program

estimated quantitation limit

field emission scanning electron microscopy

high-activity waste

inductively coupled plasma mass spectroscopy

inductively coupled plasma optical emission spectroscopy

Integrated Disposal Facility

low-activity waste

room temperature

Pacific Northwest National Laboratory

scanning electron microscopy

Hanford Tank Waste Treatment and Immobilization Plant

$\mathrm{x}$-ray absorption fine structure

$\mathrm{x}$-ray absorption near-edge structure

$\mathrm{x}$-ray diffraction 



\section{Units of Measure}

$\begin{array}{ll}\theta & \text { angle of incidence }(\text { Bragg angle) } \\ \AA & \text { Angstrom }\left(10^{-10} \mathrm{~m} \text { or } 10^{-1} \mathrm{~nm}\right) \\ { }^{\circ} \mathrm{C} & \text { temperature in degrees Celsius }\left[\mathrm{T}\left({ }^{\circ} \mathrm{C}\right)=\mathrm{T}(\mathrm{K})-273.15\right] \\ \mathrm{eV} & \text { electron volt(s) } \\ \mathrm{g} & \text { gram(s) } \\ \mathrm{Hz} & \text { hertz } \\ \mathrm{keV} & \text { kiloelectron volt(s) } \\ \mathrm{kV} & \text { kilovolt(s) } \\ \mathrm{kW} & \text { kilowatt(s) } \\ \mu & \left.\text { micro (prefix, } 10^{-6}\right) \\ \mu \mathrm{m} & \text { micrometer(s) } \\ \mathrm{L} & \text { liter(s) } \\ \mathrm{M} & \text { molarity, mol/L } \\ \mathrm{mA} & \text { milliampere(s) } \\ \mathrm{mCi} & \text { millicurie(s) } \\ \mathrm{meq} & \text { milliequivalent(s) } \\ \mathrm{mL} & \text { milliliter(s) } \\ \mathrm{mm} & \text { millimeter(s) } \\ \mathrm{mM} & \text { millimole(s) } \\ \mathrm{ppm} & \text { parts per million }\end{array}$





\section{Contents}

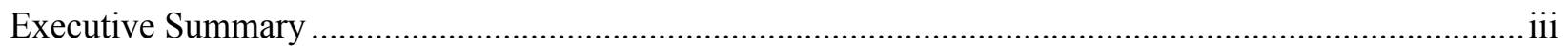

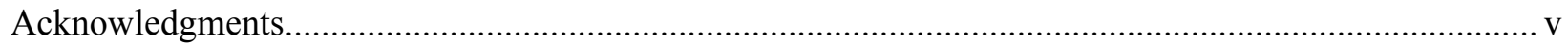

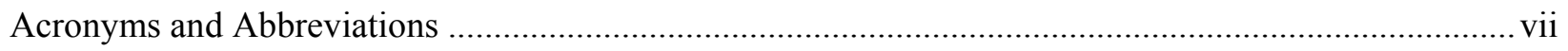

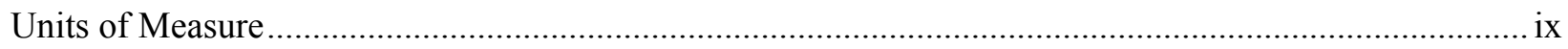

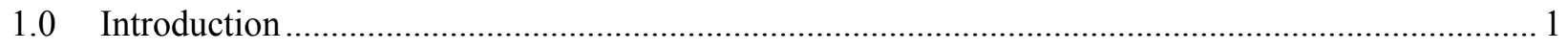

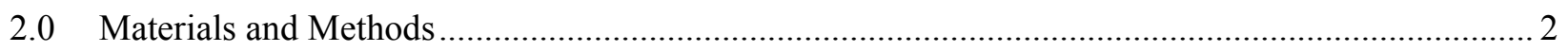

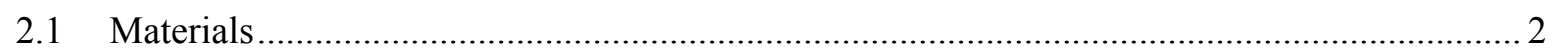

2.1.1 Synthesis of Fe (Oxy)hydroxide Minerals ............................................................ 2

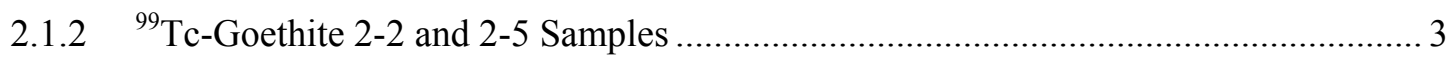

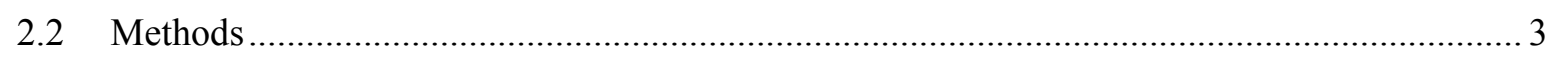

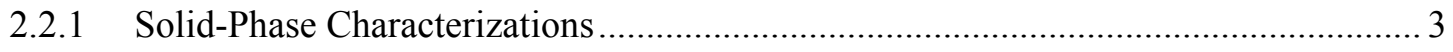

2.2.2 Mineral Transformation Effects on ${ }^{99} \mathrm{Tc}$ Removal .................................................... 4

2.2.3 Reductive Capacity Measurement ..................................................................... 7

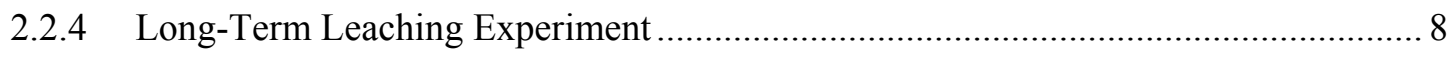

2.2.5 X-Ray Absorption Fine Structure Spectroscopy …............................................. 8

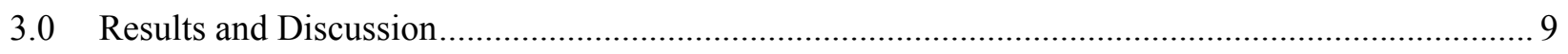

3.1 Synthesis of Fe (Oxy)hydroxide Substrates ................................................................. 9

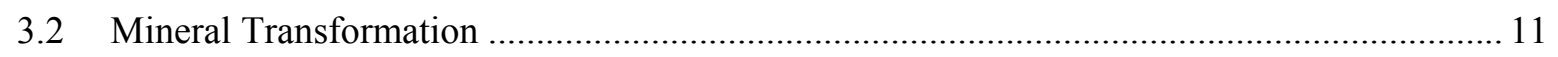

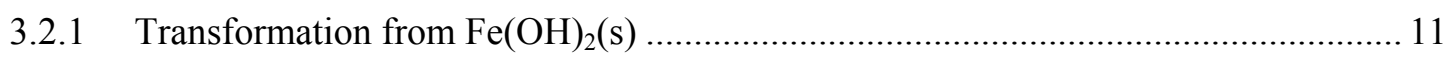

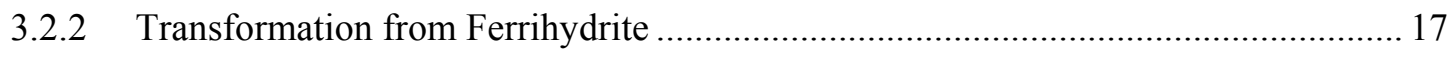

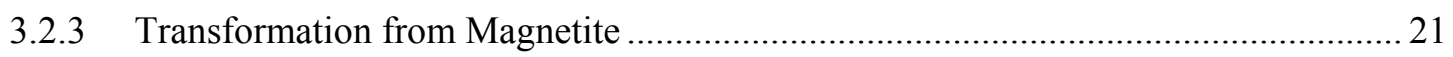

3.3 Tc Removal by Fe Oxy (hydroxide) Mineral Transformation ............................................ 23

3.3.1 Tc Removal by Fe( $\mathrm{OH})_{2}$ (s) Transformation....................................................... 23

3.3.2 Tc Removal by Magnetite Transformation .......................................................... 27

3.4 Tc-Goethite Long-Term Leaching and XAFS Analysis................................................. 29

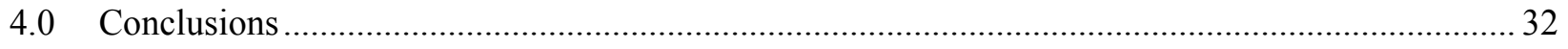

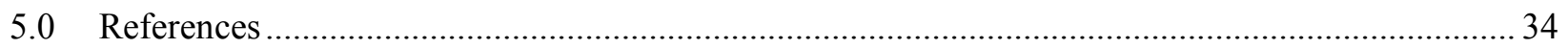




\section{Figures}

1. Centrifuge Tube Reactors Used for Mineral Transformation Tests and Tc Removal .......................6

2. XRD Patterns of Synthesized 2-line Ferrihydrite, Goethite, Magnetite, and $\mathrm{Fe}(\mathrm{OH})_{2}(\mathrm{~s})$................. 9

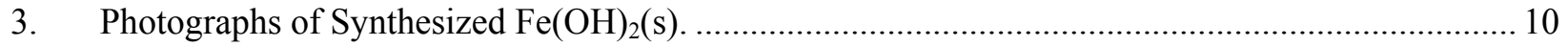

4. SEM Images and Morphology of Synthesized Ferrihydrite, Goethite, Magnetite, and

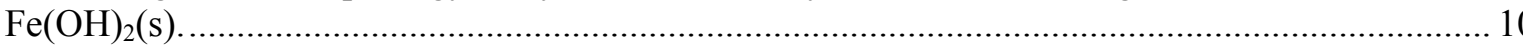

5. Mössbauer Spectra of the Fresh $\mathrm{Fe}(\mathrm{OH})_{2}(\mathrm{~s})$, Transformed $\mathrm{Fe}(\mathrm{OH})_{2}(\mathrm{~s})$ Minerals Product after $\mathrm{Fe}(\mathrm{OH})_{2}$ (s) Reacted at $\mathrm{pH} 12$ and $80^{\circ} \mathrm{C}$, and the Former $\mathrm{Fe}(\mathrm{OH})_{2}$ (s) Oxidized due to Oxygen Contact

6. XRD Pattern of Maghemite/Magnetite and Goethite Mixture Transformed from $\mathrm{Fe}(\mathrm{OH})_{2}(\mathrm{~s})$ Reacted Under $\mathrm{pH} 7$ and $\mathrm{pH} 12$ at $80^{\circ} \mathrm{C}$ with a Solution-to-Solid Ratio of 1000 for 30 Days

7. XRD Pattern of Maghemite/Magnetite and Goethite Mixture Transformed from $\mathrm{Fe}(\mathrm{OH})_{2}(\mathrm{~s})$

Reacted at $\mathrm{pH} 7$ and $\mathrm{pH} 12$ at $21^{\circ} \mathrm{C}$ with a Solution-to-Solid Ratio of 1000 for 30 Days .....

8. XRD Patterns of Transformed $\mathrm{Fe}(\mathrm{OH})_{2}(\mathrm{~s})$ Product Reacted at $\mathrm{pH} 7$ and $\mathrm{pH} 12$ at $21^{\circ} \mathrm{C}$ with Different Solution-to-Solid Ratios of 1000 or 100 for 30 Days.

9. Comparison of Mineral Transformation Products from $\mathrm{Fe}(\mathrm{OH})_{2}(\mathrm{~s})$ to Goethite and Maghemite/Magnetite Using Goethite and Maghemite/Magnetite "Fingerprint XRD Peak" Under Different Slurry pHs, Temperatures, and Reaction Days

10. XRD Patterns of Goethite Transformed from Ferrihydrite under $\mathrm{pH} 7$ and $\mathrm{pH} 12$ at $80^{\circ} \mathrm{C}$ with a Solution-to-Solid Ratio of 1000 After Reacting for 30 Days

11. XRD Patterns of Goethite Transformed from Ferrihydrite at $\mathrm{pH} 7$ and $\mathrm{pH} 12$ at $\mathrm{RT}\left(21^{\circ} \mathrm{C}\right)$ with a Solution-to-Solid Ratio of 1000 After Reacting for 30 Days

12. XRD Patterns of Goethite Transformed from Ferrihydrite at $\mathrm{pH} 7$ and $80^{\circ} \mathrm{C}$ and at $\mathrm{pH} 12$ and RT $\left(21^{\circ} \mathrm{C}\right)$ with a Solution-to-Solid Ratio of 100 After Reacting for Three Days

13. Comparison of Mineral Transformation Products from Ferrihydrite to Goethite Using Goethite "Fingerprint XRD Peak" Among Different Slurry pHs, Temperatures, and Reaction Days

14. XRD Patterns of Goethite Transformed from Ferrihydrite Under Different pHs (7 and 12), and $\mathrm{RT}$ and $80^{\circ} \mathrm{C}$ Conditions after Reacting for 30 Days .....

15. XRD Patterns of Transformed Magnetite at $\mathrm{pH} 7$ and $80^{\circ} \mathrm{C}$ Conditions with a Solution-to-Solid Ratio of 1000 after Reacting for Three Days.

16. XRD Patterns of Transformed Magnetite at $\mathrm{pH} 12$ and $80^{\circ} \mathrm{C}$ Conditions with a Solution-to-Solid Ratio of 1000 after Reacting for 30 Days.

17. Comparisons of the Final ${ }^{99} \mathrm{Tc}$ Concentrations Between the Control Solution and the Solutions in the Reactors After Seven Days Reacting at Both Room $\left(21^{\circ} \mathrm{C}\right)$ and High $\left(75^{\circ} \mathrm{C}\right)$ Temperatures with Various Ferrous Iron Concentrations Added in the System

18. The Remaining ${ }^{99} \mathrm{Tc}$ Concentration (in percentage) in the $\mathrm{Fe}(\mathrm{OH})_{2}(\mathrm{~s})$ Reactors after Reacting for Seven Days at Both Room $\left(21^{\circ} \mathrm{C}\right)$ and $75^{\circ} \mathrm{C}$ Temperatures with Different Ferrous Iron Concentrations Added in the System

19. Comparisons of the Final ${ }^{99} \mathrm{Tc}$ Concentrations Between the Control Solution and the Solutions in the Reactors After Seven Days Reacting at Both Room $\left(21^{\circ} \mathrm{C}\right)$ and High $\left(75^{\circ} \mathrm{C}\right)$ Temperatures with Various ${ }^{99} \mathrm{Tc}$-spiked Concentrations in the System 
20. The Remaining ${ }^{99} \mathrm{Tc}$ Aqueous Concentration (\%) in the $\mathrm{Fe}(\mathrm{OH})_{2}(\mathrm{~s})$ Reactors after Reacting for Seven Days at Both Room $\left(21^{\circ} \mathrm{C}\right)$ and $75^{\circ} \mathrm{C}$ Temperatures with Different ${ }^{99} \mathrm{Tc}$-spiked Concentrations of $10^{-5}, 10^{-4}$, and $10^{-3} \mathrm{M}$ in the System

21. Removed ${ }^{99} \mathrm{Tc}$ Mass Normalized by the Initial $\mathrm{Fe}(\mathrm{OH})_{2}(\mathrm{~s})$ Mass versus the Initial ${ }^{99} \mathrm{Tc}$ Aqueous Concentrations

22. Comparisons of ${ }^{99} \mathrm{Tc}$ Removal Between the Control Solutions and the Solutions in the Reactors after Reacting for 14 Days and 42 Days at Both RT $\left(21^{\circ} \mathrm{C}\right)$ and $75^{\circ} \mathrm{C}$ with Varied ${ }^{99}$ Tc Concentrations.

23. The Remaining Tc Mass (in percentage) in the Magnetite Reactors after Reacting for 14 and 42 Days at Both RT $\left(21^{\circ} \mathrm{C}\right)$ and $75^{\circ} \mathrm{C}$ with Varied Spiked Tc Mass in the System.

24. Normalized ${ }^{99}$ Tc XANES Spectra and Fits for ${ }^{99}$ Tc-Goethite 2-5 Samples Reacted Under Different Conditions.

\section{Tables}

1. Experimental Setup for ${ }^{99} \mathrm{Tc}$ Removal Through Mineral Transformation ....................................... 5

2. Measured $\mathrm{pH}$ and Concentrations of ${ }^{99} \mathrm{Tc}$ and Fe(total) of Tc-Goethite Sample 2-5 After Long-Term Leaching in IDF Solution 30

3. XANES Fit Results for ${ }^{99} \mathrm{Tc}$ Species in ${ }^{99} \mathrm{Tc}-$ Goethite 2-5 Samples 



\subsection{Introduction}

About $1900 \mathrm{~kg}$ of ${ }^{99} \mathrm{Tc}$ has been produced as fission product of ${ }^{239} \mathrm{Pu}$ at the U.S. Department of Energy's (DOE's) Hanford Site in southeastern Washington State (Darab and Smith 1996) during the Cold War era and most of the radioactive ${ }^{99}$ Tc waste is presently stored in 177 underground Hanford storage tanks. Even with careful engineering controls, volatilization of a fraction of the ${ }^{99} \mathrm{Tc}$ during vitrification of both the high-activity waste (HAW) and low-activity waste (LAW) streams is expected. Because of the extremely complex chemical behavior of technetium, novel methods for controlling it in vitrification systems are critical to the safe and cost-effective treatment of ${ }^{99} \mathrm{Tc}$-containing nuclear waste. In the high temperatures $\left(\sim 1000-1200^{\circ} \mathrm{C}\right)$ of the melters used in vitrification, a significant fraction of the ${ }^{99} \mathrm{Tc}$ volatilizes and is collected in an off-gas scrubber system. Although scrubber solutions can be recycled back to the melters, some or most of this captured ${ }^{99} \mathrm{Tc}$ ultimately can leave the vitrification facilities at the Hanford Tank Waste Treatment and Immobilization Plant (WTP) as a secondary waste stream, which requires additional treatment and immobilization processes in a low-temperature environment. Risk assessments indicate that ${ }^{99} \mathrm{Tc}$ is a significant contributor to the environmental impact from the disposal of secondary wastes in low-activity disposal facilities like the Integrated Disposal Facility (IDF) at Hanford, because of the long half-life and high mobility of ${ }^{99} \mathrm{Tc}$ in oxidizing subsurface environments (Bondietti and Francis 1979). Under reducing conditions, ${ }^{99} \mathrm{Tc}$ can precipitate as ${ }^{99} \mathrm{Tc}(\mathrm{IV}) \mathrm{O}_{2} \cdot 2 \mathrm{H}_{2} \mathrm{O}$ (Lee and Bondietti 1983; Lukens et al. 2002), sorb to mineral phases (Bondietti and Francis 1979) more strongly, and be retained in various natural environments (Keith-Roach et al. 2003; Fredrickson et al. 2004; Burke et al. 2006) and engineered waste forms (Gilliam et al. 1990; Lukens et al. 2005). However, the reoxidation of ${ }^{99} \mathrm{Tc}(\mathrm{IV})$ by changing background to oxic conditions, such as contact with atmospheric oxygen and infiltrating fresh pore water solution, can result in an enhanced release of ${ }^{99} \mathrm{Tc}$ into the environment right after reoxidation of ${ }^{99} \mathrm{Tc}$ (IV) to ${ }^{99} \mathrm{Tc}(\mathrm{VII})$ (Burke et al. 2006), leading to the prediction of high ${ }^{99} \mathrm{Tc}$ release risk in many performance assessments (Smith and Walton 1993; Lukens et al. 2005). There are, therefore, incentives to decrease the impacts of ${ }^{99} \mathrm{Tc}$ both within the low-temperature waste form and at the waste disposal facility with a sustaining reduction environment.

Goethite, an iron-bearing oxyhydroxide mineral found in nature, could be a key to stabilize ${ }^{99} \mathrm{Tc}$. Through a coprecipitation process with respect to goethite, this mineral has proven effective in capturing and sequestering ${ }^{99} \mathrm{Tc}$ from simulated off-gas scrubber solutions (Um et al. 2010). Tests have shown that over 90 percent of ${ }^{99} \mathrm{Tc}$ in highly alkaline waste streams was captured into the goethite mineral structure as reduced ${ }^{99} \mathrm{Tc}(\mathrm{IV})$ species. Most of the ${ }^{99} \mathrm{Tc}$ sequestering agents studied to date remove pertechnetate ${ }^{99} \mathrm{Tc}(\mathrm{VII}) \mathrm{O}_{4}^{-}$, the stable technetium oxidation state under oxidizing conditions, from the waste stream using redox processes where pertechnetate is ultimately reduced to ${ }^{99} \mathrm{Tc}(\mathrm{IV})$ prior to being immobilized in a solid matrix. Because ${ }^{99} \mathrm{Tc}(\mathrm{IV})$ and $\mathrm{Fe}^{3+}$ have similar ionic radii, ${ }^{99} \mathrm{Tc}(\mathrm{IV})$ tends to have a full compatibility with the goethite and hematite lattice (Um et al. 2011; Geckeis et al. 2012) and quantum chemistry calculations predict energetically more favorable incorporation of ${ }^{99} \mathrm{Tc}(\mathrm{IV})$ in the hematite lattice than ${ }^{99} \mathrm{Tc}(\mathrm{VII})$ (Skomurski et al. 2010). However, upon contact with $\mathrm{O}_{2}$, reduced ${ }^{99} \mathrm{Tc}(\mathrm{IV})$ species generally reoxidizes rapidly, and reoxidation leads to formation of the soluble ${ }^{99} \mathrm{Tc}$ (VII) oxyanion (Lukens et al. 2005) in cementitious waste form. Thus, both the stability of the waste form material and its ability to prevent reoxidation of ${ }^{99} \mathrm{Tc}(\mathrm{IV})$ to ${ }^{99} \mathrm{Tc}(\mathrm{VII})$ to limit the ${ }^{99} \mathrm{Tc}$ leachability are key to the success of any proposed immobilization strategy for waste form development. While many of the proposed disposal options rely on isolating ${ }^{99} \mathrm{Tc}(\mathrm{IV})$ from oxidizing components in gas or aqueous fluid, 
the reductive capacity of the material hosting ${ }^{99} \mathrm{Tc}(\mathrm{IV})$ and the mechanism preventing the reoxidation of ${ }^{99} \mathrm{Tc}(\mathrm{IV})$ that affect ${ }^{99} \mathrm{Tc}$ remobilization from the waste forms have not been clearly demonstrated.

Pacific Northwest National Laboratory (PNNL) has conducted the laboratory testing for the DOE EM-21 Support Program (EMSP) subtask, "Low temperature waste forms coupled with technetium removal using an alternative immobilization process such as Fe(II) treated-goethite precipitation." Recent tests have shown that ${ }^{99} \mathrm{Tc}$ can be removed from caustic off-gas scrubber simulants by a process that reduces pertechnetate, ${ }^{99} \mathrm{Tc}$ (VII) to ${ }^{99} \mathrm{Tc}(\mathrm{IV})$, which then coprecipitates with the goethite-dominant iron (oxy)hydroxide mineral phase (Um et al. 2010). The final product also exhibits very slow weathering and low ${ }^{99} \mathrm{Tc}$ leachability rates in subsurface environment conditions (Um et al. 2011, 2012). Despite the positive results for ${ }^{99} \mathrm{Tc}$ removal and long-term sequestration in a solidifying goethite waste form, more fundamental understanding of the processes that control the ${ }^{99} \mathrm{Tc}(\mathrm{VII})$ reduction and the location of ${ }^{99} \mathrm{Tc}(\mathrm{IV})$ in the final $\mathrm{Fe}$ (oxy)hydroxide mineral lattice is needed. In addition, the long-term stability and the mechanism of reoxidation of ${ }^{99} \mathrm{Tc}(\mathrm{IV})$ in the final $\mathrm{Fe}$ (oxy)hydroxide mineral lattice needs to be determined so that this ${ }^{99} \mathrm{Tc}$ sequestration process will be sustained for the thousands of years required in shallow land burial environments such as the Hanford IDF.

The goal for this task in FY 2013 was to obtain additional fundamental understanding of the ${ }^{99} \mathrm{Tc}$-goethite coprecipitation process. The data and results generated by the laboratory tests described in this report provide both empirical and more fundamental scientific information to increase our understanding of the ${ }^{99} \mathrm{Tc}$ removal process in $\mathrm{Fe}$ (oxy) hydroxide products. In addition, the new understanding will aid development of a large-scale process design to sequester ${ }^{99} \mathrm{Tc}$ in various waste streams at the Hanford Site. The overall objectives of this task were to

- Evaluate the Fe (oxy)hydroxide solids' transformation process to goethite for ${ }^{99} \mathrm{Tc}$ removal

- Determine the long-term ${ }^{99} \mathrm{Tc}$ oxidation state change and determine a scientific mechanism for limiting ${ }^{99} \mathrm{Tc}$ reoxidation in a final ${ }^{99} \mathrm{Tc}$-goethite product.

It is expected that the results of this task will provide a more credible basis for the goethite precipitation process as an alternative immobilization process for ${ }^{99} \mathrm{Tc}$ removal from WTP secondary waste and LAW streams.

\subsection{Materials and Methods}

\subsection{Materials}

\subsubsection{Synthesis of Fe (Oxy)hydroxide Minerals}

Three different $\mathrm{Fe}$ (oxy) hydroxide minerals, $\mathrm{Fe}(\mathrm{OH})_{2}(\mathrm{~s})$, ferrihydrite $\left[\mathrm{Fe}(\mathrm{OH})_{3}\right]$, and magnetite $\left[\mathrm{Fe}_{3} \mathrm{O}_{4}\right]$, were synthesized as initial $\mathrm{Fe}$ (oxy)hydroxide substrate and used for testing to formulate ${ }^{99} \mathrm{Tc}(\mathrm{IV})$-goethite final solid product under different reaction conditions. All three minerals were synthesized in the laboratory using well-known recipes (Schwertmann and Cornell 1991). In brief, $\mathrm{Fe}(\mathrm{OH})_{2}(\mathrm{~s})$ was prepared using $0.07 \mathrm{M}$ of $\mathrm{FeCl}_{2} \bullet 4 \mathrm{H}_{2} \mathrm{O}$ with a $\mathrm{pH}$ increasing to near 7.5 using $\mathrm{NaOH}$ solution (1 M) inside an anaerobic chamber (Coy Laboratory Products) equipped with a $\mathrm{H}_{2} / \mathrm{O}_{2}$ gas analyzer and palladium-coated alumina catalyst. A mixture of $\mathrm{N}_{2}(97 \%)$ and $\mathrm{H}_{2}(3 \%)$ was used as the 
anaerobic gas in the chamber. Because $\mathrm{Fe}(\mathrm{OH})_{2}(\mathrm{~s})$ is very unstable, the entire process was conducted inside the anaerobic chamber and the final powder sample after filtration and drying was also stored inside the anaerobic chamber before any analysis and use. Two-line ferrihydrite was synthesized using dissolved ferric nitrate $\left[8.0 \mathrm{~g}\right.$ of $\left.\mathrm{Fe}\left(\mathrm{NO}_{3}\right)_{3} \cdot 9 \mathrm{H}_{2} \mathrm{O}\right]$ in NANOpure ${ }^{\circledR}$ water $(100 \mathrm{~mL})$ in a polyethylene bottle $(250 \mathrm{~mL})$ with addition of $1 \mathrm{M} \mathrm{NaOH}$ dropwise while stirring the slurry, until a $\mathrm{pH}$ of 6 was obtained. To obtain a $\mathrm{pH}$ of 7 to 8 , additional low-concentration $\mathrm{NaOH}$ (i.e., $0.01 \mathrm{M}$ ) was added while continuously stirring. The final product was filtered from solution by vacuum filtration and dried in air before use. Magnetite synthesis was carried out using $80 \mathrm{~g}$ of $\mathrm{FeSO}_{4} \cdot 7 \mathrm{H}_{2} \mathrm{O}$ dissolved in $560 \mathrm{~mL}$ of previously $\mathrm{N}_{2}$-flushed deionized (DI) water inside the anaerobic chamber. After preparing $240 \mathrm{~mL}$ of an oxygen-free solution containing $6.64 \mathrm{~g} \mathrm{KNO}_{3}$ and $44.9 \mathrm{~g} \mathrm{KOH}$, this solution was mixed with $\mathrm{FeSO}_{4} \cdot 7 \mathrm{H}_{2} \mathrm{O}$ solution stepwise at $90^{\circ} \mathrm{C}$ for $30-60$ minutes. The black precipitates was filtered out, washed with DI water several times, and dried before use. All the synthesized Fe (oxy) hydroxide minerals were confirmed by $\mathrm{x}$-ray diffraction (XRD) analysis right after synthesis and before use.

\subsection{2 $\quad{ }^{99}$ TC-Goethite 2-2 and 2-5 Samples}

A previously well-developed method was used to prepare ${ }^{99} \mathrm{Tc}$-goethite samples designated 2-2 (prepared without additional armoring process) and 2-5 (with additional Fe(III) armoring) according to the method in Um et al. (2010, 2011). Between 2.75 and $3.5 \mathrm{~g}$ of synthesized goethite powder were resuspended in $250 \mathrm{~mL}$ of DI water in the anaerobic chamber to minimize the oxidation of the ferrous solution prior to its use. The $\mathrm{pH}$ was adjusted to $\mathrm{pH} \sim 2.0$ by adding nitric acid $\left(2 \mathrm{M} \mathrm{HNO}_{3}\right)$, and an aliquot of $\mathrm{FeCl}_{2} \bullet 4 \mathrm{H}_{2} \mathrm{O}(3.48 \mathrm{~g})$ solid was directly added to the goethite slurry as the Fe(II) source to make $0.07 \mathrm{M}$ of dissolved $\mathrm{Fe}(\mathrm{II})$ concentration, while the suspension was continuously mixed at low $\mathrm{pH}(\sim 2.0)$ in the anaerobic chamber. After one day of mixing, $0.25 \mathrm{~mL}$ of ${ }^{99} \mathrm{Tc}(\mathrm{VII})$ from a $\mathrm{NaTcO}_{4}$ solution $\left(2.2 \times 10^{-2} \mathrm{M}\right)$ was added to make a total $2.2 \times 10^{-5} \mathrm{M}$ of ${ }^{99} \mathrm{Tc}$ in the $\mathrm{Fe}(\mathrm{II})$-goethite slurry $(250 \mathrm{~mL})$. As soon as the ${ }^{99} \mathrm{Tc}(\mathrm{VII})$ was added, the bottle was immediately capped and mixed in a platform shaker for one to two days. After reaction, $2 \mathrm{M} \mathrm{NaOH}$ was added and the bottle was placed in an oven at $80^{\circ} \mathrm{C}$ for seven days to promote additional precipitation of a ${ }^{99} \mathrm{Tc}$-goethite solid. After seven days reaction, the final ${ }^{99}$ Tc-goethite solids were separated by filtration, washed using DI water, air dried, and used for additional analysis. In selected experiments, the ${ }^{99} \mathrm{Tc}$-goethite solids were further modified to armor the

${ }^{99} \mathrm{Tc}$-goethite solids with additional goethite precipitates using separately prepared $\mathrm{Fe}\left(\mathrm{NO}_{3}\right)_{3} \bullet 9 \mathrm{H}_{2} \mathrm{O}$ $(11.4 \mathrm{~g} / 100 \mathrm{~mL})$ and $2 \mathrm{M} \mathrm{NaOH}(150 \mathrm{~mL})$ solutions. These two solutions were added sequentially to the ${ }^{99} \mathrm{Tc}$-goethite slurry in a series of additional experiments. After one to two days of reaction with sodium hydroxide solution, the bottle containing the final slurry was placed inside an oven at $80^{\circ} \mathrm{C}$ for seven days. The final slurry was subsequently filtered and both the solution and solid samples were used for further analyses. Both the ${ }^{99}$ Tc-goethite 2-2 sample prepared without the additional armoring process and the ${ }^{99} \mathrm{Tc}$-goethite 2-5 sample with additional $\mathrm{Fe}$ (III) armoring performed were used for long-term ${ }^{99} \mathrm{Tc}$ oxidation state change in ${ }^{99} \mathrm{Tc}$-goethite solid sample and reductive capacity measurement.

\subsection{Methods}

\subsubsection{Solid-Phase Characterizations}

The morphology and crystallinity of three different synthesized iron oxides (or hydroxides) $\left[\left(\mathrm{Fe}(\mathrm{OH})_{2}(\mathrm{~s})\right.\right.$, ferrihydrite, and magnetite $]$ and their related final product (goethite) after mineral 
transformation reaction under different conditions were tested using a scanning electron microscope (SEM) and a powder [or capillary sample for $\left.\mathrm{Fe}(\mathrm{OH})_{2}\right)(\mathrm{s})$ ] X-ray diffractometer, respectively.

Characterizations of morphology and chemical composition were made by field emission scanning electron microscopy (FESEM) and energy dispersive x-ray spectroscopy (EDS) using a LEO982 FESEM system (JEOL, Peabody, Massachusetts) with an Oxford ISIS energy dispersive x-ray detector. The dried powder specimens were carefully mounted with double-sided carbon tape attached to an aluminum stud without either polishing or carbon-coating. X-ray diffractograms were collected using a Phillips X'Pert $\mathrm{x}$-ray diffractometer with a $\mathrm{Cu}-\mathrm{K} \alpha$ radiation $\mathrm{x}$-ray tube $(\lambda=1.5418 \AA)$ and a graphite monochromator. Normal operating power is $40 \mathrm{kV}$ and $50 \mathrm{~mA}(2.0 \mathrm{~kW})$. Data were collected from 10 to 80 degrees $2 \theta$ with a scanning step size of 0.05 degree and dwell time of 1.5 seconds. Additional micro-XRD using a Rigaku MicroMax diffractometer was used for $\mathrm{Fe}(\mathrm{OH})_{2}(\mathrm{~s})$ analysis. The $\mathrm{Fe}(\mathrm{OH})_{2}$ (s) powder was loaded into a glass capillary tube $(0.5 \mathrm{~mm}$ in diameter and $80 \mathrm{~mm}$ high $)$ and the top opening was sealed with grease. A rotating anode source at $875 \mathrm{~W}$ was used to generate $\mathrm{Cr} \mathrm{K} \alpha \mathrm{x}$-rays and the beam was collimated to $300 \mu \mathrm{m}$ in diameter for the sample. The diffraction patterns were recorded on a two-dimensional image plate detector by integrating between 10 and 150 degrees 2 theta. Mineral identification was conducted using JADE® software (Materials Data Inc., Livermore, California) with a database published by the Joint Committee on Powder Diffraction Standards (International Center for Diffraction Data, Newtown Square, Pennsylvania).

The initial synthesized $\mathrm{Fe}(\mathrm{OH})_{2}(\mathrm{~s})$ and its final mineral products after 30 days reaction at $\mathrm{pH} 12$ were characterized using Mössbauer spectroscopy. The Mössbauer sample was prepared by mixing a dried sample with Vaseline ${ }^{\circledR}$ in a $\mathrm{Cu}$ holder sealed at one end with Kapton tape. After mixing the sample in the holder, the open end of the holder was sealed with Kapton tape. Then both the ends of the sample holder were secured with rings made of carbonized polyethyletherketone (PEEK) to ensure tightness. All sample preparation was carried out in an anaerobic environmental chamber ( $<0 \mathrm{ppm}$ oxygen). The Mössbauer spectra were collected using a 50-mCi (initial strength) ${ }^{57} \mathrm{Co} / \mathrm{Rh}$ single-line thin source, and the velocity transducer, MVT-1000 (WissEL), was operated in a constant acceleration mode $(23 \mathrm{~Hz}) \mathrm{in}$ the velocity range of \pm 5 or $\pm 12 \mathrm{~mm} / \mathrm{s}$. An Ar-Kr proportional counter was used to detect the radiation transmitted through the holder, and the counts were stored in a multichannel scalar as a function of energy (transducer velocity) using a 1024-channel analyzer. Data were folded to 512 channels to give a flat background and a zero-velocity position corresponding to the center shift (CS) of a metal Fe foil at room temperature (RT). Calibration spectra were obtained with a $25-\mu$ m-thick metal Fe foil (Amersham, England) placed in the same position as the samples to minimize any errors due to changes in geometry. The Mössbauer data were modeled with Recoil software (University of Ottawa, Canada) using a Voigtbased structural fitting routine. The coefficient of variation of the spectral areas of the individual sites generally ranged between $1 \%$ and $2 \%$ of the fitted values.

\subsubsection{Mineral Transformation Effects on ${ }^{99} \mathrm{Tc}$ Removal}

Three sets of experiments were conducted to investigate the mineral transformation effects on ${ }^{99} \mathrm{Tc}$ removal in solution. First, screening tests of pure mineral transformations without ${ }^{99} \mathrm{Tc}$ spiking were designed to identify the suitable $\mathrm{Fe}$ (oxy)hydroxide mineral candidates as the substrates being used and to determine the optimal conditions for mineral transformation (temperature and $\mathrm{pH}$ ). Secondly, the tested minerals showing possible mineral transformation to goethite (or other crystalline Fe oxide or oxyhydroxide minerals) were tested spiked with a constant ${ }^{99} \mathrm{Tc}$ concentration $\left(10^{-5} \mathrm{M}\right)$ under conditions with or without ferrous $\mathrm{Fe}^{2+}$ ion addition because surface-sorbed $\mathrm{Fe}(\mathrm{II})$ is expected to behave as a catalyst 
and dramatically enhance the ${ }^{99} \mathrm{Tc}$ removal from solutions after reduction of ${ }^{99} \mathrm{Tc}(\mathrm{VII})$ to ${ }^{99} \mathrm{Tc}(\mathrm{IV})$. Finally, the mineral transformation was tested with varied spiked ${ }^{99} \mathrm{Tc}$ concentrations in slurry to investigate the maximum ${ }^{99} \mathrm{Tc}$ loadings that can be retained by the final product using the selected minerals and conditions. Table 1 lists the experimental matrix in this testing, and examples of the mineral transformation reactors (50-mL polyethylene centrifuge tubes) are shown in Figure 1.

Table 1. Experimental Setup for ${ }^{99}$ Tc Removal Through Mineral Transformation

\begin{tabular}{|c|c|c|c|c|c|c|}
\hline $\begin{array}{c}\text { Initial Mineral } \\
\text { Types }\end{array}$ & $\begin{array}{c}\begin{array}{c}\text { Solution to } \\
\text { Solid Ratio } \\
(\mathrm{mL} / \mathrm{g})\end{array} \\
\end{array}$ & $\begin{array}{c}\text { Temperature } \\
\left({ }^{\circ} \mathbf{C}\right) \\
\end{array}$ & Contact Times & $\begin{array}{c}\text { Final } \\
\text { pH }\end{array}$ & $\begin{array}{c}\mathrm{Fe}^{2+} \\
\text { Addition } \\
(\mathrm{M}) \\
\end{array}$ & $\begin{array}{c}{ }^{99} \mathrm{Tc} \\
\text { Spike } \\
(\mathrm{M}) \\
\end{array}$ \\
\hline \multirow{8}{*}{$\begin{array}{l}\mathrm{Fe}(\mathrm{OH})_{2}(\mathrm{~s}) \\
\text { Ferrihydrite, or } \\
\text { Magnetite }\end{array}$} & \multirow{4}{*}{100} & \multirow{2}{*}{$21^{\circ} \mathrm{C}$} & $3 \mathrm{~d}, 14 \mathrm{~d}, 30 \mathrm{~d}$ & $\sim 7$ & 0 & No \\
\hline & & & $3 \mathrm{~d}, 14 \mathrm{~d}, 30 \mathrm{~d}$ & $\sim 12$ & 0 & No \\
\hline & & \multirow[b]{2}{*}{$80^{\circ} \mathrm{C}$} & $3 \mathrm{~d}, 14 \mathrm{~d}, 30 \mathrm{~d}$ & $\sim 7$ & 0 & No \\
\hline & & & $3 \mathrm{~d}, 14 \mathrm{~d}, 30 \mathrm{~d}$ & $\sim 12$ & 0 & No \\
\hline & \multirow{4}{*}{1,000} & \multirow{2}{*}{$21^{\circ} \mathrm{C}$} & $3 \mathrm{~d}, 14 \mathrm{~d}, 30 \mathrm{~d}$ & $\sim 7$ & 0 & No \\
\hline & & & $3 \mathrm{~d}, 14 \mathrm{~d}, 30 \mathrm{~d}$ & $\sim 12$ & 0 & No \\
\hline & & \multirow{2}{*}{$80^{\circ} \mathrm{C}$} & $3 \mathrm{~d}, 14 \mathrm{~d}, 30 \mathrm{~d}$ & $\sim 7$ & 0 & No \\
\hline & & & $3 \mathrm{~d}, 14 \mathrm{~d}, 30 \mathrm{~d}$ & $\sim 12$ & 0 & No \\
\hline \multirow{11}{*}{$\mathrm{Fe}(\mathrm{OH})_{2}(\mathrm{~s})$} & \multirow{11}{*}{1,000} & \multirow{4}{*}{$21^{\circ} \mathrm{C}$} & \multirow{4}{*}{$7 d$} & \multirow{4}{*}{$\sim 12$} & 0 & \multirow{4}{*}{$1 \mathrm{E}-05$} \\
\hline & & & & & 7E-06 & \\
\hline & & & & & $2 \mathrm{E}-05$ & \\
\hline & & & & & $\begin{array}{c}2 \mathrm{E}-04 \\
0\end{array}$ & \\
\hline & & \multirow{3}{*}{$75^{\circ} \mathrm{C}$} & \multirow{3}{*}{$7 d$} & \multirow{3}{*}{$\sim 12$} & 7E-06 & \multirow{3}{*}{$1 \mathrm{E}-05$} \\
\hline & & & & & $2 \mathrm{E}-05$ & \\
\hline & & & & & $2 \mathrm{E}-04$ & \\
\hline & & \multirow{2}{*}{$21^{\circ} \mathrm{C}$} & \multirow[t]{2}{*}{$7 d$} & \multirow[t]{2}{*}{$\sim 12$} & 0 & $1 \mathrm{E}-04$ \\
\hline & & & & & 0 & $1 \mathrm{E}-03$ \\
\hline & & \multirow{2}{*}{$75^{\circ} \mathrm{C}$} & \multirow[t]{2}{*}{$7 d$} & \multirow[t]{2}{*}{$\sim 12$} & 0 & $1 \mathrm{E}-04$ \\
\hline & & & & & 0 & $1 \mathrm{E}-03$ \\
\hline \multirow{4}{*}{$\begin{array}{c}\text { Oxidized } \\
\mathrm{Fe}(\mathrm{OH})_{2}(\mathrm{~s}) \text { with } \\
\text { predominant } \\
\text { magnetite }^{(\mathrm{a})}\end{array}$} & \multirow{4}{*}{1,000} & \multirow{3}{*}{$21^{\circ} \mathrm{C}$} & \multirow{3}{*}{$14 \mathrm{~d}, 42 \mathrm{~d}$} & \multirow{3}{*}{$\sim 12$} & \multirow{3}{*}{0} & $1 \mathrm{E}-05$ \\
\hline & & & & & & $1 \mathrm{E}-04$ \\
\hline & & & & & & $1 \mathrm{E}-03$ \\
\hline & & $75^{\circ} \mathrm{C}$ & $14 \mathrm{~d}, 42 \mathrm{~d}$ & $\sim 12$ & 0 & $\begin{array}{l}1 \mathrm{E}-05 \\
1 \mathrm{E}-04\end{array}$ \\
\hline
\end{tabular}

(a) Initial $\mathrm{Fe}(\mathrm{OH})_{2}$ (s) that was oxidized by air contact showed predominantly magnetite mineral based on Mössbauer analysis. 

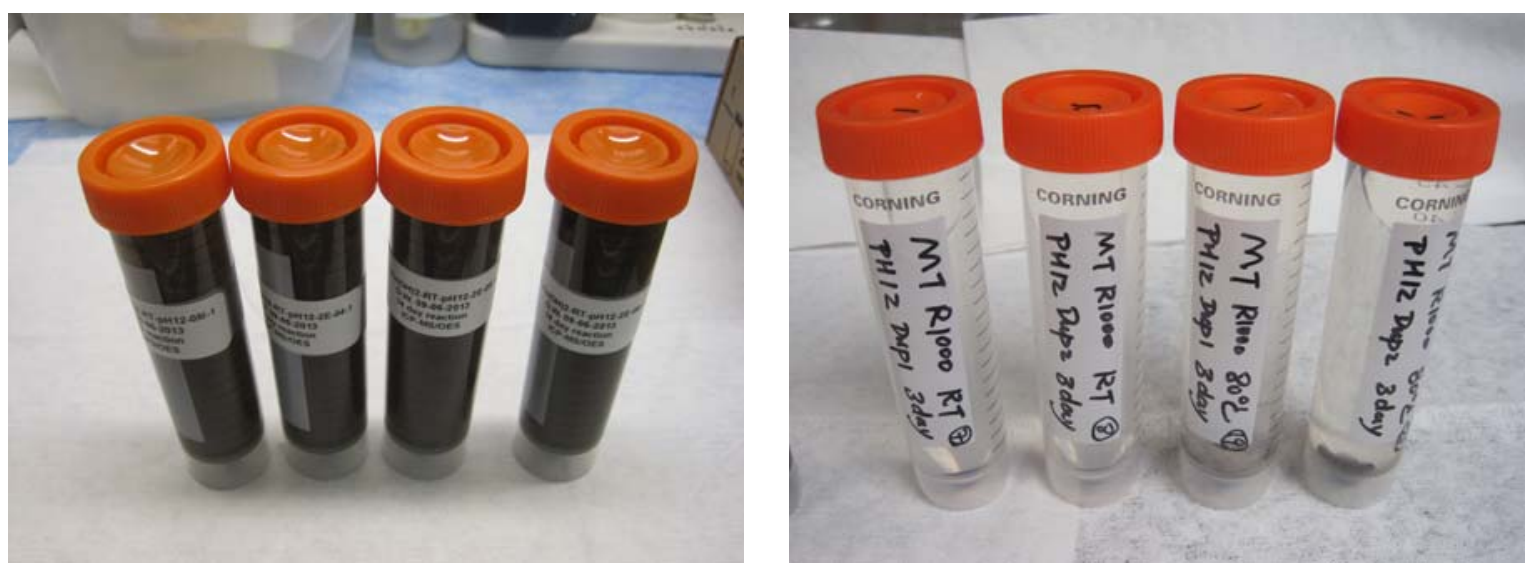

Figure 1. Centrifuge Tube Reactors Used for Mineral Transformation Tests and Tc Removal. Left: ${ }^{99} \mathrm{Tc}$-spiked $\mathrm{Fe}(\mathrm{OH})_{2}$ (s) slurries prepared at $\mathrm{pH} \sim 12$ with various ferrous Fe concentration additions at room temperature (RT) after 18 hours reaction; right: pure magnetite used for mineral transformation screening tests at $\mathrm{pH} \sim 12$ and $\mathrm{RT}$ conditions after reacting for three days.

Mineral transformation of three synthesized initial Fe (oxy)hydroxide minerals [ferrihydrite, magnetite, and $\mathrm{Fe}(\mathrm{OH})_{2}(\mathrm{~s})$ ] to a more crystalline $\mathrm{Fe}$ (oxy)hydroxide such as goethite was tested under various experimental conditions. The mineral transformation was conducted at two different temperatures $\left(21^{\circ} \mathrm{C}\right.$ and $\left.75-80^{\circ} \mathrm{C}\right)$ under two $\mathrm{pH}$ conditions (circumneutral $\mathrm{pH}$ of 6-7.5 and basic $\mathrm{pH}$ of 12). About $0.05 \mathrm{~g}$ or $0.1 \mathrm{~g}$ of the synthesized individual mineral solid was resuspended in $50 \mathrm{~mL}$ or $10 \mathrm{~mL}$ DI water in centrifuge tubes to achieve two solution-to-solid ratios of 1000 and 100, respectively. The initial solution pHs ( $\sim 7$ and 12) in the reactors were adjusted by addition of $1 \mathrm{M} \mathrm{HNO}_{3}$ or $\mathrm{NaOH}$. Duplicate parallel reaction tubes for each testing condition were set up with varying reaction times of 3 , 14, and 30 days to observe the mineral transformation kinetics. High-temperature-condition samples were reacted inside an oven. The reaction tubes were hand shaken at least once per day during the entire testing period. At the designed time intervals, the reaction tubes were moved out of the sample batches, and both $21^{\circ} \mathrm{C}$ and $80^{\circ} \mathrm{C}$ reaction tubes were kept right side up overnight to enable the solid particles to separate from solution through settlement. Then the supernatant was carefully decanted out of the reaction tubes, and the remaining mineral slurry was filtered using a $0.02-\mu \mathrm{m}$ syringe filter and dried in air. The final solid samples were used for the solid characterization by XRD and SEM analysis to confirm the mineral transformation if there was any. For the experiment using $\mathrm{Fe}(\mathrm{OH})_{2}(\mathrm{~s})$, the solid was initially resuspended in deoxygenated DI water and the solution $\mathrm{pH}$ was adjusted inside an anaerobic chamber, then the reaction tubes containing $\mathrm{Fe}(\mathrm{OH})_{2}(\mathrm{~s})$ were completely sealed and moved outside of the chamber to react at $21^{\circ} \mathrm{C}$ and $80^{\circ} \mathrm{C}$ conditions. The supernatant $\mathrm{pH}$ was measured with a solid-state $\mathrm{pH}$ electrode and a pH meter (Hanna, Model HI 4521). Before taking the measurement, the $\mathrm{pH}$ probe was calibrated with National Bureau of Standards buffers $\left(\mathrm{pH}=7.0,10.0\right.$, and/or 13.0 at $\left.25^{\circ} \mathrm{C}\right)$.

The mineral transformation screening test results showed that both ferrihydrite and $\mathrm{Fe}(\mathrm{OH})_{2}(\mathrm{~s})$ could be successfully transformed into goethite, especially under high temperature $\left(80^{\circ} \mathrm{C}\right)$ and high $\mathrm{pH}(\sim 12)$ conditions at a solution-to-solid ratio of 1000. More details can be found in Section 3.0. Therefore, further ${ }^{99} \mathrm{Tc}$ removal experiments were prepared using $\mathrm{Fe}(\mathrm{OH})_{2}(\mathrm{~s})$ as an initial Fe mineral substrate with varying ferrous Fe solution concentrations. Inside an anaerobic chamber, 0.0, 0.0006, 0.0017, and $0.0166 \mathrm{~g}$ of $\mathrm{FeCl}_{2} \bullet 4 \mathrm{H}_{2} \mathrm{O}$ was dissolved in $210 \mathrm{~mL}$ DI water to achieve ferrous Fe solutions of about 0.0 , 
$14 \times 10^{-6}, 4 \times 10^{-5}$, and $4 \times 10^{-4} \mathrm{M}$, respectively. The $0.0 \mathrm{M}$ ferrous Fe solution (i.e., pure DI water) was used as a control condition to illustrate the ferrous Fe effects on the ${ }^{99} \mathrm{Tc}$ removal by mineral transformation. All the solution $\mathrm{pHs}$ were initially adjusted to $\sim \mathrm{pH} 3.3$ using $2 \mathrm{M} \mathrm{HNO}_{3}$ to avoid any ferrous Fe precipitating from the solution at higher $\mathrm{pH}$ conditions. Then $0.05 \mathrm{~g}$ of the synthesized $\mathrm{Fe}(\mathrm{OH})_{2}(\mathrm{~s})$ was resuspended in $25 \mathrm{~mL}$ of each of the four different ferrous Fe solutions in 50-mL-size centrifuge tubes, and kept inside the chamber overnight. The solution with a ${ }^{99} \mathrm{Tc}$ spike of $2 \times 10^{-5} \mathrm{M}$ was prepared outside the anaerobic chamber with DI water in which the solution $\mathrm{pH}$ was adjusted to $\mathrm{pH} \sim 12$ using $1 \mathrm{M} \mathrm{NaOH}$. The $25 \mathrm{~mL}$ of $\mathrm{Fe}(\mathrm{OH})_{2}$ slurries with different ferrous Fe concentrations were mixed with $25 \mathrm{~mL}$ of ${ }^{99} \mathrm{Tc}$-spiked solution outside the anaerobic chamber, leading to a final solution-to-solid ratio of 1,000 with a final $\mathrm{pH}$ value ranging 9 to 11.5 immediately after each solution was mixed. Because of 1:2 dilution with mixing two $25-\mathrm{mL}$ solutions, the final concentrations of $\mathrm{Fe}(\mathrm{II})$ and ${ }^{99} \mathrm{Tc}$ as shown in Table 1 are half of those initially prepared in each $25-\mathrm{mL}$ solution. The reaction tubes were immediately sealed after mixing the two solutions and the initial slurry still had a greenish color like that of green rust. The reaction lasted for seven days at both $21^{\circ} \mathrm{C}$ and $75^{\circ} \mathrm{C}$ temperatures with hand shaking at least once per day. After the reaction, about $4 \mathrm{~mL}$ of supernatant was collected and filtered using a $0.02-\mu \mathrm{m}$ syringe filter, and the concentrations of ${ }^{99} \mathrm{Tc}$ and total $\mathrm{Fe}$ were determined using inductively coupled plasma mass spectroscopy (ICP-MS) and inductively coupled plasma optical emission spectroscopy (ICP-OES) analysis, respectively.

In addition, the ${ }^{99} \mathrm{Tc}$ removal capacity by the dominant mineral for transformation, $\mathrm{Fe}(\mathrm{OH})_{2}(\mathrm{~s})$, was tested with varying ${ }^{99} \mathrm{Tc}$ concentrations and no ferrous Fe addition. Although the original plan was to determine the maximum ${ }^{99} \mathrm{Tc}$ removal capacity by only pure $\mathrm{Fe}(\mathrm{OH})_{2}(\mathrm{~s})$, practically an extra Tc-removal-capacity experiment was also conducted by using oxidized $\mathrm{Fe}(\mathrm{OH})_{2}$ (s), i.e., the former synthesized $\mathrm{Fe}(\mathrm{OH})_{2}(\mathrm{~s})$ had been identified as oxidized and become a magnetite-dominated Fe mineral, which was confirmed by Mössbauer analysis later. Because $\mathrm{O}_{2}(\mathrm{~g})$ contamination of 1 ppm $\mathrm{O}_{2}(\mathrm{~g})$ concentration was detected inside the anaerobic chamber, the formerly synthesized $\mathrm{Fe}(\mathrm{OH})_{2}(\mathrm{~s})$ that had been stored in the same chamber, even in a capped vial, for more than six months could have contacted $\mathrm{O}_{2}(\mathrm{~g})$ and oxidized to become the magnetite-dominant solid sample. Therefore, in this experiment, the Tc-removal capacity experiments were carried out by using both new-synthesized fresh $\mathrm{Fe}(\mathrm{OH})_{2}(\mathrm{~s})$ and the oxidized one. About $0.05 \mathrm{~g}$ of the fresh or oxidized $\mathrm{Fe}(\mathrm{OH})_{2}(\mathrm{~s})$ solid was directly resuspended in $50 \mathrm{~mL}$ of ${ }^{99} \mathrm{Tc}$-spiked solutions with three different ${ }^{99} \mathrm{Tc}$ concentrations of $10^{-5}, 10^{-4}$, and $10^{-3} \mathrm{M}$ at adjusted $\mathrm{pH}$ values of $\sim 12$. No ferrous Fe was added in these slurries to investigate the effect of ferrous $\mathrm{Fe}$ from $\mathrm{Fe}(\mathrm{OH})_{2}(\mathrm{~s})$ itself on ${ }^{99} \mathrm{Tc}$ removal. Similar to the conditions of the above $\mathrm{Fe}(\mathrm{OH})_{2}(\mathrm{~s})$-ferrous Fe- ${ }^{99} \mathrm{Tc}$ experiments, these tests were also conducted at both $21^{\circ} \mathrm{C}$ and $75^{\circ} \mathrm{C}$ temperature conditions, whereas the reaction time intervals of seven days for the fresh-synthesized $\mathrm{Fe}(\mathrm{OH})_{2}(\mathrm{~s})$, and 14 and 42 days for the oxidized $\mathrm{Fe}(\mathrm{OH})_{2}(\mathrm{~s})$ were adopted. For the experiments using oxidized $\mathrm{Fe}(\mathrm{OH})_{2}(\mathrm{~s})$, after the 14-day reaction, about $2 \mathrm{~mL}$ of supernatant was collected for ${ }^{99} \mathrm{Tc}$ analysis and the reaction was continued with the remaining $48-\mathrm{mL}$ solution until the next sampling time of 42 days. The influence of withdrawing $2 \mathrm{~mL}$ supernatant from the reactor system was ignored due to its small volume reduction ( $4 \%$ of the initial total solution volume).

\subsubsection{Reductive Capacity Measurement}

The Ce(IV) method was used to determine the reductive capacity of the previous ${ }^{99} \mathrm{Tc}$-goethite powder samples (2-2 and 2-5) as synthesized. The ${ }^{99} \mathrm{Tc}$-goethite powder samples, sample 2-2 that was prepared without an additional armoring process and sample 2-5 that was prepared with an armoring 
process (Um et al. 2011) were ground to a homogeneous powder and used to determine reductive capacity. In the $\mathrm{Ce}(\mathrm{IV})$ method, a $\mathrm{Ce}(\mathrm{IV})$ stock solution $\left[\left(\mathrm{NH}_{4}\right)_{4} \mathrm{Ce}\left(\mathrm{SO}_{4}\right)_{4} \cdot 2 \mathrm{H}_{2} \mathrm{O}\right]$ was prepared in $10 \%$ $\mathrm{H}_{2} \mathrm{SO}_{4}$ with a concentration of $30-60 \mathrm{mM}$ depending on the reductive capacity of the specimen. Approximately $0.1 \mathrm{~g}$ of each sample was mixed with $15 \mathrm{~mL}$ of the Ce(IV) stock solution in a 20-mL quartz vial. Immediately after mixing, the vial was tightly closed and placed on a platform shaker. The sample was reacted at RT for seven days. After the seven-day reaction, the supernatant solution was filtered through a $0.45-\mu \mathrm{m}$ syringe filter and $0.05 \mathrm{~mL}$ of ferroine solution $[0.025 \mathrm{M} \mathrm{Fe}(\mathrm{o}-$ phenanthroline $)_{3}{ }^{2+}$ ] was added to $5 \mathrm{~mL}$ of the filtrate. The final solution was titrated using $20 \mathrm{mM}$ ammonium ferrous sulfate prepared in $4 \% \mathrm{H}_{2} \mathrm{SO}_{4}$ solution until the solution developed and retained a lilac color. The reductive capacity was calculated by determining the difference between the oxidizing equivalent in $\mathrm{Ce}(\mathrm{IV})$ solution [meq $\mathrm{Ce}(\mathrm{IV})$ ] and the reducing equivalent of $\mathrm{Fe}(\mathrm{II})$ needed to neutralize excess $\mathrm{Ce}(\mathrm{IV})$ after reaction with the sample [meq Fe(II)]. The final reductive capacity per gram of sample was determined by dividing the reductive capacity (meq) by the mass of the sample (g).

\subsubsection{Long-Term Leaching Experiment}

A long-term batch leaching experiment was conducted using a homogeneously ground ${ }^{99} \mathrm{Tc}$-goethite powder sample, sample 2-5 that was prepared with further armoring process, at a solid concentration of $1 \mathrm{~g} / \mathrm{L}(\sim 0.1 \mathrm{~g} / 100 \mathrm{~mL})$ with synthetic Hanford vadose zone pore water solution. The synthetic Hanford pore water with $\mathrm{pH}=7.2$ and ionic strength $=0.05 \mathrm{M}$ was prepared to simulate the IDF pore water condition in the Hanford Site 200 East Area using the chemicals, $\mathrm{CaSO}_{4}\left(1.2 \times 10^{-2} \mathrm{M}\right), \mathrm{NaNO}_{3}$ $\left(3.4 \times 10^{-3} \mathrm{M}\right), \mathrm{NaHCO}_{3}\left(3.0 \times 10^{-4} \mathrm{M}\right), \mathrm{NaCl}\left(2.1 \times 10^{-3} \mathrm{M}\right), \mathrm{MgSO}_{4}\left(2.6 \times 10^{-3} \mathrm{M}\right), \mathrm{MgCl}_{2}$ $\left(2.4 \times 10^{-3} \mathrm{M}\right)$, and $\mathrm{KCl}\left(7.0 \times 10^{-4} \mathrm{M}\right)$. Independent leaching solutions were prepared as duplicates for different leaching times. For each ${ }^{99}$ Tc-goethite leaching test, a subsample $(2 \mathrm{~mL})$ of supernate was collected from samples leached for three months, six months, one year, and two years after the test commenced using a $0.45-\mu \mathrm{m}$ Nalgene ${ }^{\circledR}$ syringe filter and submitted for analyses of dissolved $\mathrm{Fe}$ (total) and ${ }^{99} \mathrm{Tc}$ concentrations. The $\mathrm{pH}$ was directly measured in the slurry leaching solution, and concentrations of $\mathrm{Fe}$ (total) and ${ }^{99} \mathrm{Tc}$ were determined using ICP-OES and ICP-MS, respectively. For the three-year reacted sample, the filtered solid powder sample that had been leached two years in the IDF solution was exposed to atmosphere for one more year. After the sample collection at the designated leaching and reaction times was completed, the powder ${ }^{99} \mathrm{Tc}$-goethite sample 2-5 was separated by filtration and used to determine ${ }^{99} \mathrm{Tc}$ oxidation state change using x-ray absorption fine structure (XAFS) spectroscopy.

\subsubsection{X-Ray Absorption Fine Structure Spectroscopy}

The XAFS spectra were collected on Beamline 4-1 at the Stanford Synchrotron Radiation Laboratory. The ${ }^{99}$ Tc-goethite solid samples were mounted on Teflon ${ }^{\circledR}$ sample holders and sealed with Kapton tape. A Si(220) double-flat crystal monochromator was used and the energy was calibrated by using the first inflection point of the ${ }^{99} \mathrm{Tc} \mathrm{K}$ edge spectrum of the ${ }^{99} \mathrm{Tc}(\mathrm{VII})$ standard $\left(\mathrm{KTcO}_{4}\right)$ defined as $21.044 \mathrm{keV}$. The XAFS spectra of ${ }^{99} \mathrm{Tc}$-standards and ${ }^{99} \mathrm{Tc}$-goethite samples were collected in transmission and fluorescence mode, respectively, at RT using a 13-element germanium detector. Data reduction and analysis were performed using the software IFEFFIT (Newville 2001) and Athena/Artemis (Ravel and Newville 2005) after correction for detector dead-time. The x-ray absorption near-edge structure (XANES) spectra for the ${ }^{99} \mathrm{Tc}$-goethite 2-5 samples were fit using a linear combination of the XANES 
spectra of $\mathrm{KTcO}_{4}$ as the $\mathrm{Tc}(\mathrm{VII})$ standard spectrum and $\mathrm{TcO}_{2} \cdot 2 \mathrm{H}_{2} \mathrm{O}$ as the $\mathrm{Tc}(\mathrm{IV})$ standard spectrum, respectively (Lukens et al. 2002).

\subsection{Results and Discussion}

\subsection{Synthesis of Fe (Oxy)hydroxide Substrates}

The XRD and SEM analysis results on the synthesized ferrihydrite, $\mathrm{Fe}(\mathrm{OH})_{2}(\mathrm{~s})$, and magnetite, as well as the potential transformed product, goethite, are shown in Figure 2. The two broad XRD patterns are typical for amorphous 2-line ferrihydrite, while the other three crystalline iron oxides showed sharp XRD patterns that matched well with the JADE reference peaks of each mineral. In the case of the synthesized $\mathrm{Fe}(\mathrm{OH})_{2}(\mathrm{~s})$, more than $90 \%$ of the synthesized minerals can be roughly identified as $\mathrm{Fe}(\mathrm{OH})_{2}(\mathrm{~s})$, while less than $10 \%$ of the minerals were identified to be a mixture of fougerite $[\mathrm{Fe}(\mathrm{OH}, \mathrm{Cl})]$ and magnetite. A naturally occurring green rust mineral, fougerite forms a layered double hydroxide structure containing $\mathrm{Fe}(\mathrm{II})$ and $\mathrm{Fe}(\mathrm{III})$ in cation sites and $\mathrm{OH}^{-}, \mathrm{Cl}^{-}$, or $\mathrm{CO}_{3}{ }^{2-}$ in anion sites. It is bluish-green in color with hexagonal platelets of submicron diameter (Figure 2 and Figure 3 ) and the ideal formula is $\left[\mathrm{Fe}(\mathrm{II})_{4} \mathrm{Fe}(\mathrm{III})_{2}(\mathrm{OH})_{12}\right]\left[\mathrm{CO}_{3}\right] \cdot 3 \mathrm{H}_{2} \mathrm{O}$, where $\mathrm{OH}^{-}$and $\mathrm{CO}_{3}{ }^{2-}$ can be replaced by $\mathrm{Cl}^{-}$. For $\mathrm{Fe}(\mathrm{OH})_{2}(\mathrm{~s}) \mathrm{XRD}$ analysis, more magnetite content was detected in an oxidized darker grain sample. The amorphous morphology of ferrihydrite and the well-crystallized shapes of goethite, magnetite, and $\mathrm{Fe}(\mathrm{OH})_{2}(\mathrm{~s})$ were also detected in the SEM images (Figure 4). Amorphous shapes of ferrihydrite and $\mathrm{Fe}(\mathrm{OH})_{2}(\mathrm{~s})$ were clearly detected, while needle and hexagonal shapes typical of goethite and magnetite, respectively, were also found.
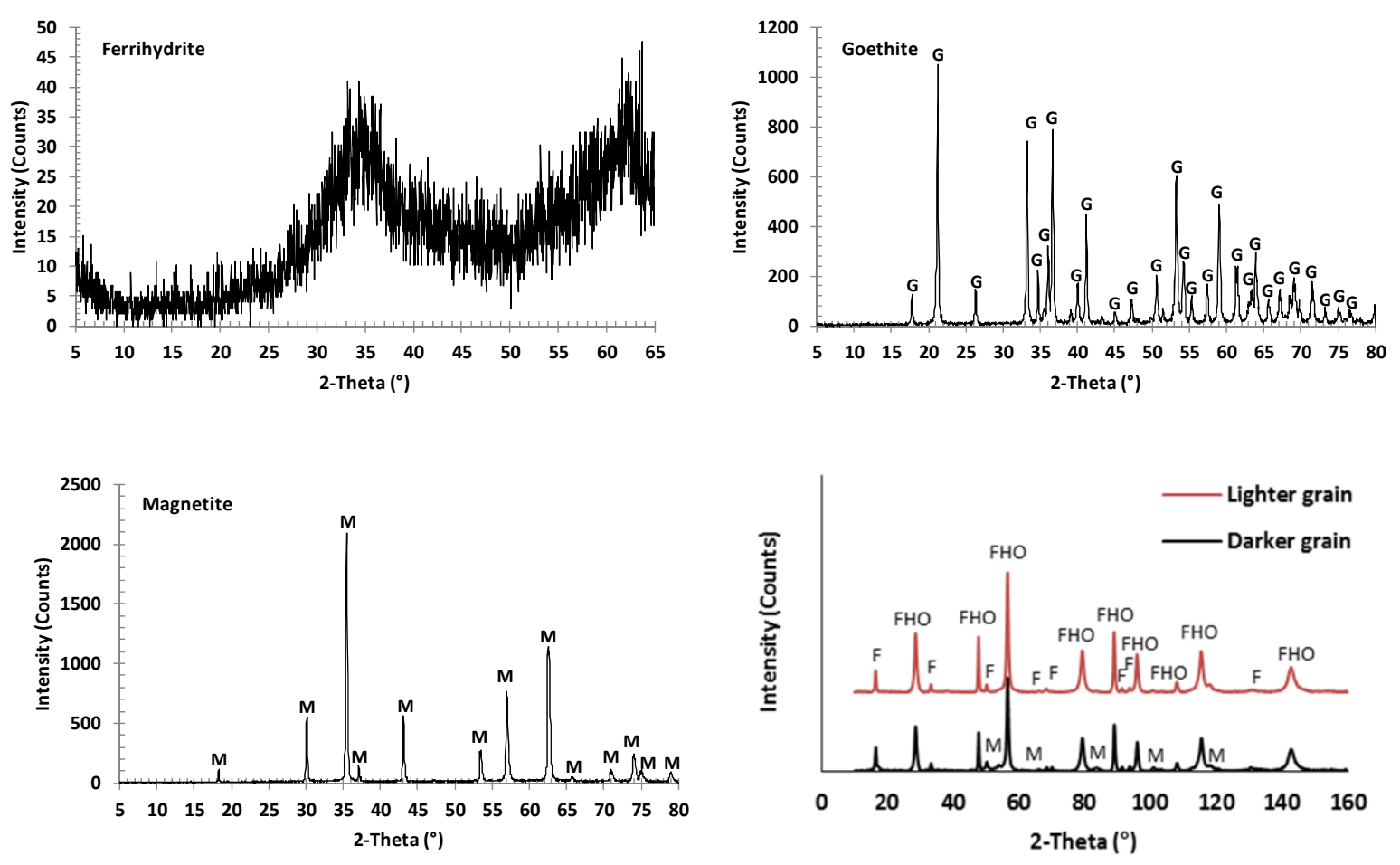

Figure 2. XRD Patterns of Synthesized 2-line Ferrihydrite, Goethite, Magnetite, and $\mathrm{Fe}(\mathrm{OH})_{2}(\mathrm{~s})$ : $\mathrm{G}=$ goethite, $\mathrm{M}=$ magnetite, $\mathrm{FHO}=\mathrm{Fe}(\mathrm{OH})_{2}(\mathrm{~s}), \mathrm{F}=$ Fougerite. 

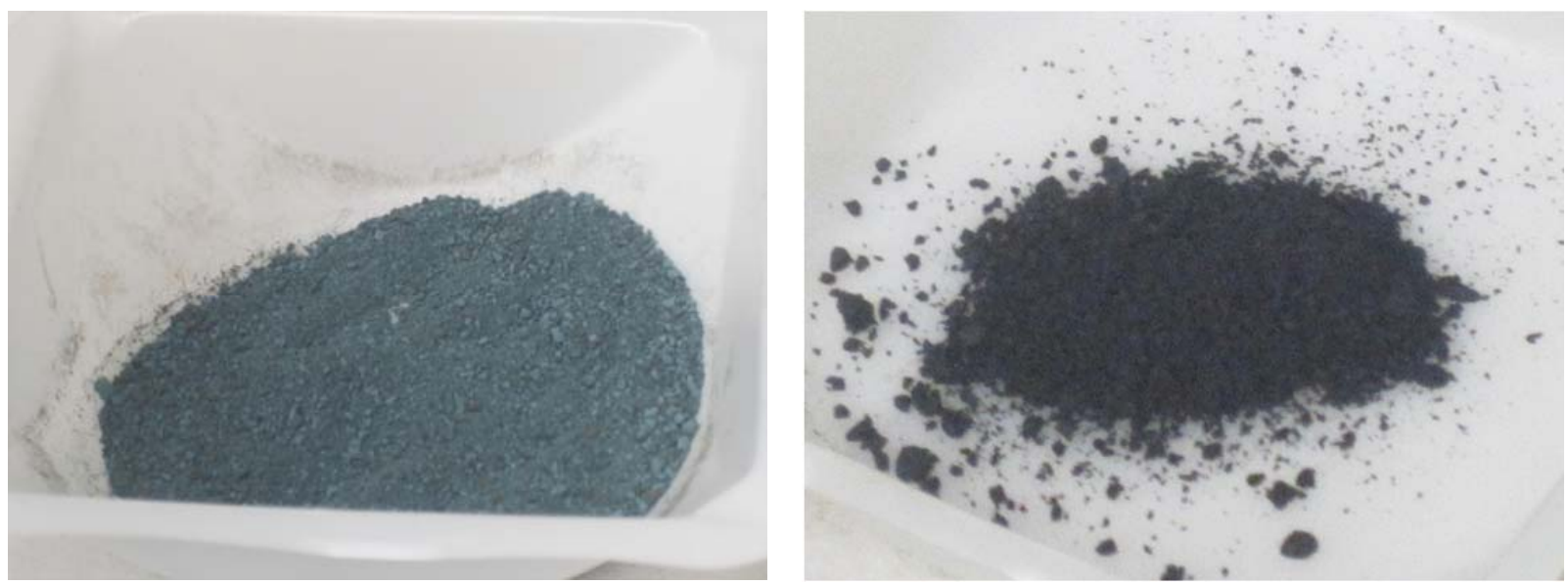

Figure 3. Photographs of Synthesized $\mathrm{Fe}(\mathrm{OH})_{2}(\mathrm{~s})$. Left: $\mathrm{Fe}(\mathrm{OH})_{2}(\mathrm{~s})$ with more fougerite; right: oxidized $\mathrm{Fe}(\mathrm{OH})_{2}(\mathrm{~s})$ showing darker color due to the presence of magnetite
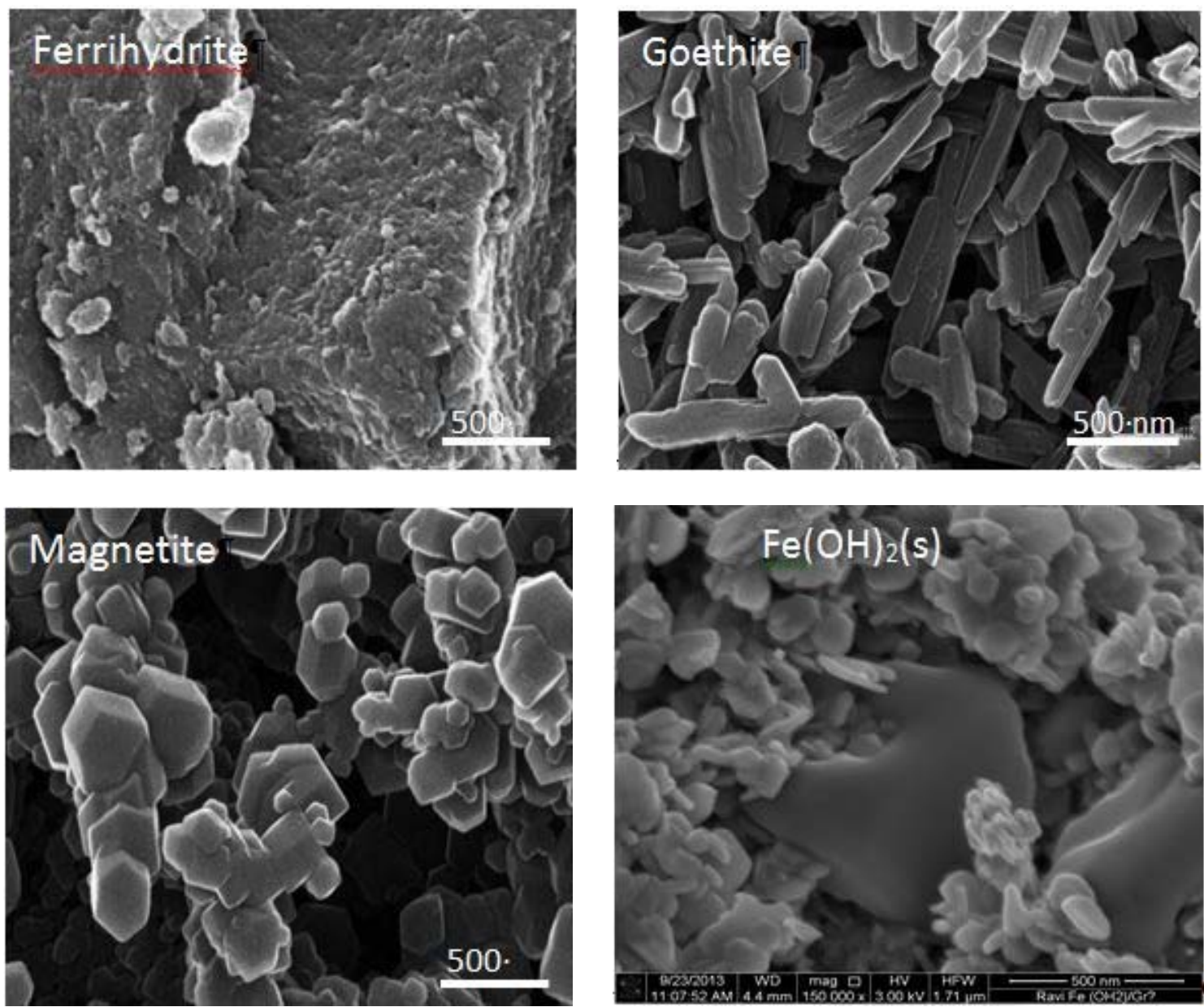

Figure 4. SEM Images and Morphology of Synthesized Ferrihydrite, Goethite, Magnetite, and $\mathrm{Fe}(\mathrm{OH})_{2}(\mathrm{~s})$ 
The freshly synthesized $\mathrm{Fe}(\mathrm{OH})_{2}(\mathrm{~s})$ and the oxidized $\mathrm{Fe}(\mathrm{OH})_{2}(\mathrm{~s})$ due to oxygen contact, as well as the final mineral product of $\mathrm{Fe}(\mathrm{OH})_{2}(\mathrm{~s})$ reacted for 30 days at $80^{\circ} \mathrm{C}$ and $\mathrm{pH} 12$ were characterized using Mössbauer spectroscopy. The Mössbauer spectra of these three $\mathrm{Fe}(\mathrm{OH})_{2}(\mathrm{~s})$ samples are shown in Figure 5. The freshly synthesized $\mathrm{Fe}(\mathrm{OH})_{2}(\mathrm{~s})$ Mössbauer spectrum indicates that besides $\mathrm{Fe}(\mathrm{OH})_{2}(\mathrm{~s})$, other iron oxides containing Fe(II) and Fe(III) are also present. This agrees well with the XRD pattern of $\mathrm{Fe}(\mathrm{OH})_{2}(\mathrm{~s})$ (Figure 2), which shows that less than $10 \%$ of the minerals are identified to be a mixture of fougerite and magnetite. This is not surprising since the pure white colored $\mathrm{Fe}(\mathrm{OH})_{2}(\mathrm{~s})$ is amorphous and quite unstable, and thus even a trace amount of oxygen contact can lead to oxidation of part of the $\mathrm{Fe}(\mathrm{OH})_{2}(\mathrm{~s})$ materials, resulting in greenish colored green rust like fougerite (Figure 3). Figure 5 also shows that after reacting at $\mathrm{pH} 12$ and $80^{\circ} \mathrm{C}$ for 30 days, the initial $\mathrm{Fe}(\mathrm{OH})_{2}(\mathrm{~s})$-fougerite green rust mixture was transformed into maghemite, goethite, and other small-particle iron oxides (Figure 5-middle). This is expected since $\mathrm{Fe}(\mathrm{OH})_{2}(\mathrm{~s})$ is very reactive, and a mixture of $\mathrm{Fe}(\mathrm{OH})_{2}(\mathrm{~s})$ and fougerite green rust can be easily transformed to more stable and crystalline iron oxides, such as maghemite/magnetite and goethite. The Mössbauer spectrum fit of the former $\mathrm{Fe}(\mathrm{OH})_{2}(\mathrm{~s})$ oxidized due to the anaerobic chamber failure (Figure 5-bottom) also indicates that the initial $\mathrm{Fe}(\mathrm{OH})_{2}(\mathrm{~s})$ has been transformed to non-stoichiometric (NS) magnetite ( $>90 \%$ ), i.e., partially oxidized magnetite (a mixture of maghemite and magnetite).

\subsection{Mineral Transformation}

Mineral transformation without ferrous Fe addition and ${ }^{99} \mathrm{Tc}$ spiking was tested under various conditions for all three synthesized $\mathrm{Fe}$ (oxy) hydroxide minerals [ferrihydrite, magnetite, and $\mathrm{Fe}(\mathrm{OH})_{2}(\mathrm{~s})$ ]. The fate and transformed final products differed from the initial mineral substrates depending on the transformation reaction conditions.

\subsubsection{Transformation from $\mathrm{Fe}(\mathrm{OH})_{2}(\mathrm{~s})$}

The mineral transformation from $\mathrm{Fe}(\mathrm{OH})_{2}(\mathrm{~s})$ to a mixture of maghemite/magnetite and goethite was confirmed by XRD analysis. Figure 6 and Figure 7, respectively, show the mineral transformation of $\mathrm{Fe}(\mathrm{OH})_{2}(\mathrm{~s})$ to a maghemite/magnetite and goethite mixture at $\mathrm{pH} 7$ or $\mathrm{pH} 12$ at both $80^{\circ} \mathrm{C}$ and $\mathrm{RT}\left(21^{\circ} \mathrm{C}\right)$ conditions after reacting for 30 days. Similar XRD patterns were found in the final product of maghemite/magnetite and goethite mixture generated from transformation of $\mathrm{Fe}(\mathrm{OH})_{2}(\mathrm{~s})$ with solution-to-solid ratio of 1000 or 100 at $\mathrm{RT}$ and $\mathrm{pH} 7$ or $\mathrm{pH} 12$ after reacting for 30 days (Figure 8). However, much higher XRD peak intensity was found with the low solution-to-solid ratio of 100 under the same transformation conditions, because more solid content was used in the lower solution-to-solid ratio of 100 than 1000 . The well-crystallized magnetite or goethite is thermodynamically more stable than the ferrous hydroxide, $\mathrm{Fe}(\mathrm{OH})_{2}(\mathrm{~s})$. Even under anaerobic conditions, the ferrous hydroxide $\left[\mathrm{Fe}(\mathrm{OH})_{2}(\mathrm{~s})\right]$ can be oxidized by protons of the water present to form magnetite by the Schikorr reaction (Schikorr 1933; Ardizzone and Formaro 1983):

$$
3 \mathrm{Fe}(\mathrm{OH})_{2} \rightarrow \mathrm{Fe}_{3} \mathrm{O}_{4}+\mathrm{H}_{2}+2 \mathrm{H}_{2} \mathrm{O}
$$



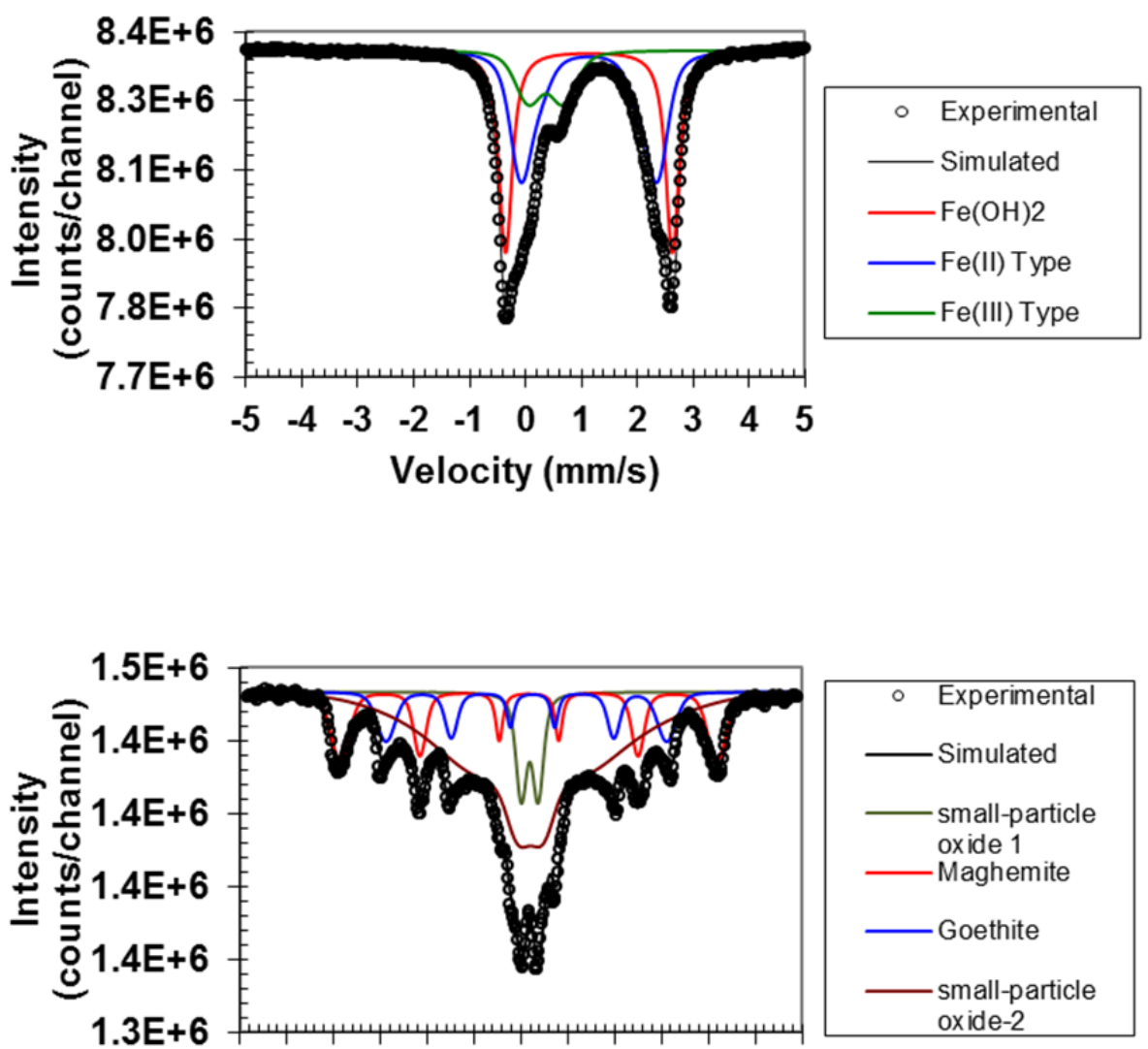

$\begin{array}{llllllllllll}-12-10 & -8 & -6 & -4 & -2 & 0 & 2 & 4 & 6 & 8 & 10 & 12\end{array}$

Velocity $(\mathrm{mm} / \mathrm{s})$

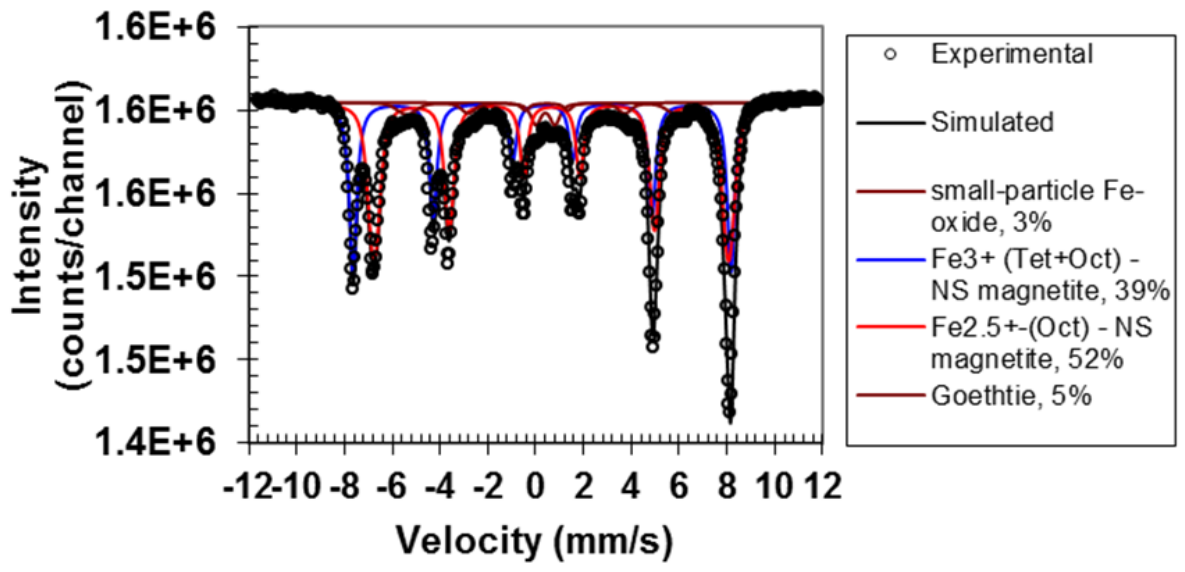

Figure 5. Mössbauer Spectra of the Fresh $\mathrm{Fe}(\mathrm{OH})_{2}$ (s) (top), Transformed $\mathrm{Fe}(\mathrm{OH})_{2}$ (s) Minerals Product after $\mathrm{Fe}(\mathrm{OH})_{2}(\mathrm{~s})$ Reacted at $\mathrm{pH} 12$ and $80^{\circ} \mathrm{C}$ (middle), and the Former $\mathrm{Fe}(\mathrm{OH})_{2}(\mathrm{~s})$ Oxidized due to Oxygen Contact (bottom)

Compared with the XRD patterns of pure synthesized magnetite and goethite (Figure 2), the XRD intensity peaks in the regions of about 21.24 and 35.60 two-theta degree can be identified as goethite and 
magnetite/maghemite "fingerprints" in this study. With the help of these "fingerprint" intensity counts, the mineral transformations under different transformation reaction conditions were compared. Figure 9 shows comparisons of mineral transformation products from $\mathrm{Fe}(\mathrm{OH})_{2}(\mathrm{~s})$ to maghemite/magnetite and goethite using goethite and maghemite/magnetite "fingerprint peaks" under different pHs, temperatures, and reaction durations under transformation conditions.

The results of comparison graphs show that $\mathrm{pH} 12$ slurries under high temperature $\left(80^{\circ} \mathrm{C}\right)$ led to the most goethite products whereas less goethite was observed under $\mathrm{pH} 7$ and RT reaction conditions. Under the same temperature condition, either RT or $80^{\circ} \mathrm{C}$, more goethite was produced from $\mathrm{Fe}(\mathrm{OH})_{2}(\mathrm{~s})$ at the higher $\mathrm{pH}$ condition of 12 than at $\mathrm{pH} 7$. Even though the higher temperature and high $\mathrm{pH}$ condition produces more goethite from $\mathrm{Fe}(\mathrm{OH})_{2}(\mathrm{~s})$, certain amounts of goethite can be still produced even at $\mathrm{pH}=7$ and RT, which can allow a much easier operating process in a field site. Regarding the products with maghemite/magnetite mineral mixture, no significant differences were observed among different $\mathrm{Fe}(\mathrm{OH})_{2}(\mathrm{~s})$ transformation reaction conditions. This result implies that higher $\mathrm{pH}$ and heating condition favors the formation of more goethite product, while transformation from $\mathrm{Fe}(\mathrm{OH})_{2}(\mathrm{~s})$ to a maghemite/magnetite mixture does not depend on a specific condition and will be possible even in natural environmental geochemical conditions. This observation is also supported by the different XRD intensity counts for goethite ( $\sim 60$ to 125 counts) and for maghemite/magnetite ( $\sim 250$ counts). Regarding the mineral transformation kinetics, the mineral transformation was relatively fast in most of $\mathrm{Fe}(\mathrm{OH})_{2}(\mathrm{~s})$ reaction conditions based on the results in Figure 9. It seems that three-seven days could be long enough to produce goethite and maghemite/magnetite mixtures from $\mathrm{Fe}(\mathrm{OH})_{2}(\mathrm{~s})$ substrate. 

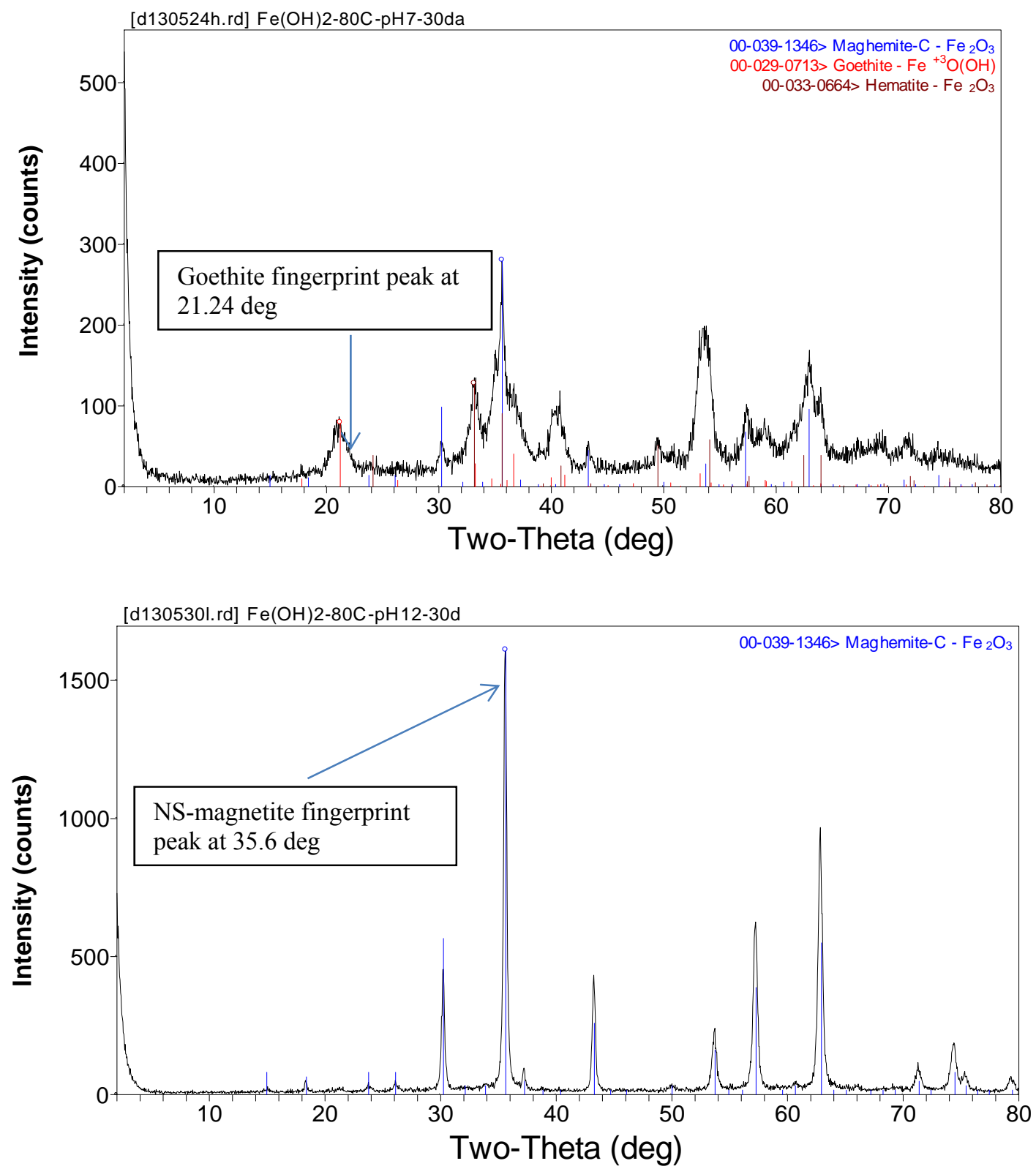

Figure 6. XRD Pattern of Maghemite/Magnetite and Goethite Mixture Transformed from $\mathrm{Fe}(\mathrm{OH})_{2}(\mathrm{~s})$ Reacted Under $\mathrm{pH} 7$ (top) and $\mathrm{pH} 12$ (bottom) at $80^{\circ} \mathrm{C}$ with a Solution-to-Solid Ratio of 1000 for 30 Days 

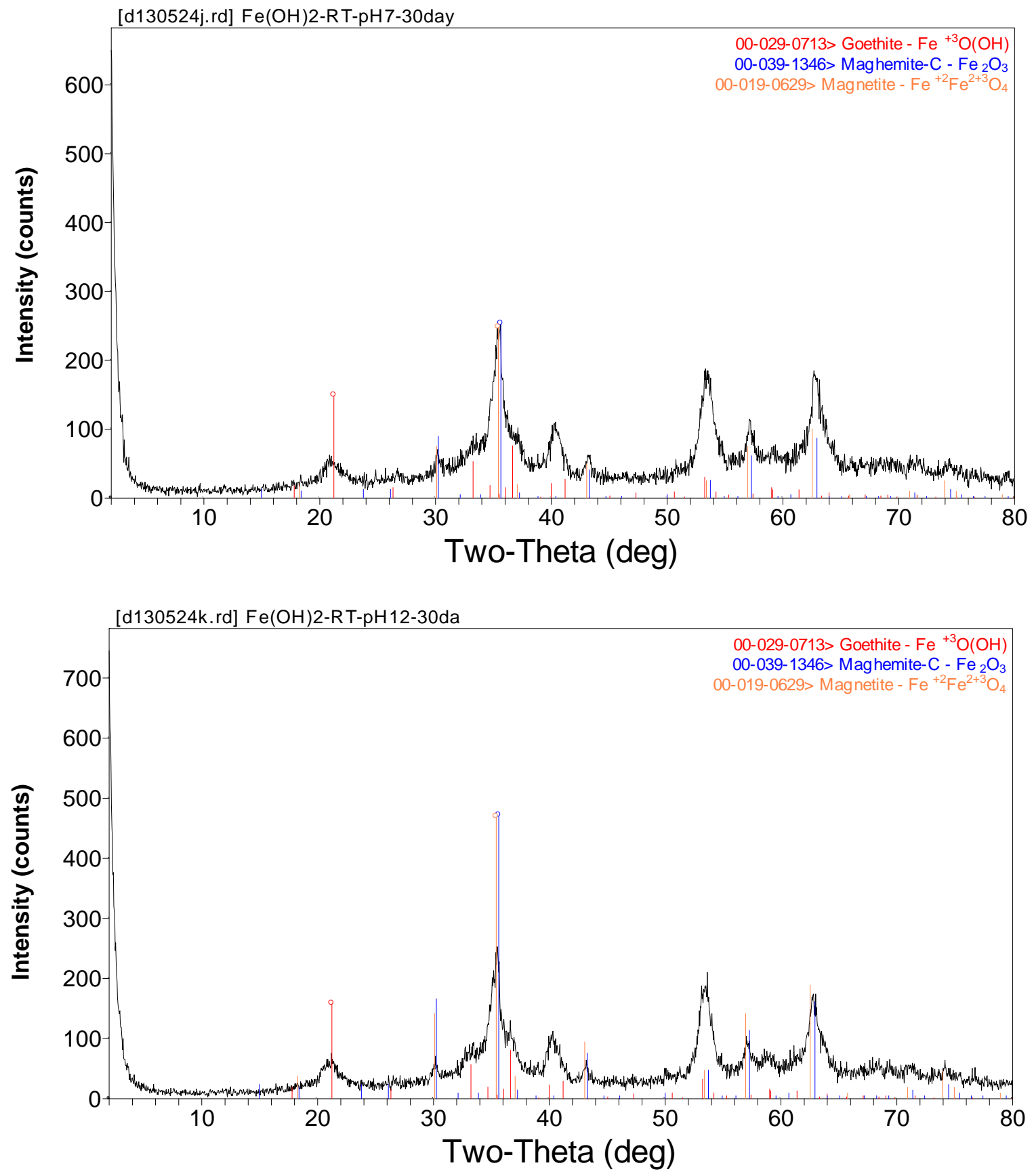

Figure 7. XRD Pattern of Maghemite/Magnetite and Goethite Mixture Transformed from $\mathrm{Fe}(\mathrm{OH})_{2}(\mathrm{~s})$ Reacted at $\mathrm{pH} 7$ (top) and $\mathrm{pH} 12$ (bottom) at $21^{\circ} \mathrm{C}$ with a Solution-to-Solid Ratio of 1000 for 30 Days 

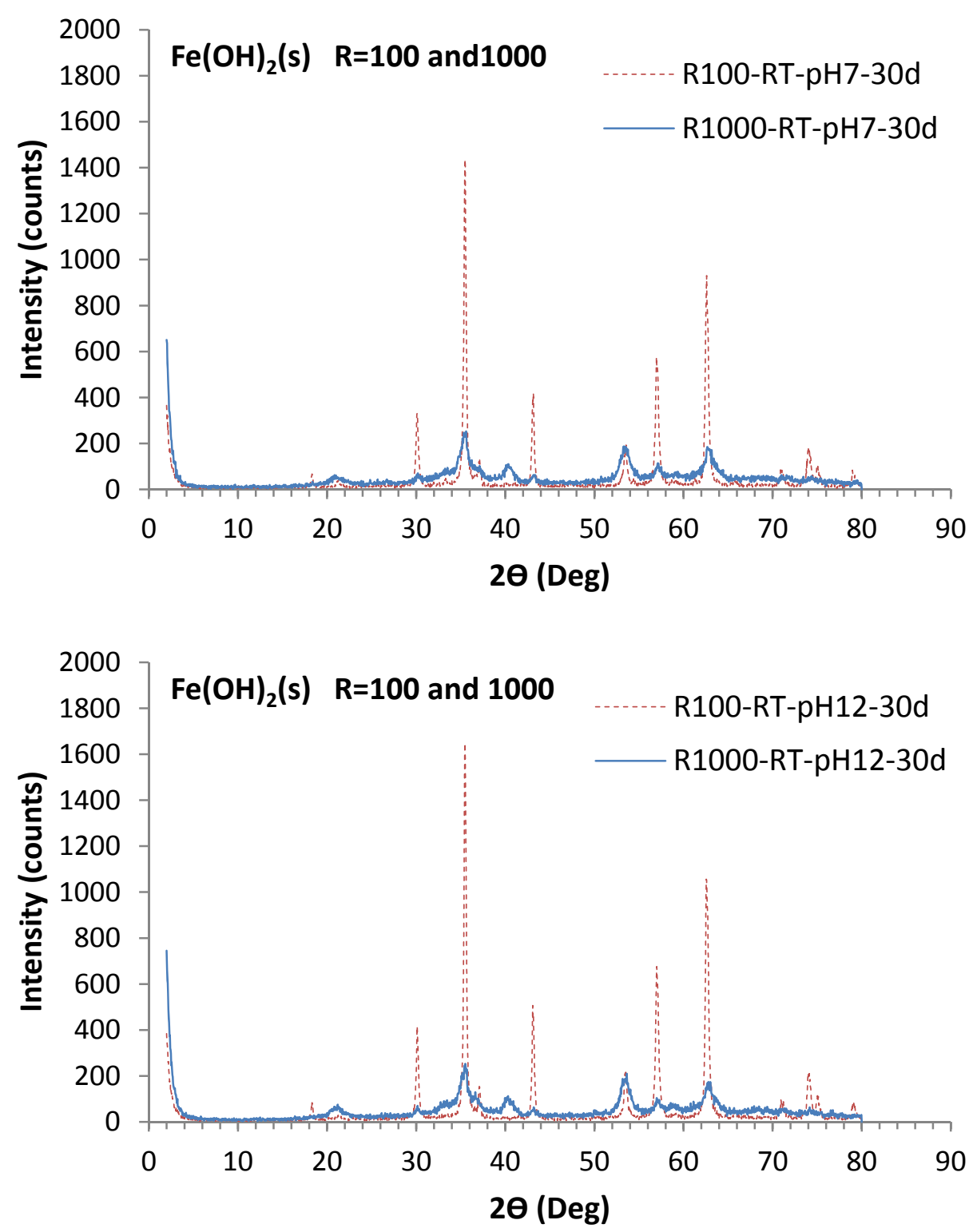

Figure 8. XRD Patterns of Transformed $\mathrm{Fe}(\mathrm{OH})_{2}$ (s) Product Reacted at $\mathrm{pH} 7$ (top) and $\mathrm{pH} 12$ (bottom) at $21^{\circ} \mathrm{C}$ with Different Solution-to-Solid Ratios of 1000 or 100 for 30 Days. The higher intensity of XRD peaks was found with the ratio of 100 because more $\mathrm{Fe}(\mathrm{OH})_{2}(\mathrm{~s})$ was used at the low solution-to-solid ratio of $100\left[0.1 \mathrm{~g}\right.$ of $\mathrm{Fe}(\mathrm{OH})_{2}$ (s) for ratio $100 \mathrm{vs} .0 .05 \mathrm{~g}$ of $\mathrm{Fe}(\mathrm{OH})_{2}(\mathrm{~s})$ for ratio 1000]. 

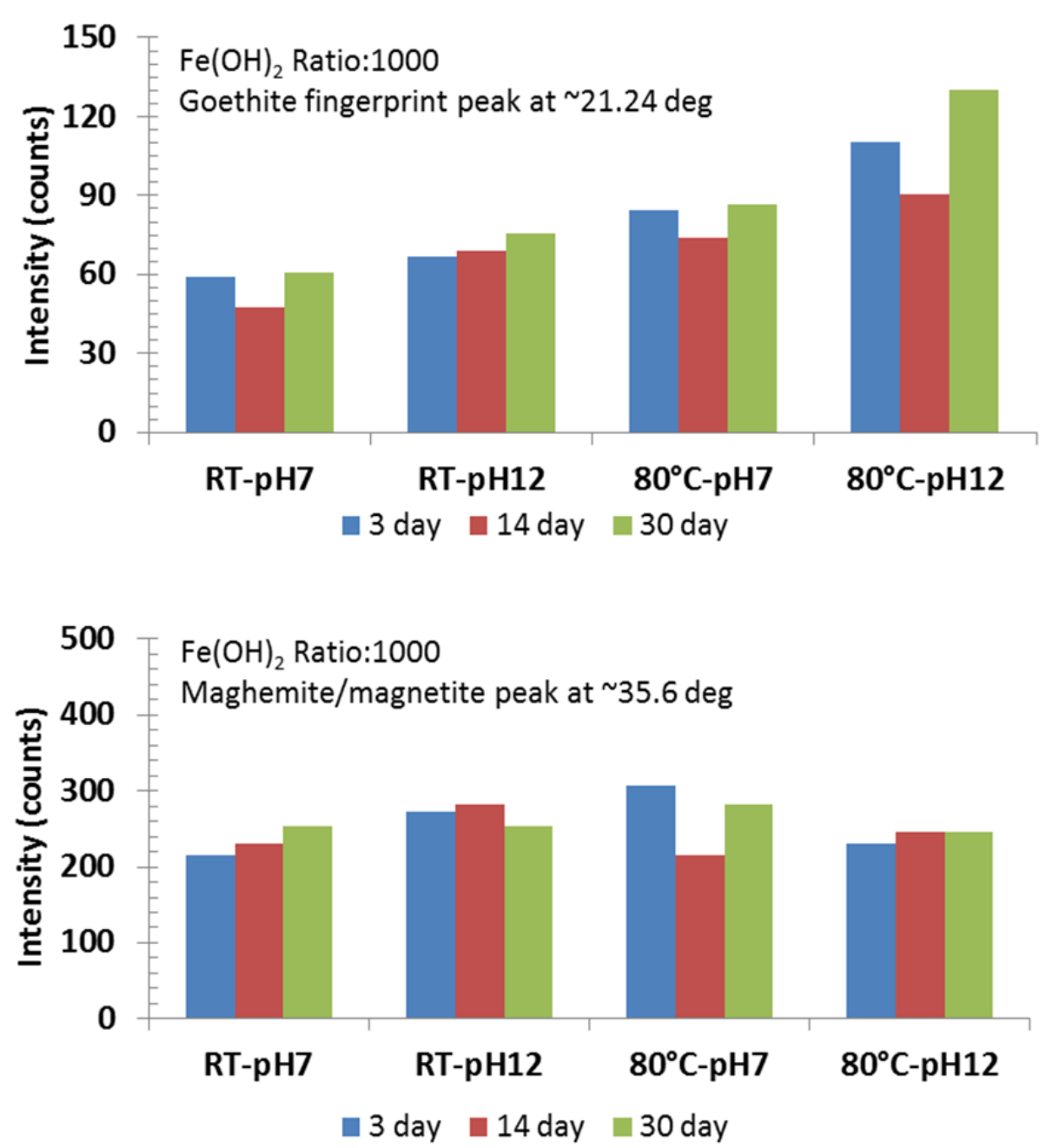

Figure 9. Comparison of Mineral Transformation Products from $\mathrm{Fe}(\mathrm{OH})_{2}$ (s) to Goethite (top) and Maghemite/Magnetite (bottom) Using Goethite and Maghemite/Magnetite "Fingerprint XRD Peak" Under Different Slurry pHs, Temperatures, and Reaction Days

\subsubsection{Transformation from Ferrihydrite}

The difference in XRD patterns before and after the transformation reactions from ferrihydrite that was used as initial substrate illustrated the potential of ferrihydrite transformation to solely goethite. The XRD patterns of the goethite produced from ferrihydrite transformation under $\mathrm{pH} 7$ or $\mathrm{pH} 12$ at both $80^{\circ} \mathrm{C}$ and RT $\left(21^{\circ} \mathrm{C}\right)$ conditions after reacting for 30 days are shown in Figure 10 and Figure 11, respectively. The XRD patterns for ferrihydrite transformation reactions were similar for solution-to-solid ratios of 100 and 1000 (Figure 12). Using the same comparison method previously applied for $\mathrm{Fe}(\mathrm{OH})_{2}(\mathrm{~s})$ transformation products, the goethite "fingerprint" peak at $\sim 21.24^{\circ}$ two-theta, the products of transformation from ferrihydrite under different reaction conditions were evaluated. Figure 13 compares results of mineral transformation product from ferrihydrite among different $\mathrm{pHs}$, temperatures, and reaction durations. Figure 14 shows the complete XRD patterns for both $\mathrm{pH} 7$ and 12 and temperature $21^{\circ} \mathrm{C}$ and $80^{\circ} \mathrm{C}$ conditions after reacting for 30 days with a solution-to-solid ratio of 1000 . Except at conditions of high $\mathrm{pH}(=12)$ and temperature $\left(80^{\circ} \mathrm{C}\right)$ for 14 and 30 days reaction, most of the ferrihydrite 
transformation product seems to be similar to goethite with the same intensity no matter what $\mathrm{pH}$ and temperature condition was used. It is clear that both comparison results from $\mathrm{Fe}(\mathrm{OH})_{2}(\mathrm{~s})$ and ferrihydrite substrates imply that a high slurry $\mathrm{pH}$ and high temperature condition favors more goethite formation from ferrihydrite transformation. Regarding the mineral transformation kinetics, since no great intensity difference was observed for different reaction durations (Figure 13), it appears that three-seven days could be long enough for most of the experimental setup to complete mineral transformation.
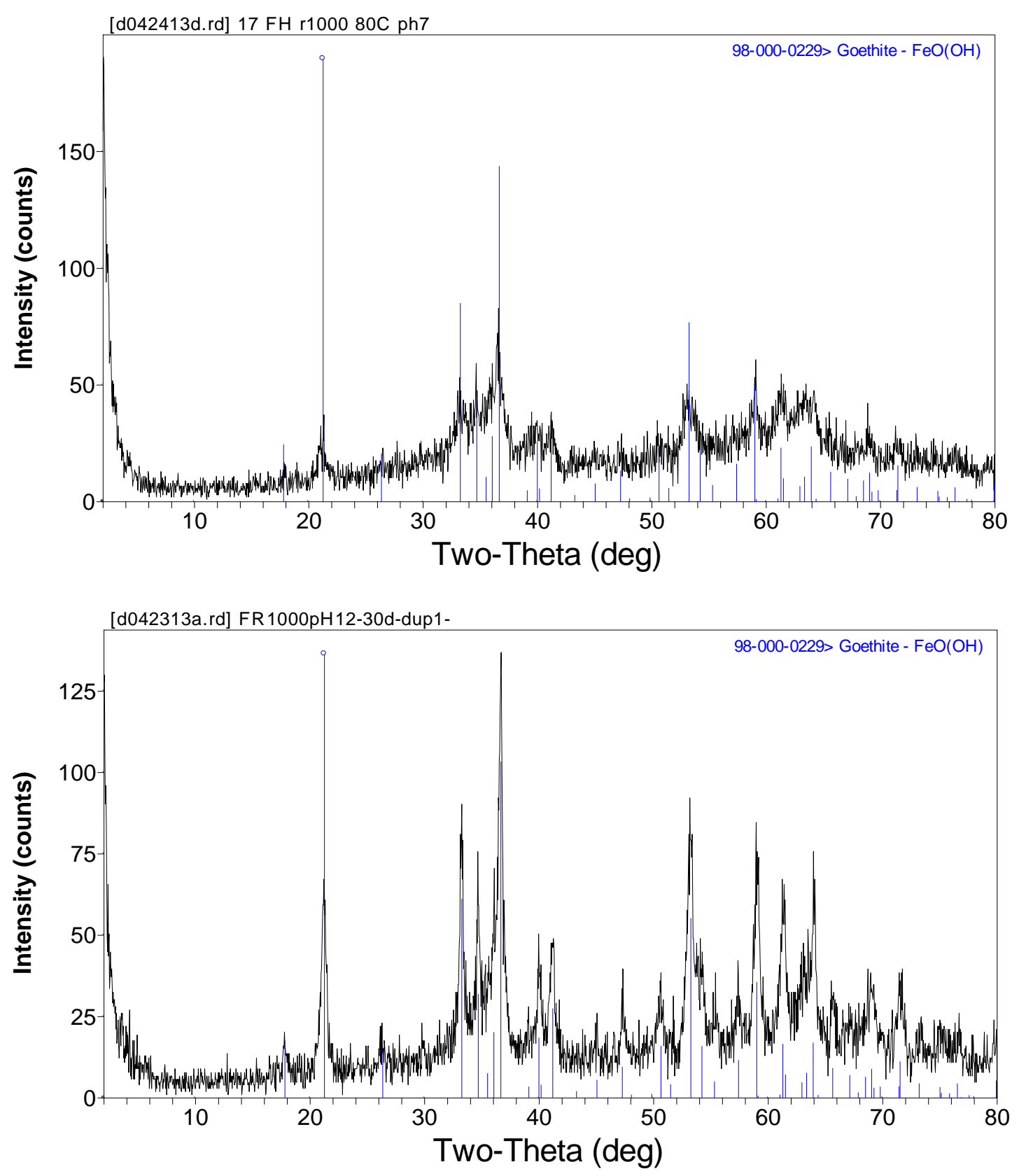

Figure 10. XRD Patterns of Goethite Transformed from Ferrihydrite under $\mathrm{pH} 7$ (top) and $\mathrm{pH} 12$ (bottom) at $80^{\circ} \mathrm{C}$ with a Solution-to-Solid Ratio of 1000 After Reacting for 30 Days 

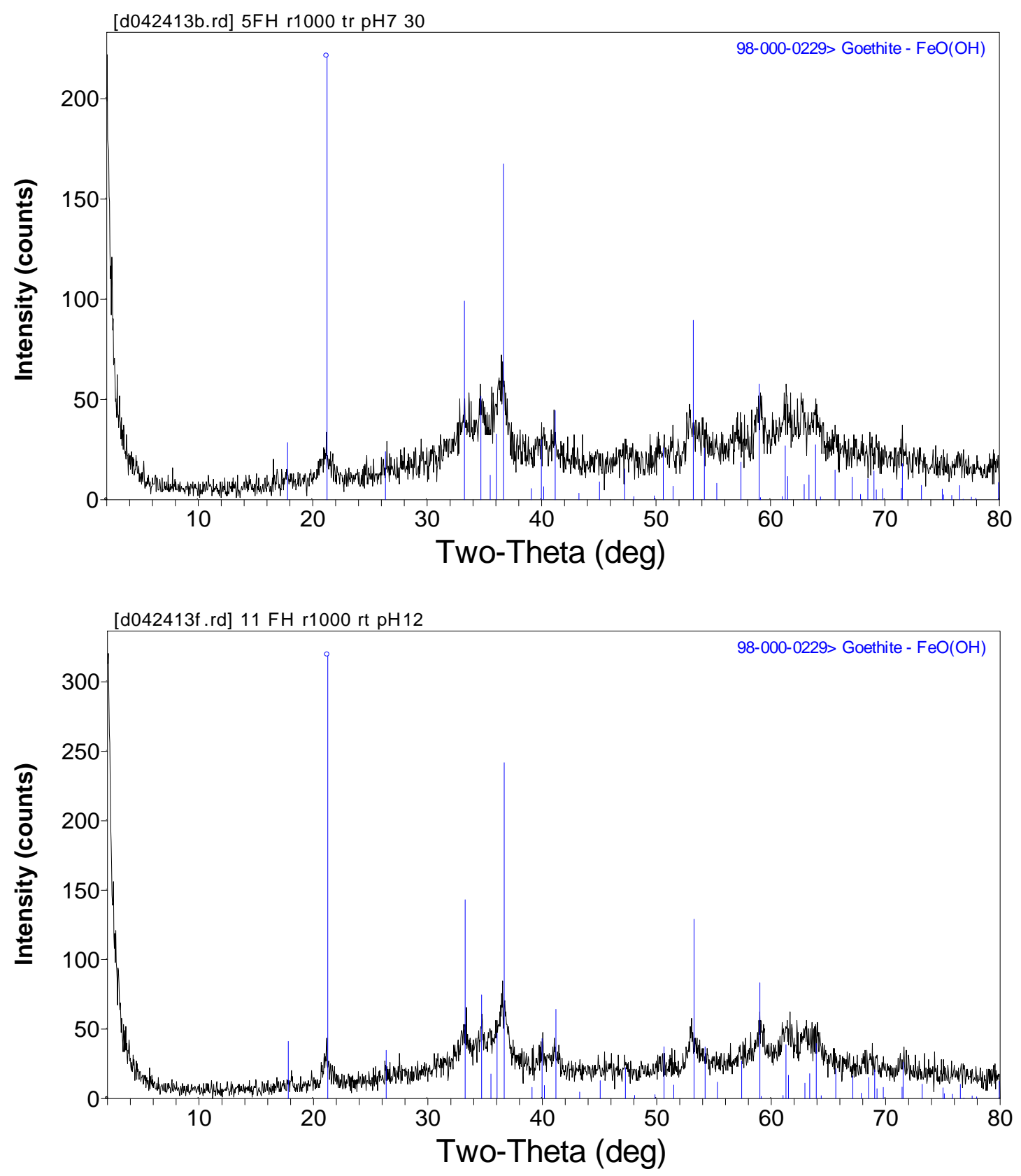

Figure 11. XRD Patterns of Goethite Transformed from Ferrihydrite at $\mathrm{pH} 7$ (top) and $\mathrm{pH} 12$ (bottom) at RT $\left(21^{\circ} \mathrm{C}\right)$ with a Solution-to-Solid Ratio of 1000 After Reacting for 30 Days 

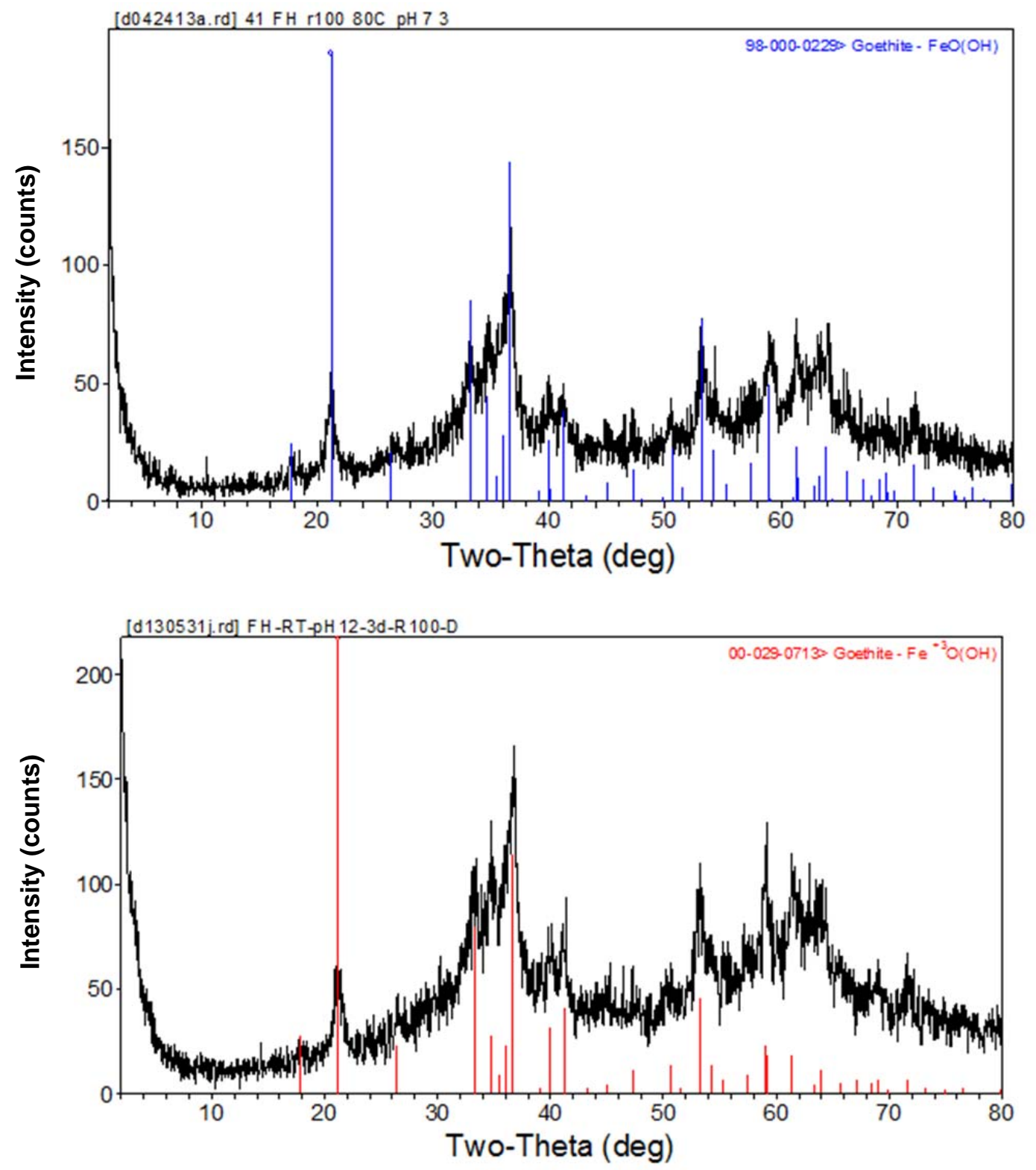

Figure 12. XRD Patterns of Goethite Transformed from Ferrihydrite at $\mathrm{pH} 7$ and $80^{\circ} \mathrm{C}$ (top) and at $\mathrm{pH} 12$ and RT $\left(21^{\circ} \mathrm{C}\right)$ (bottom) with a Solution-to-Solid Ratio of 100 After Reacting for Three Days 


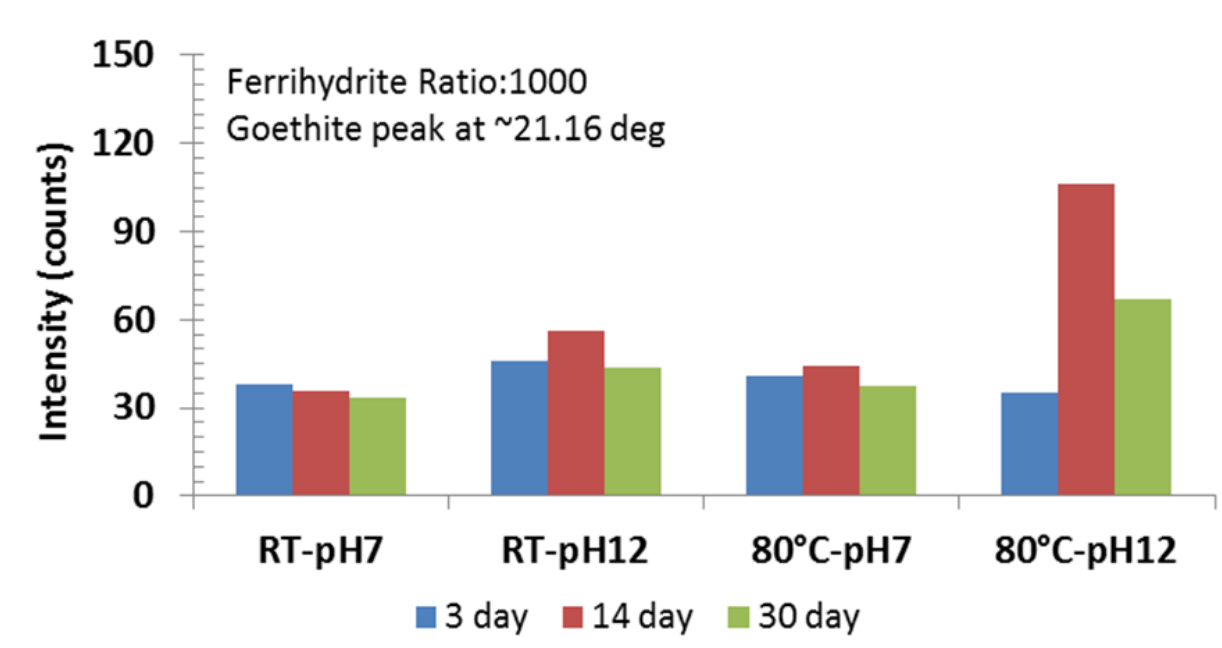

Figure 13. Comparison of Mineral Transformation Products from Ferrihydrite to Goethite Using Goethite "Fingerprint XRD Peak" Among Different Slurry pHs, Temperatures, and Reaction Days

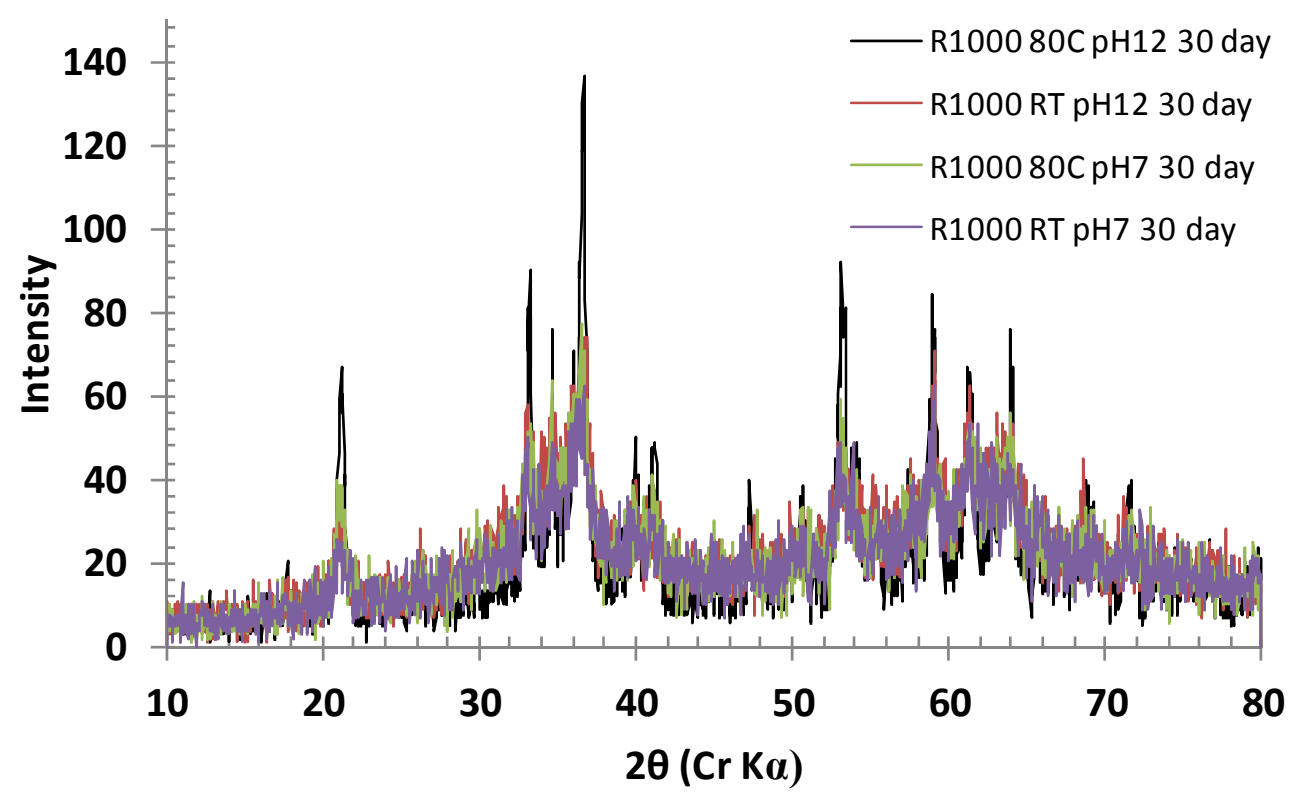

Figure 14. XRD Patterns of Goethite Transformed from Ferrihydrite Under Different pHs (7 and 12), and RT and $80^{\circ} \mathrm{C}$ Conditions after Reacting for 30 Days. R1000 indicates the solution-to-solid ratio of 1000 .

\subsubsection{Transformation from Magnetite}

The XRD patterns before and after the reactions of magnetite illustrated that the transformation of magnetite was quite limited, implying that magnetite is stable in most of the experimental conditions. No obviously new transformed mineral product was created after slurry with a solution-to-solid ratio of 1000 reacted for three days at $80^{\circ} \mathrm{C}$ and $\mathrm{pH} 7$ (Figure 15). Only a limited amount of the magnetite was 
transformed to maghemite, goethite, and hematite while the majority of the magnetite remained unchanged even at $\mathrm{pH} 12$ and $80^{\circ} \mathrm{C}$ conditions with a solution-to-solid ratio of 1000 after reacting for 30 days (Figure 16).

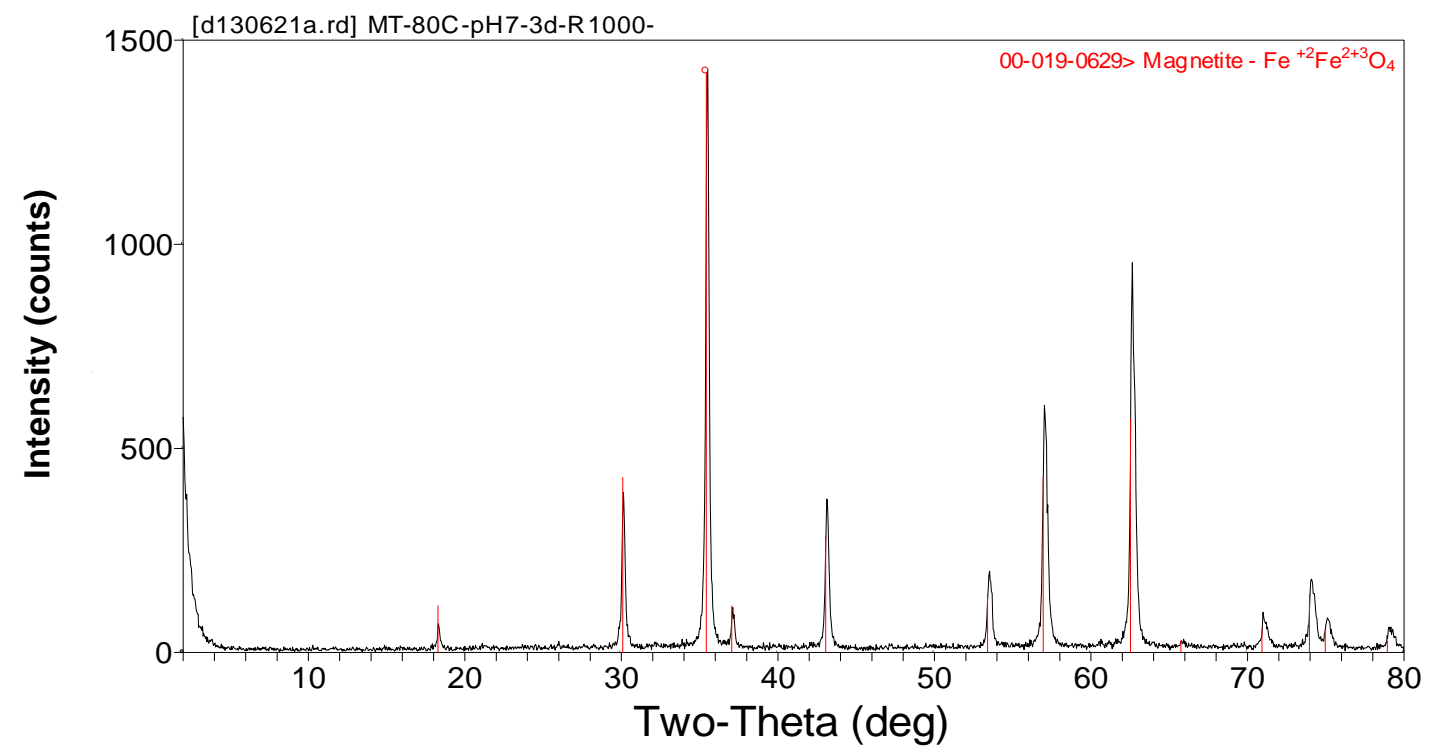

Figure 15. XRD Patterns of Transformed Magnetite at $\mathrm{pH} 7$ and $80^{\circ} \mathrm{C}$ Conditions with a Solution-to-Solid Ratio of 1000 after Reacting for Three Days. No changes were observed.

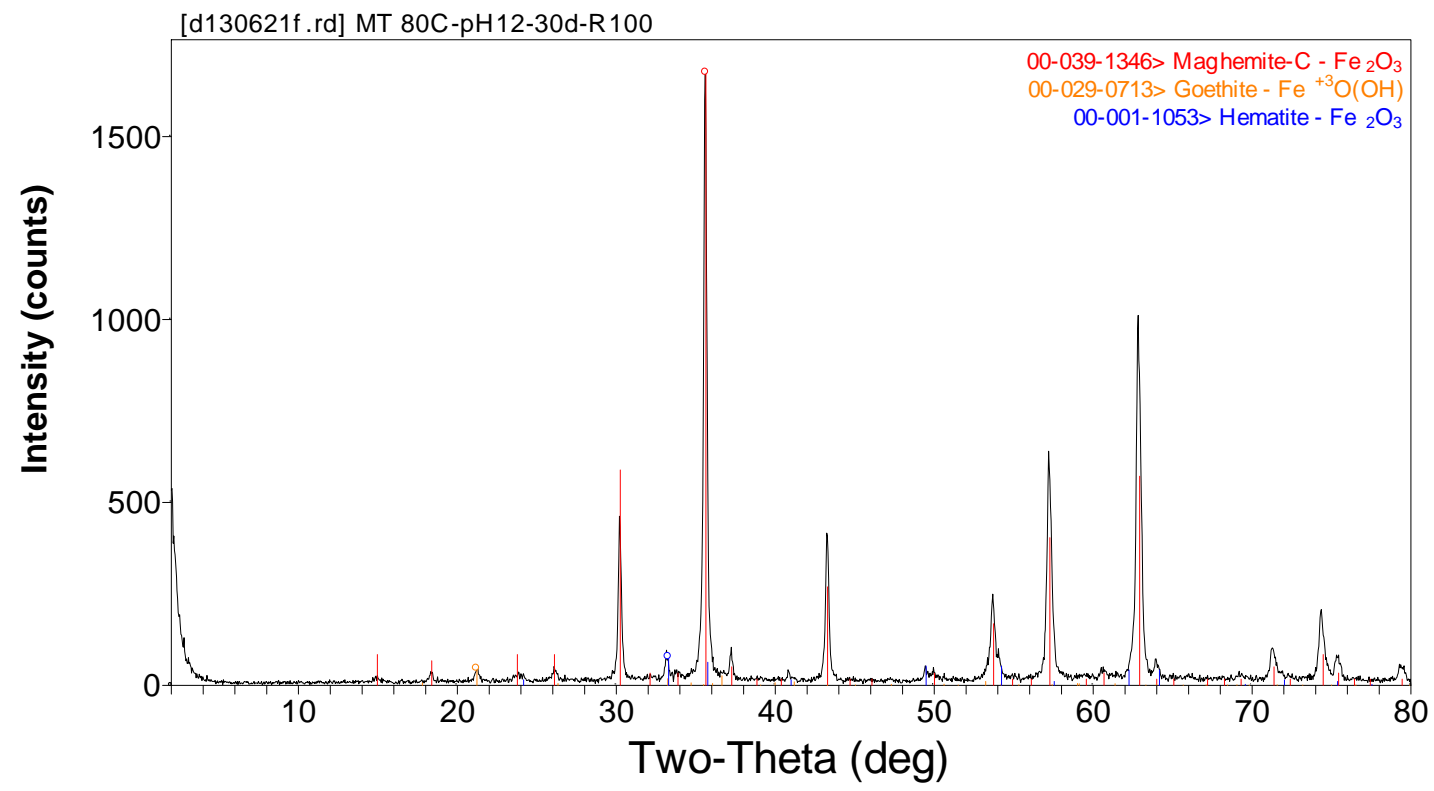

Figure 16. XRD Patterns of Transformed Magnetite at $\mathrm{pH} 12$ and $80^{\circ} \mathrm{C}$ Conditions with a Solution-to-Solid Ratio of 1000 after Reacting for 30 Days. Limited mineral transformation of magnetite to maghemite was observed, with the major content of magnetite unchanged. 


\subsection{Tc Removal by Fe Oxy (hydroxide) Mineral Transformation}

\subsubsection{Tc Removal by $\mathrm{Fe}(\mathrm{OH})_{2}(\mathrm{~s})$ Transformation}

Removal of ${ }^{99} \mathrm{Tc}(\mathrm{VII})$ from ${ }^{99} \mathrm{Tc}$-spiked solution at $\mathrm{pH} \sim 12$ by $\mathrm{Fe}(\mathrm{OH})_{2}$ (s) transformation reaction at both room $\left(21^{\circ} \mathrm{C}\right)$ and elevated $\left(75^{\circ} \mathrm{C}\right)$ temperatures was tested with or without addition of aqueous ferrous iron, $\mathrm{Fe}(\mathrm{II}) . \mathrm{A}^{99} \mathrm{Tc}$-spiked solution with a high $\mathrm{pH}$ of 12 was prepared to mimic the alkaline $\mathrm{pH}$ value of the off-gas scrubber secondary waste stream. Comparisons of the final ${ }^{99} \mathrm{Tc}$ concentrations to that of the control solution $\left[{ }^{99} \mathrm{Tc}\right.$-spiked solution without $\mathrm{Fe}(\mathrm{OH})_{2}(\mathrm{~s})$ addition] and the reaction solutions $\left[{ }^{99} \mathrm{Tc}\right.$-spiked solution with $\left.\mathrm{Fe}(\mathrm{OH})_{2}(\mathrm{~s})\right]$ after reacting for seven days with varied aqueous $\mathrm{Fe}(\mathrm{II})$ concentrations added in the system are shown in Figure 17. In all the cases, the ${ }^{99} \mathrm{Tc}$ concentration in the reaction solutions was completely removed from the initial $10^{-5} \mathrm{M}$ concentration, indicating that most of the ${ }^{99} \mathrm{Tc}$ originally in solution was sequestered into the solid phases due to the presence of $\mathrm{Fe}(\mathrm{OH})_{2}(\mathrm{~s})$ in the reaction system. In terms of ${ }^{99} \mathrm{Tc}$ mass, Figure 18 illustrates that about only $2-4 \%$ of the spiked ${ }^{99} \mathrm{Tc}$ still remained in the aqueous phase, which means that $96-98 \%$ of the ${ }^{99} \mathrm{Tc}$ was removed from solution within seven days of reaction.

\section{Tc concentration in solution (M)}

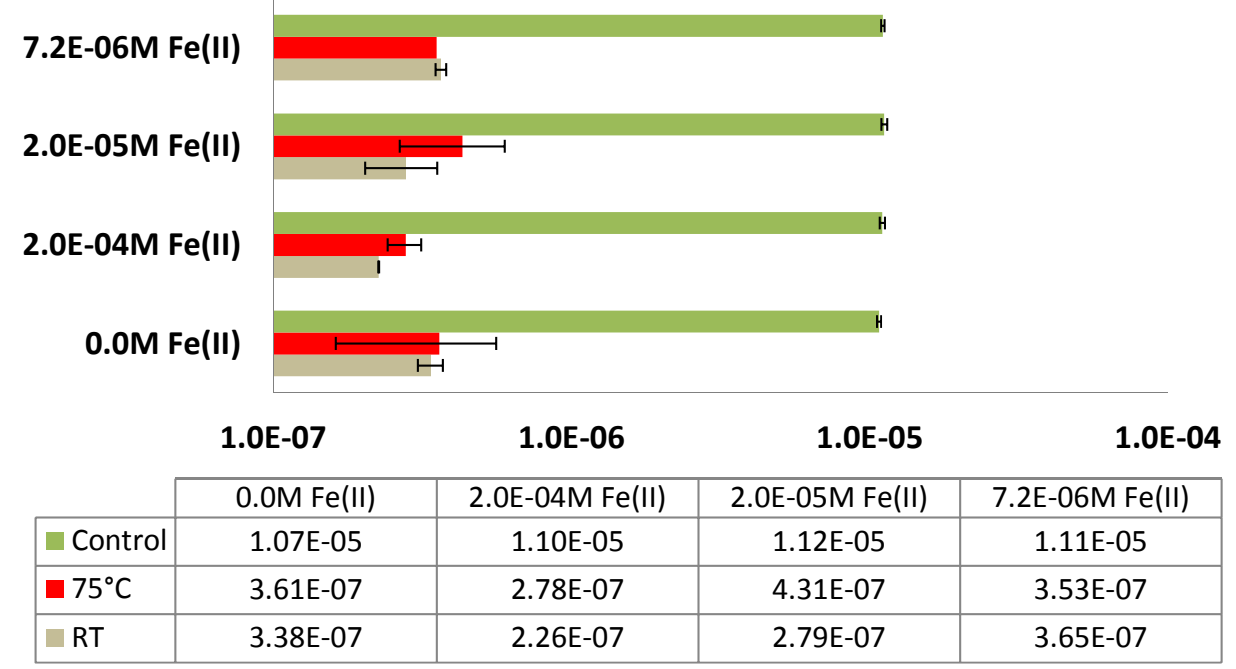

Figure 17. Comparisons of the Final ${ }^{99} \mathrm{Tc}$ Concentrations Between the Control Solution $\left[{ }^{99} \mathrm{Tc}\right.$-spiked solution without $\left.\mathrm{Fe}(\mathrm{OH})_{2}(\mathrm{~s})\right]$ and the Solutions in the Reactors $\left[{ }^{99} \mathrm{Tc}\right.$-spiked solution with $\left.\mathrm{Fe}(\mathrm{OH})_{2}(\mathrm{~s})\right]$ After Seven Days Reacting at Both Room $\left(21^{\circ} \mathrm{C}\right)$ and High $\left(75^{\circ} \mathrm{C}\right)$ Temperatures with Various Ferrous Iron Concentrations Added in the System. The solution-to-solid ratio in the reactors was 1000 . 


\section{Remaining Tc mass in solution (\%)}

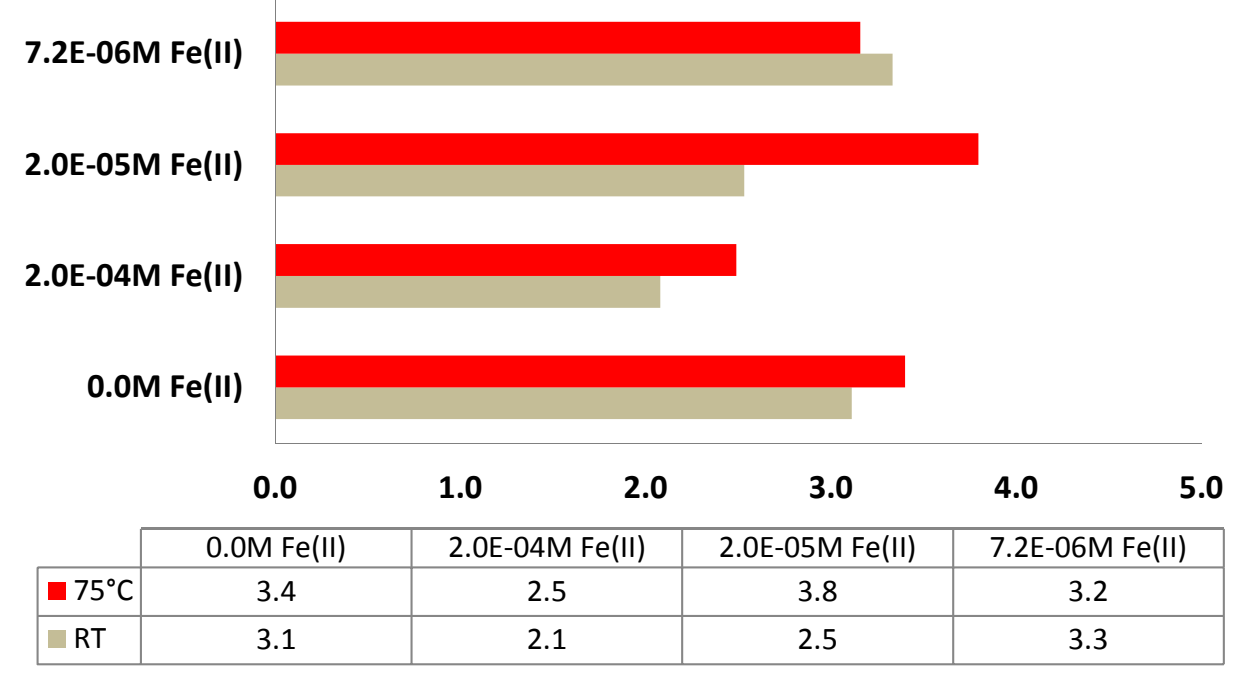

Figure 18. The Remaining ${ }^{99} \mathrm{Tc}$ Concentration (in percentage) in the $\mathrm{Fe}(\mathrm{OH})_{2}(\mathrm{~s})$ Reactors after Reacting for Seven Days at Both Room $\left(21^{\circ} \mathrm{C}\right)$ and $75^{\circ} \mathrm{C}$ Temperatures with Different Ferrous Iron Concentrations Added in the System. The solution-to-solid ratio in the reactors was 1000 .

Figure 17 and Figure 18 illustrate that the ${ }^{99} \mathrm{Tc}$ removal from solution was almost independent of the aqueous $\mathrm{Fe}(\mathrm{II})$ concentrations added in the reactor solutions, at least as long as $\mathrm{Fe}(\mathrm{OH})_{2}(\mathrm{~s})$ was present. In all the cases, the remaining ${ }^{99} \mathrm{Tc}$ concentration percentages in the final reacted solutions showed similar values of $2.1-3.3 \%$ and $2.5-3.8 \%$ for the experiments conducted at $21^{\circ} \mathrm{C}$ and $75^{\circ} \mathrm{C}$, respectively. The remaining ${ }^{99} \mathrm{Tc}$ concentration in percentage at $75^{\circ} \mathrm{C}(2.5-3.8 \%)$ was a little bit higher than the values $(2.1-3.3 \%)$ of ${ }^{99} \mathrm{Tc}$ concentration at RT. However, this difference is negligible since it is considered within the analytical uncertainty range $( \pm 5 \%)$, and also might be from potential evaporation of the solutions at high temperature. There was no ${ }^{99} \mathrm{Tc}$ removal found in any of the control solution samples under different conditions, and the final pHs of reaction solutions were between 9 and 11.5. There is also no significant difference in ${ }^{99} \mathrm{Tc}$ removal $\left(2.5-3.3 \%\right.$ and $3.2-3.8 \%$ of remaining ${ }^{99} \mathrm{Tc}$ for $21^{\circ} \mathrm{C}$ and $75^{\circ} \mathrm{C}$, respectively) among the reaction solutions with different aqueous $\mathrm{Fe}$ (II) concentrations even without $\mathrm{Fe}(\mathrm{II})$ addition. However, carefully comparing the ${ }^{99} \mathrm{Tc}$ removal percentages in the solution with $10^{-4} \mathrm{M}$ $\mathrm{Fe}(\mathrm{II})$ added with results of the other experiments shows clearly that the solution with $10^{-4} \mathrm{M} \mathrm{Fe}(\mathrm{II})$ added showed the highest ${ }^{99} \mathrm{Tc}$ removal, resulting in the minimum ${ }^{99} \mathrm{Tc}$ concentration remaining in the solution, with values of 2.1 and $2.5 \%$ for $21^{\circ} \mathrm{C}$ and $75^{\circ} \mathrm{C}$ temperatures, respectively. This indicates that $\mathrm{Fe}$ (II) addition still helps the ${ }^{99} \mathrm{Tc}$ removal from solution, but the main ${ }^{99} \mathrm{Tc}$ removal is considered to result from the mineral transformation, i.e., from $\mathrm{Fe}(\mathrm{OH})_{2}$ (s) transformed to maghemite, magnetite, and goethite (Figure 9). During this mineral transformation process, $\mathrm{Fe}(\mathrm{II})$ in the $\mathrm{Fe}(\mathrm{OH})_{2}$ (s) solid structure can oxidize to $\mathrm{Fe}$ (III) by releasing electrons, resulting in the formation of magnetite $\left(\mathrm{Fe}_{3} \mathrm{O}_{4}\right)$, maghemite $\left(\gamma-\mathrm{Fe}_{2} \mathrm{O}_{3}\right)$, which is considered an $\mathrm{Fe}(\mathrm{II})$-deficient magnetite with the same structure as magnetite, or goethite $(\alpha-\mathrm{FeOOH})$, while ${ }^{99} \mathrm{Tc}(\mathrm{VII})$ is reduced to ${ }^{99} \mathrm{Tc}(\mathrm{IV})$ by electron acceptance before being incorporated within the final transformed mineral structure. The mineral transformation could be confirmed by the color change of $\mathrm{Fe}(\mathrm{OH})_{2}(\mathrm{~s})$ in the solutions. The initial blue-greenish color of $\mathrm{Fe}(\mathrm{OH})_{2}$ (s) turned to black after one day reacting under this condition. Removal of ${ }^{99} \mathrm{Tc}$ is also possible through a coprecipitation process with respect to maghemite or magnetite as reduced Tc(IV) species. 
Geckeis et al. (2012) found that ${ }^{99} \mathrm{Tc}(\mathrm{IV})$ tends to be fully compatible with the hematite lattice, and Um et al. (2012) reported removal of Tc(IV) using goethite through coprecipitation. However, further tests for solid characterization, with ${ }^{99} \mathrm{Tc}$ speciation analysis as well as Fe(II) concentration changes in solutions, should be conducted to confirm ${ }^{99} \mathrm{Tc}$ incorporation into the $\mathrm{Fe}(\mathrm{OH})_{2}(\mathrm{~s})$ transformed minerals.

Removal of ${ }^{99} \mathrm{Tc}(\mathrm{VII})$ from ${ }^{99} \mathrm{Tc}$-spiked solution at $\mathrm{pH} \sim 12$ by $\mathrm{Fe}(\mathrm{OH})_{2}(\mathrm{~s})$ transformation reaction at both room $\left(21^{\circ} \mathrm{C}\right)$ and elevated $\left(75^{\circ} \mathrm{C}\right)$ temperatures was also tested with varied ${ }^{99} \mathrm{Tc}$-spiked amount in the system. The initial ${ }^{99} \mathrm{Tc}$ aqueous concentration in the reaction system was of $10^{-5}, 10^{-4}$, and $10^{-3} \mathrm{M}$. Comparisons of the final ${ }^{99} \mathrm{Tc}$ concentrations of the reaction solutions $\left[{ }^{99} \mathrm{Tc}\right.$-spiked solution with $\left.\mathrm{Fe}(\mathrm{OH})_{2}(\mathrm{~s})\right]$ with varied initial aqueous ${ }^{99} \mathrm{Tc}$ concentrations spiked in the system after reacting for seven days to that of the control solution $\left[{ }^{99} \mathrm{Tc}\right.$-spiked solution without $\mathrm{Fe}(\mathrm{OH})_{2}(\mathrm{~s})$ addition] for the same seven-day reaction are shown in Figure 19. More ${ }^{99} \mathrm{Tc}$ removal was found at elevated $\left(75^{\circ} \mathrm{C}\right)$ temperature than room $\left(21^{\circ} \mathrm{C}\right)$ temperature, even though the ${ }^{99} \mathrm{Tc}$ removals at $21^{\circ} \mathrm{C}$ and $75^{\circ} \mathrm{C}$ temperatures with initial ${ }^{99} \mathrm{Tc}$ concentration of $10^{-5} \mathrm{M}$ after seven days reaction were similar (or slightly opposite compared to the other results). In terms of ${ }^{99} \mathrm{Tc}$ mass, Figure 20 illustrates that about $3 \%, 14-23 \%$, and $35-36 \%$ of the spiked ${ }^{99} \mathrm{Tc}$ remained in the aqueous phase after seven-day reaction with the initial ${ }^{99} \mathrm{Tc}$ concentrations of $10^{-5}, 10^{-4}$, and $10^{-3} \mathrm{M}$ in $\mathrm{Fe}(\mathrm{OH})_{2}(\mathrm{~s})$ slurry, respectively, which means that $97 \%, 77-86 \%$, and $64-65 \%$ of the ${ }^{99} \mathrm{Tc}$ was removed accordingly from solutions within seven days of reaction. Increasing ${ }^{99} \mathrm{Tc}$ removal percentage from $\mathrm{Fe}(\mathrm{OH})_{2}(\mathrm{~s})$ transformation was found with increasing ${ }^{99} \mathrm{Tc}$ initial concentration up to $10^{-3}$ $\mathrm{M}$ as shown a linear relationship between the sequestered ${ }^{99} \mathrm{Tc}$ mass normalized by the initial $\mathrm{Fe}(\mathrm{OH})_{2}(\mathrm{~s})$ mass versus the initial ${ }^{99} \mathrm{Tc}$ aqueous concentrations (Figure 20).

\section{Tc concentration in solution (M)}

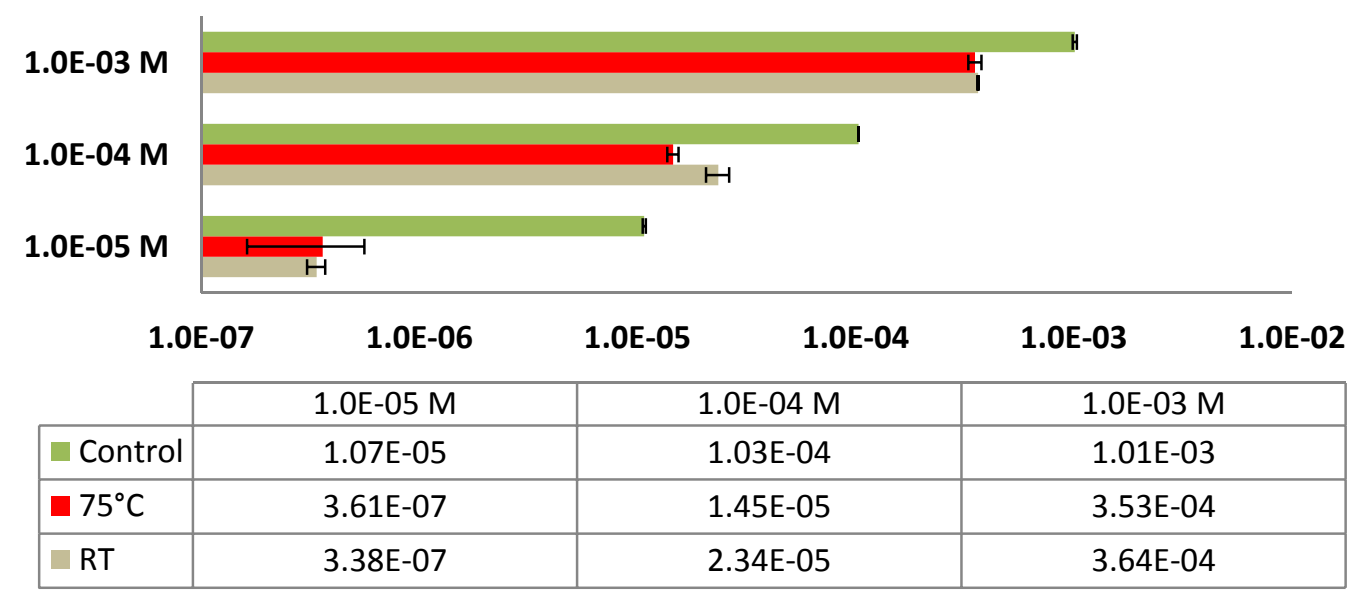

Figure 19. Comparisons of the Final ${ }^{99} \mathrm{Tc}$ Concentrations Between the Control Solution $\left[{ }^{99} \mathrm{Tc}\right.$-spiked solution without $\left.\mathrm{Fe}(\mathrm{OH})_{2}(\mathrm{~s})\right]$ and the Solutions in the Reactors $\left[{ }^{99} \mathrm{Tc}\right.$-spiked solution with $\left.\mathrm{Fe}(\mathrm{OH})_{2}(\mathrm{~s})\right]$ After Seven Days Reacting at Both Room $\left(21^{\circ} \mathrm{C}\right)$ and High $\left(75^{\circ} \mathrm{C}\right)$ Temperatures with Various ${ }^{99} \mathrm{Tc}$-spiked Concentrations in the System. The solution-to-solid ratio in the reactors was 1000 . 


\section{Remaining Tc mass in solution (\%)}

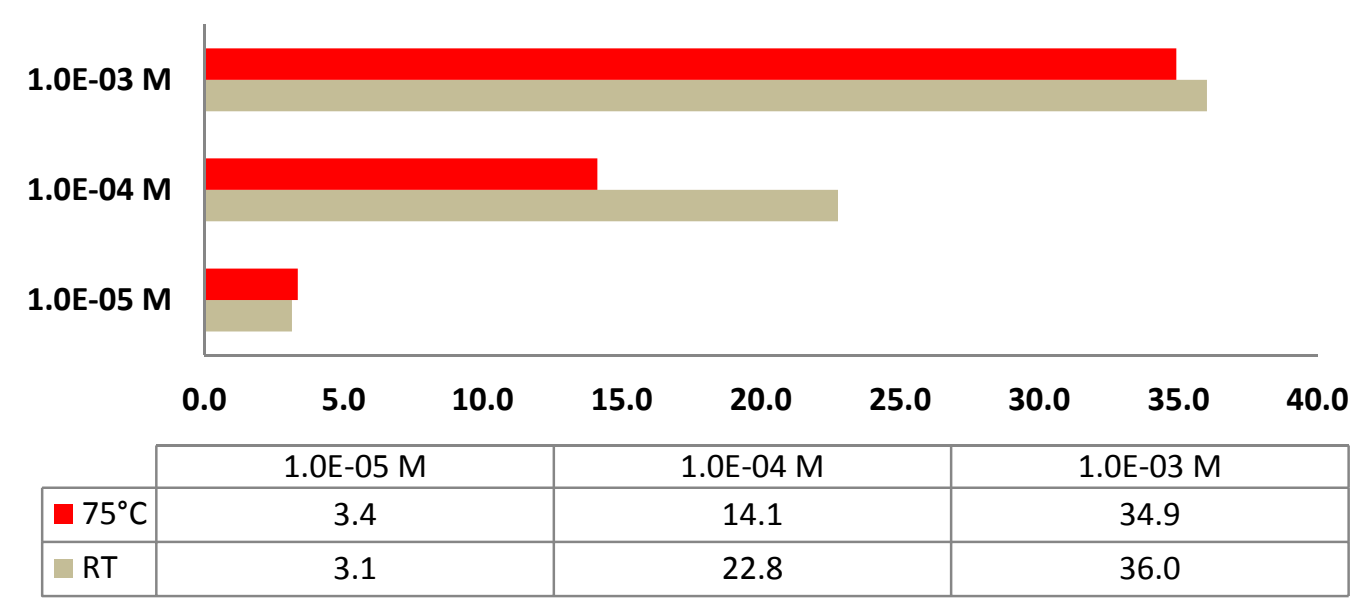

Figure 20. The Remaining ${ }^{99} \mathrm{Tc}$ Aqueous Concentration (\%) in the $\mathrm{Fe}(\mathrm{OH})_{2}$ (s) Reactors after Reacting for Seven Days at Both Room $\left(21^{\circ} \mathrm{C}\right)$ and $75^{\circ} \mathrm{C}$ Temperatures with Different ${ }^{99} \mathrm{Tc}$-spiked Concentrations of $10^{-5}, 10^{-4}$, and $10^{-3} \mathrm{M}$ in the System. The solution-to-solid ratio in the reactors was 1000 .

Since the finally measured $\mathrm{pHs}$ were close to 11 after seven-day reaction, ${ }^{99} \mathrm{Tc}$ removal was not possible by surface adsorption of ${ }^{99} \mathrm{Tc}(\mathrm{VII})$ on $\mathrm{Fe}(\mathrm{OH})_{2}(\mathrm{~s})$ under this high $\mathrm{pH}$ condition. It is clear that the removed ${ }^{99} \mathrm{Tc}$ mass normalized by the initial $\mathrm{Fe}(\mathrm{OH})_{2}(\mathrm{~s})$ mass after seven-day reaction increased with the increasing initial ${ }^{99} \mathrm{Tc}$ aqueous concentrations (Figure 21). Removal of ${ }^{99} \mathrm{Tc}$ is considered to follow ${ }^{99} \mathrm{Tc}(\mathrm{VII})$ reduction to ${ }^{99} \mathrm{Tc}(\mathrm{IV})$ first, which can be further incorporated within the final mixture of $\mathrm{Fe}(\mathrm{OH})_{2}(\mathrm{~s})$ transformation product. However, the presence of independent ${ }^{99} \mathrm{TcO}_{2} \cdot 2 \mathrm{H}_{2} \mathrm{O}$ (s) cannot be ruled out in this system, because of a linear relationship between the sequestered ${ }^{99} \mathrm{Tc}$ mass per the initial $\mathrm{Fe}(\mathrm{OH})_{2}(\mathrm{~s})$ and the initial ${ }^{99} \mathrm{Tc}$ aqueous concentrations. Additional XAFS study for the final product containing ${ }^{99} \mathrm{Tc}$ needs to investigate ${ }^{99} \mathrm{Tc}$ oxidation state and ${ }^{99} \mathrm{Tc}$ removal mechanism between ${ }^{99} \mathrm{Tc}(\mathrm{IV}) \mathrm{O}_{2} \cdot 2 \mathrm{H}_{2} \mathrm{O}$ (s) precipitate and ${ }^{99} \mathrm{Tc}(\mathrm{IV})$ incorporation within a final mixture of $\mathrm{Fe}(\mathrm{OH})_{2}(\mathrm{~s})$ transformation product. 


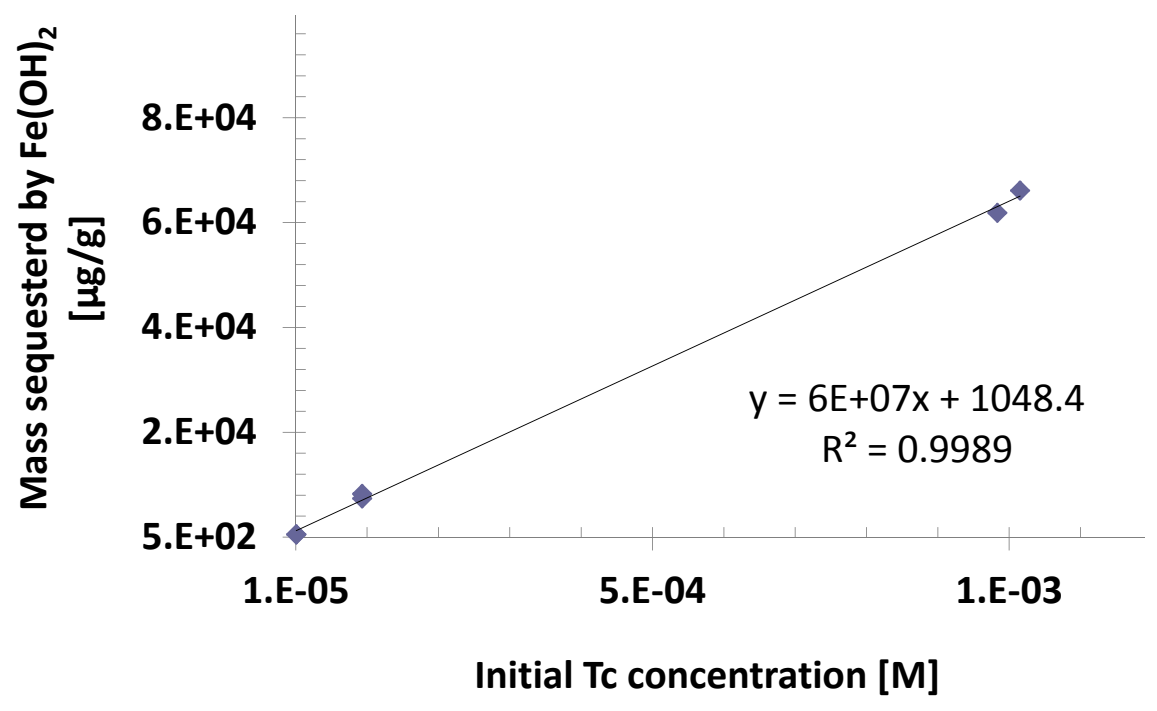

Figure 21. Removed ${ }^{99} \mathrm{Tc}$ Mass Normalized by the Initial $\mathrm{Fe}(\mathrm{OH})_{2}(\mathrm{~s})$ Mass versus the Initial ${ }^{99} \mathrm{Tc}$ Aqueous Concentrations

\subsubsection{Tc Removal by Magnetite Transformation}

Removal of ${ }^{99} \mathrm{Tc}$ (VII) from ${ }^{99} \mathrm{Tc}$-spiked solution of $\sim \mathrm{pH} 12$ by magnetite transformation at both room $\left(21^{\circ} \mathrm{C}\right)$ and elevated $\left(75^{\circ} \mathrm{C}\right)$ temperatures was tested with varied ${ }^{99} \mathrm{Tc}$ concentrations. Comparison of the ${ }^{99} \mathrm{Tc}$ concentrations between the control solutions $\left({ }^{99} \mathrm{Tc}\right.$ solution without magnetite addition) and the solutions in the reactors $\left({ }^{99} \mathrm{Tc}\right.$ solution with magnetite solid) after reacting with varied spiked ${ }^{99} \mathrm{Tc}$ concentrations for 14 days and 42 days are shown in Figure 22 . In all the cases, the ${ }^{99} \mathrm{Tc}$ concentrations in the reaction solution were unchanged and similar to the values of ${ }^{99} \mathrm{Tc}$ concentrations in the control samples, indicating that almost no ${ }^{99} \mathrm{Tc}$ was removed from the solutions. In terms of ${ }^{99} \mathrm{Tc}$ concentration, Figure 23 illustrates that more than $97 \%$ of the spiked ${ }^{99} \mathrm{Tc}$ still remained in the aqueous phase. Even considering the analytical uncertainty of $\pm 5 \%$, no ${ }^{99} \mathrm{Tc}$ removal from the solution or a very limited amount $(<3 \%)$ if any, was possible in the reactor solutions with magnetite. Only in the reaction conducted at $75^{\circ} \mathrm{C}$ combined with the lowest ${ }^{99} \mathrm{Tc}$-spiked concentration of $10^{-5} \mathrm{M}$ was measurable ${ }^{99} \mathrm{Tc}$ removal (about $9 \%$ ) observed, where the final ${ }^{99} \mathrm{Tc}$ solution concentration in the reactor was $91 \%$ of the initial values after the reactions for 14 or 42 days. This phenomenon indicates that very little ${ }^{99} \mathrm{Tc}$ could be removed from the tested solutions when magnetite is used. This result agrees well with the mineral transformation results described in Section 3.2. As we observed in the pure mineral transformation experiments, only limited mineral transformation of magnetite to maghemite could occur under conditions of $\mathrm{pH} 12$ and $80^{\circ} \mathrm{C}$, where quite limited $\mathrm{Fe}$ (II) in magnetite could oxidize to $\mathrm{Fe}(\mathrm{III})$. Therefore, a limited amount of ${ }^{99} \mathrm{Tc}$ (VII) could be reduced to ${ }^{99} \mathrm{Tc}(\mathrm{IV})$ and incorporated into newly formed maghemite structure through coprecipitation. In the experiments with high spiked ${ }^{99} \mathrm{Tc}$ concentrations, concentrations of $10^{-4}$ and $10^{-3}$ $\mathrm{M}$ of ${ }^{99} \mathrm{Tc}$ in the reactor solutions were too high compared to the releasable electrons resulting from mineral transformation of magnetite; thus no ${ }^{99} \mathrm{Tc}$ removal could be observed even if it occurred in very limited amounts after ${ }^{99} \mathrm{Tc}(\mathrm{IV})$ reduction. 


\section{Tc concentration in solution (M) at 14 days}

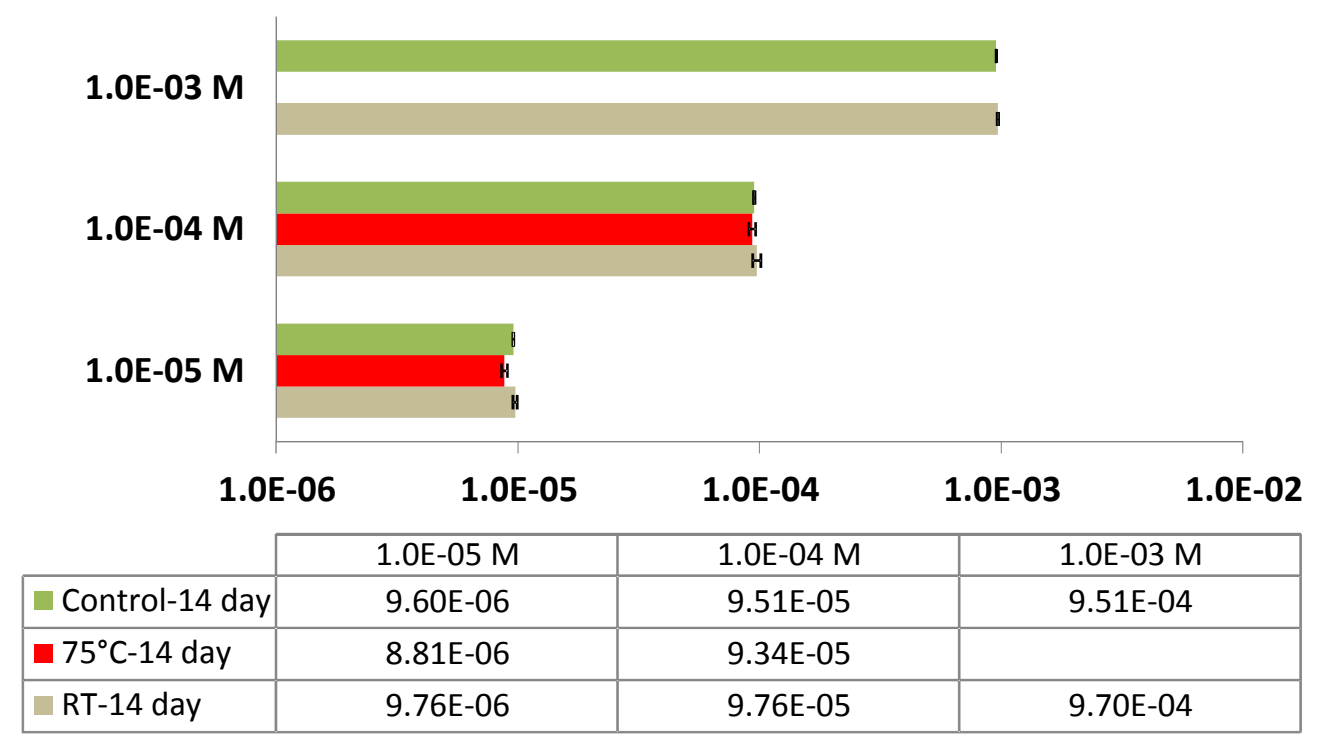

\section{Tc concentration in solution (M) at 42 days}

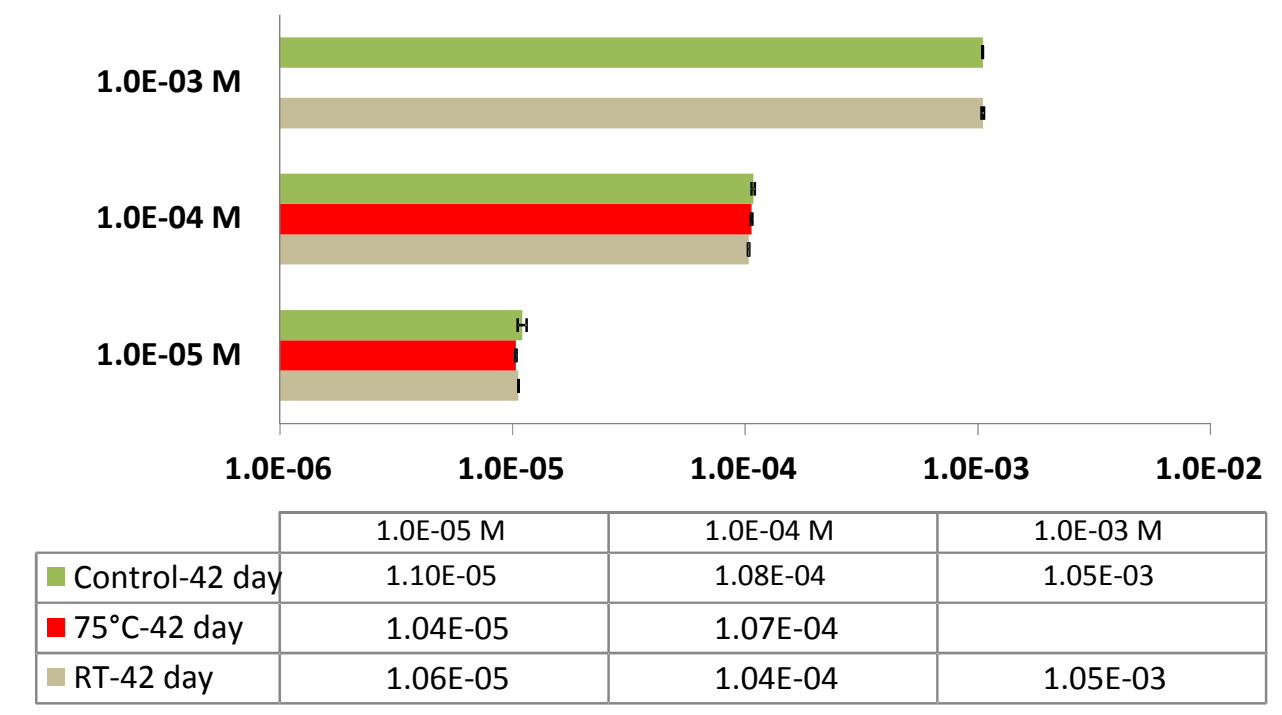

Figure 22. Comparisons of ${ }^{99} \mathrm{Tc}$ Removal Between the Control Solutions (Tc solution without magnetite) and the Solutions in the Reactors $\left({ }^{99} \mathrm{Tc}\right.$-spiked solution with magnetite) after Reacting for 14 Days and 42 Days at Both RT $\left(21^{\circ} \mathrm{C}\right)$ and $75^{\circ} \mathrm{C}$ with Varied ${ }^{99} \mathrm{Tc}$ Concentrations. The solution-to-solid ratio in the reactors was 1000 . 


\section{Remaining Tc mass in solution (\%) at $42 / 14$ days}

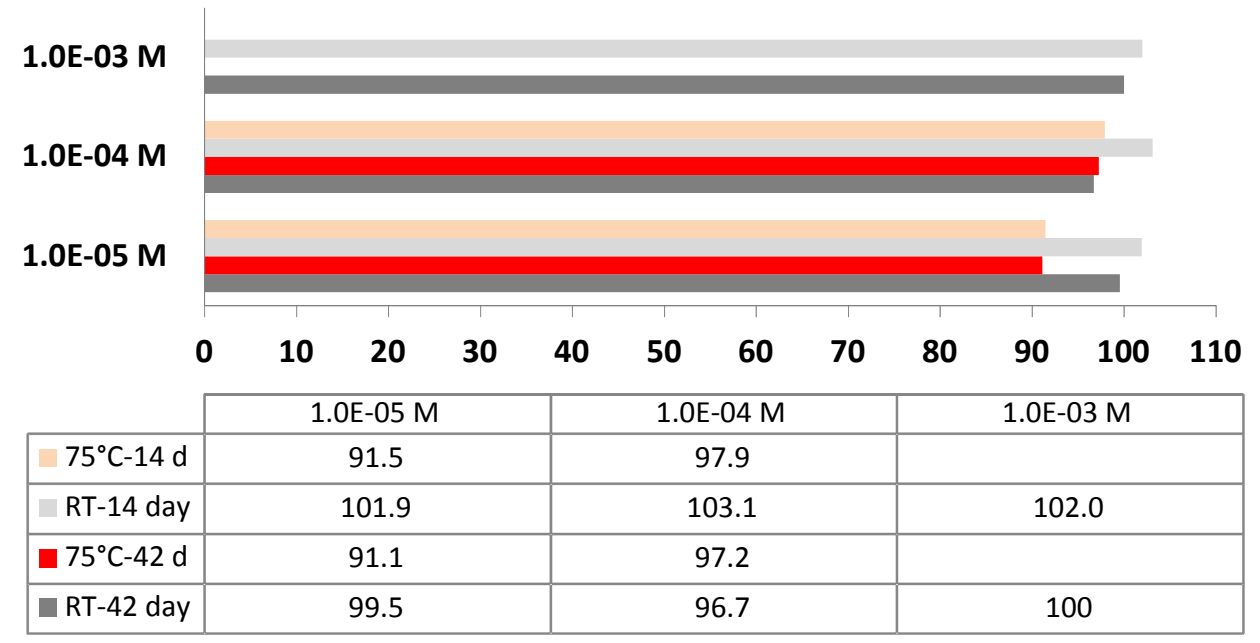

Figure 23. The Remaining Tc Mass (in percentage) in the Magnetite Reactors after Reacting for 14 and 42 Days at Both RT $\left(21^{\circ} \mathrm{C}\right)$ and $75^{\circ} \mathrm{C}$ with Varied Spiked Tc Mass in the System. The solution-to-solid ratio in the reactors was 1000 .

\subsection{Tc-Goethite Long-Term Leaching and XAFS Analysis}

Batch-leaching data for ${ }^{99} \mathrm{Tc}$ and dissolved Fe(total) as a function of time in the IDF pore water solution are shown in Table 2. The leachates were analyzed and the average values were determined for ${ }^{99} \mathrm{Tc}$ concentration and $\mathrm{pH}$. Measured $\mathrm{pH}$ values in the IDF pore water leaching solution showed no dramatic changes even after two years (Table 2), indicating no significant $\mathrm{pH}$-altering geochemical reaction such as dissolution occurred during the long-term leaching. Detectable ${ }^{99} \mathrm{Tc}$ concentrations in the leachates even after two years were close to or less than $2 \mu \mathrm{g} / \mathrm{L}$ in the IDF pore water solution. No measurable Fe(total) concentrations were detected in the IDF leachates, which were below the estimated quantitation limit (EQL) of ICP-OES $(<10 \mu \mathrm{g} / \mathrm{L})$. Because negligible amounts of total Fe concentrations were found in the IDF leachates, the ${ }^{99} \mathrm{Tc}$-hosting Fe mineral goethite was not dissolved in the circumneutral $\mathrm{pH}$ condition, which is related to the low goethite solubility at circumneutral $\mathrm{pH}$ values. Gradual increase of the measured ${ }^{99} \mathrm{Tc}$ concentrations from $1.33 \mu \mathrm{g} / \mathrm{L}$ after three months leaching to $2.03 \mu \mathrm{g} / \mathrm{L}$ after two years leaching, but not the 6-month leached ${ }^{99} \mathrm{Tc}$ concentration of $2.16 \mu \mathrm{g} / \mathrm{L}$, was attributed mainly to a slow diffusion process. However, no significantly increased ${ }^{99} \mathrm{Tc}$ concentrations found in the leachates even after two years in the oxidizing condition indicate that ${ }^{99} \mathrm{Tc}$ does not reoxidize much from ${ }^{99} \mathrm{Tc}(\mathrm{IV})$ to pertechnetate, ${ }^{99} \mathrm{Tc}(\mathrm{VII})$, in the ${ }^{99} \mathrm{Tc}$-goethite solid even during long term leaching and air exposure. Because the powdered ${ }^{99} \mathrm{Tc}$-goethite sample 2-5 was prepared with additional goethite armoring (Um et al. 2011) and showed the highest ${ }^{99} \mathrm{Tc}(\mathrm{IV})$ contribution $(\sim 100 \%)$ as prepared (Um et al. 2012), Tc-goethite sample $2-5$ is considered to the most resistant to ${ }^{99} \mathrm{Tc}$ reoxidation and leaching, even after less than three years in the oxidizing condition. 
Table 2. Measured $\mathrm{pH}$ and Concentrations of ${ }^{99} \mathrm{Tc}$ and Fe(total) of Tc-Goethite Sample 2-5 After Long-Term Leaching in IDF Solution

\begin{tabular}{lcccc}
\hline \multicolumn{1}{c}{ Reaction Conditions } & $\begin{array}{c}{ }^{99} \mathbf{T c} \\
\mathbf{C o n c e n t r a t i o n} \\
(\boldsymbol{\mu g} / \mathbf{L})\end{array}$ & $\begin{array}{c}\mathbf{F e}(\text { total) } \\
\mathbf{C o n c e n t r a t i o n} \\
(\boldsymbol{\mu g} / \mathbf{L})\end{array}$ & $\begin{array}{c}\text { XHAFS } \\
\mathbf{p H}\end{array}$ & $\begin{array}{c}\text { Sample } \\
\text { Preparation }\end{array}$ \\
\hline Three months leaching in IDF solution & 1.33 & $\mathrm{ND}^{(\mathrm{a})}$ & 6.92 & No \\
Six months leaching in IDF solution & 2.16 & $\mathrm{ND}$ & 7.20 & No \\
One year leaching in IDF solution & 1.68 & $\mathrm{ND}$ & 7.30 & Yes \\
Two years leaching in IDF solution & 2.03 & $\mathrm{ND}$ & 7.00 & Yes \\
Three years reaction & - & - & - & Yes \\
(two years in IDF solution + one year & & & & \\
in air) & & & & \\
\hline
\end{tabular}

(a) $\mathrm{ND}=$ not detected $(<10 \mu \mathrm{g} / \mathrm{L}$ of ICP-OES estimated quantitation limit).

The XANES spectra of ${ }^{99} \mathrm{Tc}$ standards $\left({ }^{99} \mathrm{TcO}_{4}{ }^{-}\right.$and $\left.{ }^{99} \mathrm{TcO}_{2} \cdot 2 \mathrm{H}_{2} \mathrm{O}\right)$ and ${ }^{99} \mathrm{Tc}$-goethite $2-5$ samples reacted in the IDF leaching solution and in air up to three years are shown in Figure 24. The ${ }^{99} \mathrm{Tc}(\mathrm{VII})$ XANES spectrum is characterized by a strong pre-edge feature found at around the 21,046 eV energy region because of the $1 \mathrm{~s}$-to- $4 \mathrm{~d}$ transition, which is allowed for the tetrahedral ${ }^{99} \mathrm{TcO}_{4}{ }^{-}$coordination. The XANES spectrum for the ${ }^{99} \mathrm{Tc}(\mathrm{IV})$ standard from ${ }^{99} \mathrm{TcO}_{2} \cdot 2 \mathrm{H}_{2} \mathrm{O}$ is very different from the ${ }^{99} \mathrm{Tc}(\mathrm{VII})$ standard spectrum, and is characteristic of ${ }^{99} \mathrm{Tc}(\mathrm{IV})$ coordinated by oxygen atoms in an octahedral geometry without showing the pre-edge feature shown for ${ }^{99} \mathrm{Tc}(\mathrm{VII})$. For comparison, the ${ }^{99} \mathrm{Tc}$ XANES spectra of ${ }^{99} \mathrm{Tc}$-goethite 2-5 samples as prepared and after 6-month leaching in the IDF pore water solution were obtained from Um et al. $(2011,2012)$, and are shown together with new XANES results for the ${ }^{99} \mathrm{Tc}$-goethite 2-5 samples reacted for three years (see Table 2 for XAFS sample information). 


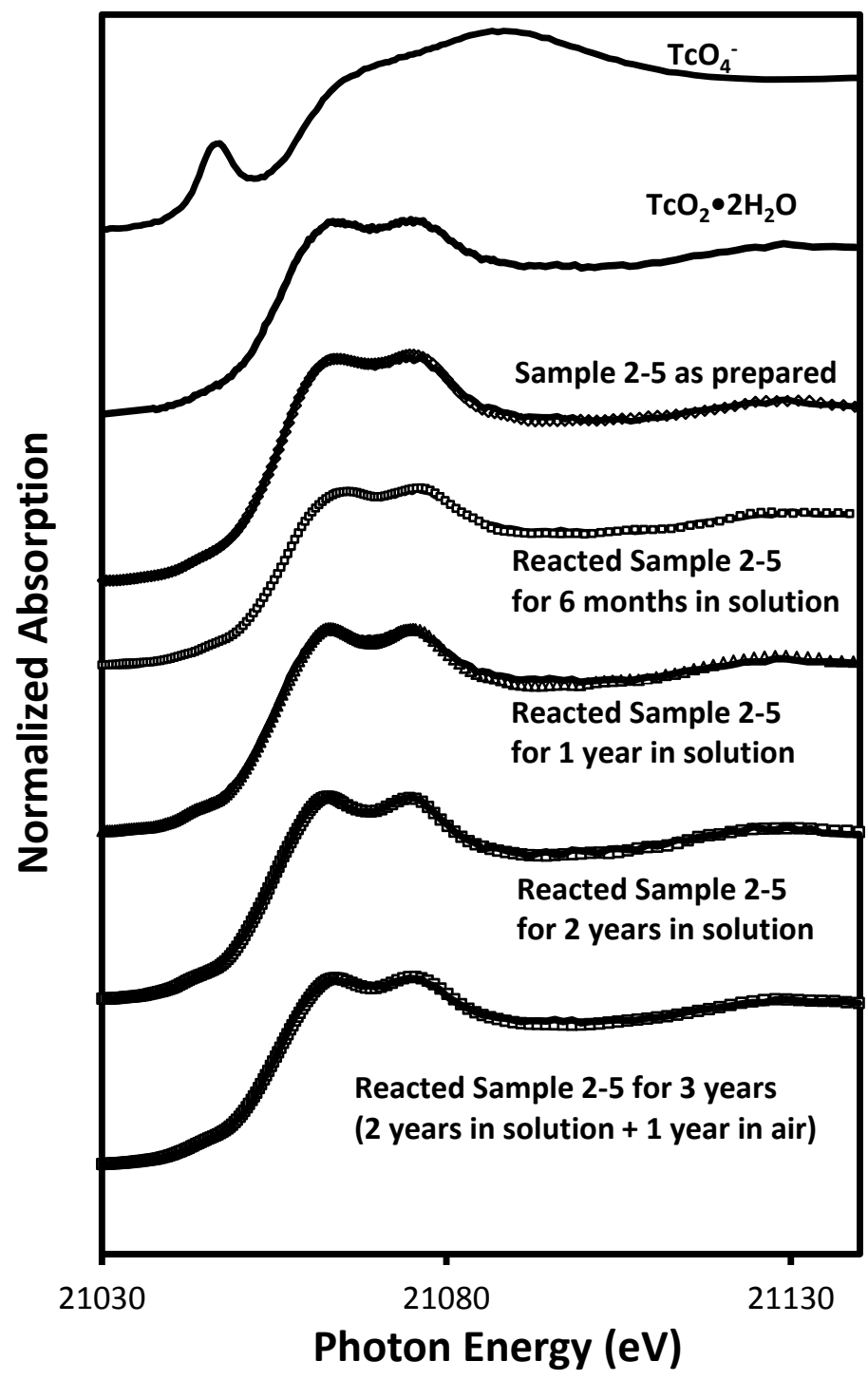

Figure 24. Normalized ${ }^{99}$ Tc XANES Spectra and Fits for ${ }^{99}$ Tc-Goethite 2-5 Samples Reacted Under Different Conditions. Data are represented by symbols, and the fits are represented by the solid lines. The contributions of each ${ }^{99} \mathrm{Tc}$ species are from ${ }^{99} \mathrm{TcO}_{4}{ }^{-}$and ${ }^{99} \mathrm{TcO}_{2} \cdot 2 \mathrm{H}_{2} \mathrm{O}$.

The oxidation state of ${ }^{99} \mathrm{Tc}$ in the reacted ${ }^{99} \mathrm{Tc}$-goethite 2-5 samples after either leaching in the IDF solution or in air was determined by fitting their XANES spectra using a linear combination model with the spectra for the ${ }^{99} \mathrm{TcO}_{4}{ }^{-}$and the ${ }^{99} \mathrm{TcO}_{2} \cdot 2 \mathrm{H}_{2} \mathrm{O}$ standards. In all cases, the fitting results indicated that only ${ }^{99} \mathrm{Tc}(\mathrm{IV})$ was present in both reacted and unreacted ${ }^{99} \mathrm{Tc}$-goethite $2-5$ samples. Even though there was two years reaction in the IDF leaching solution and one year exposure in air, the ${ }^{99} \mathrm{Tc}$ speciation and oxidation state was not changed and almost $100 \%$ of the ${ }^{99} \mathrm{Tc}(\mathrm{IV})$ was still present in the solid phase. The fraction of ${ }^{99} \mathrm{Tc}(\mathrm{VII})$ present in the reacted ${ }^{99} \mathrm{Tc}$-goethite samples even after reaction in the leached solution or air condition was less than $1 \%$ (Table 3), suggesting that the reoxidation of the ${ }^{99} \mathrm{Tc}(\mathrm{IV})$ initially incorporated within the Fe(II)-treated goethite mineral lattice (sample 2-5) was significantly limited even after being exposed to oxygen both in solution and air. It is not certain why the limited Tc reoxidation is still possible in the three-year reacted Tc-goethite sample 2-5 based on the insufficient data 
we have so far. However, it may be attributed to the armoring coating layer of $\mathrm{Fe}(\mathrm{OH})_{3}$ precipitates in Tc-goethite sample 2-5 that can effectively block oxygen access to ${ }^{99} \mathrm{Tc}(\mathrm{IV})$ present in the goethite lattice. The measured reductive capacities of the ${ }^{99} \mathrm{Tc}$-goethite 2-5 and 2-2 samples before leaching were $0.140 \mathrm{meq} / \mathrm{g}$ and $0.744 \mathrm{meq} / \mathrm{g}$, respectively. Although low reductive capacity was measured in the ${ }^{99}$ Tc-goethite 2-5 sample, which was prepared with additional armoring, than in the 2-2 sample, which was prepared without additional armoring (Um et al. 2011), more leachable ${ }^{99} \mathrm{Tc}$ concentrations were found in ${ }^{99} \mathrm{Tc}$-goethite 2-2 sample than in the 2-5 sample under the same leaching solution conditions (Um et al 2012). Therefore, the limited ${ }^{99} \mathrm{Tc}$ reoxidation found in the ${ }^{99} \mathrm{Tc}$-goethite $2-5$ sample may result from a physical barrier effect rather than chemical reductive capacity preserved in the magnetite mineral that was present more in the final ${ }^{99}$ Tc-goethite 2-2 sample.

Table 3. XANES Fit Results for ${ }^{99} \mathrm{Tc}$ Species in ${ }^{99} \mathrm{Tc}-$ Goethite 2-5 Samples

\begin{tabular}{|c|c|c|c|c|}
\hline Samples & $\begin{array}{l}\text { Time }^{(a)} \\
\text { (days) }\end{array}$ & $\begin{array}{c}\operatorname{Tc}(I V)^{(b)} \\
(\%)\end{array}$ & $\begin{array}{c}\mathrm{Tc}(\mathrm{VII})^{(\mathbf{b})} \\
(\%)\end{array}$ & Reaction Conditions \\
\hline 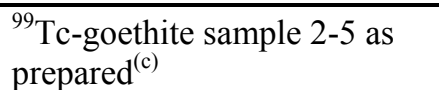 & 0 & $100 \pm 2$ & $0 \pm 2$ & No reaction \\
\hline $\begin{array}{l}{ }^{99} \text { Tc-goethite sample } 2-5 \text { after } \\
\text { six-month leaching }{ }^{(\mathrm{c})}\end{array}$ & 180 & $100 \pm 2$ & $0 \pm 2$ & Leaching in the IDF solution \\
\hline $\begin{array}{l}{ }^{99} \text { Tc-goethite sample } 2-5 \text { after } \\
\text { one-year leaching }\end{array}$ & 395 & $99 \pm 2$ & $0 \pm 2$ & Leaching in the IDF solution \\
\hline $\begin{array}{l}{ }^{99} \text { Tc-goethite sample } 2-5 \text { after } \\
\text { two-year leaching }\end{array}$ & 670 & $100 \pm 2$ & $0 \pm 2$ & Leaching in the IDF solution \\
\hline $\begin{array}{l}{ }^{99} \text { Tc-goethite sample } 2-5 \text { after } \\
\text { three years reacting }\end{array}$ & 1005 & $100 \pm 1$ & $0 \pm 2$ & $\begin{array}{l}\text { Two-year leaching in the } \\
\text { IDF solution }+ \text { one year in } \\
\text { air }\end{array}$ \\
\hline
\end{tabular}

(a) Time indicates "total time" between sample preparation and XAFS data collection.

(b) These values represent the fraction of the total Tc assumed to be present as the designated species. The sum of all species is 1.0. $\mathrm{Tc}(\mathrm{IV})=\mathrm{TcO}_{2} \bullet 2 \mathrm{H}_{2} \mathrm{O}$ and $\mathrm{Tc}(\mathrm{VII})=\mathrm{TcO}_{4}{ }^{-}$.

(c) These XANES spectra and information were obtained from Um et al. $(2011,2012)$.

\subsection{Conclusions}

Based on the results of this study, the following conclusions were drawn:

1. Mineral transformation of three synthesized Fe (oxy)hydroxide minerals [ferrihydrite, magnetite, and $\left.\mathrm{Fe}(\mathrm{OH})_{2}(\mathrm{~s})\right]$ was tested under various conditions of $\mathrm{pH}$, temperature, and solution-to-solid ratios, and showed that a mixture of magnetite, maghemite, and goethite was obtained from that $\mathrm{Fe}(\mathrm{OH})_{2}(\mathrm{~s})$ transformation, while ferrihydrite transformed to solely goethite and very limited transformation of magnetite to maghemite was found.

2. No matter which Fe (oxy)hydroxide mineral was used as initial substrate material, a high slurry $\mathrm{pH}$ and high temperature condition was the best for forming more transformed products, including goethite.

3. ${ }^{99} \mathrm{Tc}$ removal from solution was possible with $\mathrm{Fe}(\mathrm{OH})_{2}(\mathrm{~s})$ presence even without adding aqueous $\mathrm{Fe}(\mathrm{II})$ because $\mathrm{Fe}(\mathrm{OH})_{2}$ (s) could provide aqueous $\mathrm{Fe}(\mathrm{II})$ to reduce ${ }^{99} \mathrm{Tc}(\mathrm{VII})$ to ${ }^{99} \mathrm{Tc}(\mathrm{IV})$ before being incorporated within the mineral structure of the transformation product. However, no significant 
${ }^{99} \mathrm{Tc}$ removal was found in the reactor solution with magnetite used as initial solid substrate because of very limited transformation from magnetite even under high $\mathrm{pH}$ and temperature conditions. Due to high $\mathrm{pH}$ condition ( $\sim 9-11.0)$ in a final reactor solution of transformation from $\mathrm{Fe}(\mathrm{OH})_{2}(\mathrm{~s})$, a surface adsorption mechanism cannot account for ${ }^{99} \mathrm{Tc}$ removal from this high $\mathrm{pH}$ solution, but after ${ }^{99} \mathrm{Tc}$ is reduced to ${ }^{99} \mathrm{Tc}(\mathrm{IV})$ its incorporation into the mineral structure of the transformed product is possible.

4. Mineral transformation from $\mathrm{Fe}(\mathrm{OH})_{2}(\mathrm{~s})$ to more stable $\mathrm{Fe}$ (oxy)hydroxide mineral can be used to remove ${ }^{99} \mathrm{Tc}$ even from an alkaline solution that is similar in concentration to a secondary or LAW off-gas scrubber waste stream. However, additional analysis of ${ }^{99} \mathrm{Tc}$ speciation in the final transformed product is still required to confirm ${ }^{99} \mathrm{Tc}$ incorporation within the mineral structure of transformed product.

5. Reductive capacity measurement of both ${ }^{99} \mathrm{Tc}$-goethite $2-2$ and 2-5 samples showed that a higher reduction capacity of $0.744 \mathrm{meq} / \mathrm{g}$ was found in ${ }^{99} \mathrm{Tc}$-goethite $2-2$, which was not prepared with additional armoring process, while the reduction capacity of $0.140 \mathrm{meq} / \mathrm{g}$ was found in ${ }^{99} \mathrm{Tc}$-goethite 2-5 sample that was prepared with additional armoring process. The ${ }^{99} \mathrm{Tc}$-goethite $2-2$ sample has more magnetite content than the ${ }^{99} \mathrm{Tc}$-goethite 2-5 sample, which is consistent with higher reduction capacity being measured in sample 2-2 than in sample 2-5 before leaching because more Fe(II) is present in magnetite as found in sample 2-2 than in sample 2-5.

6. Even after long-term leaching in the IDF pore water solution for two years, very limited amounts of ${ }^{99} \mathrm{Tc}$ and $\mathrm{Fe}$ (total) were detected in the leachates. The limited ${ }^{99} \mathrm{Tc}$ release was attributed to more stabilized ${ }^{99} \mathrm{Tc}(\mathrm{IV})$ present in the ${ }^{99} \mathrm{Tc}$-goethite lattice even after long-term exposure to oxygen, while zero detected $\mathrm{Fe}$ (total) concentration indicated that structure of the final goethite mineral was stable at the circumneutral $\mathrm{pH}$ condition germane to the IDF pore water.

7. ${ }^{99} \mathrm{Tc}(\mathrm{IV})$ that is reduced and incorporated within the goethite lattice is unlikely to be reoxidized to ${ }^{99} \mathrm{Tc}(\mathrm{VII})$, even when the final ${ }^{99} \mathrm{Tc}$ goethite product (sample 2-5) is exposed to oxidizing conditions for three years. The limited reoxidation and release of ${ }^{99} \mathrm{Tc}$ is attributed to ${ }^{99} \mathrm{Tc}(\mathrm{IV})$ being coprecipitated within goethite lattices and subsequently armored with additional goethite layers as well as to the chemical and structural stability of goethite in the circumneutral Hanford pore water solution, suggesting potential use of goethite as a low-temperature Fe oxide solid waste form. 



\subsection{References}

Ardizzone S and L Formaro. 1983. "Temperature induced phase transformation of metastable $\mathrm{Fe}(\mathrm{OH})_{3}$ in the presence of ferrous ions." Materials Chemistry and Physics 8(2):125-133.

Bondietti EA and CW Francis. 1979. "Geologic migration potential of Tc-99 and Np-237." Science 203:1337-1340.

Burke IT, C Boothman, JR Lloyd, FR Livens, JM Charnock, JM Mcbeth, RJG Mortimer, and K Morris. 2006. "Reoxidation behavior of technetium, iron, and sulfur in estuarine sediments." Environmental Science and Technology 40:3529-3535.

Darab JG and PA Smith. 1996. "Chemistry of technetium and rhenium species during low-level radioactive waste vitrification.” Chemistry of Materials 9:1004-1021.

Fredrickson JK, JM Zachara, DW Kennedy, RK Kukkadapu, JP McKinley, SC Heald, C Liu, and AE Plymale. 2004. "Reduction of TcO4- by sediment associated biogenic Fe(II)." Geochimica et Cosmochimica Acta. 68:3171-3187.

Geckeis VMH, E González-Robles, A Loida, C Bube, and B Kienzler. 2012. "Radionuclide behavior in the near-field of a geological repository for spent nuclear fuel." Radiochima Acta 100:699-713.

Gilliam TM, RD Spence, WD Bostick, and JL Shoemaker. 1990. "Solidification/ stabilization of technetium in cement-based grouts." Journal of Hazardous Materials 24:189-197.

Keith-Roach MJ, K Morris, and H Dahlgaard. 2003. "An investigation into technetium binding in sediments." Marine Chemistry 81:149-162.

Lee SY and EA Bondietti. 1983. "In technetium behavior in sulfide and ferrous iron solutions." Materials Research Society Symposium Proceedings 315-322.

Lukens WW, JJ Bucher, NM Edelstein, and DK Shuh. 2002. "Products of pertechnetate radiolysis in highly alkaline solution: Structure of TcO2•xH2O." Environmental Science and Technology 36:1124-1129.

Lukens WW, JJ Bucher, DK Shuh, and NM Edelstein. 2005. "Evolution of technetium speciation in reducing grout." Environmental Science and Technology 39:8064-8070.

Newville M. 2001. "IFFEFIT: Interactive XAFS analysis and FEFF fitting." Journal of Synchrotron Radiation 8:322-324.

Schikorr G. 1933. "The iron (II) hydroxide and a ferromagnetic iron (III) hydroxide." Zeitschrift für Anorganische und Allgemeine Chemie 212 (1): 33-39. doi:10.1002/zaac.19332120105.

Schwertmann U and RM Cornell. 1991. Iron Oxides in the Laboratory: Preparation and Characterization. VCH Publishers, Weinheim, Germany.

Skomurski FN, KM Rosso, KM Krupka, and BP McGrail. 2010. "Technetium incorporation into hematite $\left(\alpha-\mathrm{Fe}_{2} \mathrm{O}_{3}\right)$.” Environmental Science and Technology 44:5855-5861. 
Smith RW and JC Walton. 1993. "In the role of oxygen diffusion in the release of technetium from reducing cementitious waste forms." Materials Research Society Symposium Proceedings 247-253.

Ravel B and M Newville. 2005. "ATHENA, ARTEMIS, HEPHAESTUS: Data analysis for X-ray absorption spectroscopy using IFEFFIT." Journal of Synchrotron Radiation 12:537-541.

Um W, H-S Chang, JP Icenhower, NP Qafoku, SC Smith, RJ Serne, EC Buck, RK Kukkadapu, ME Bowden, JH Westsik, Jr., and WW Lukens. 2010. Immobilization and Limited Reoxidation of Technetium-99 by Fe(II)-Goethite. PNNL-19833, Pacific Northwest National Laboratory, Richland, Washington.

Um W, H-S Chang, JP Icenhower, WW Lukens, RJ Serne, NP Qafoku, JH Westsik, Jr., EC Buck, and SC Smith. 2011. "Immobilization of 99-Technetium (VII) by Fe(II)-Goethite and Limited Reoxidation." Environmental Science and Technology 45(11):4904-4913.

Um W, HS Chang, JP Icenhower, WW Lukens, RJ Serne, NP Qafoku, RK Kukkadapu, and JH Westsik. 2012. "Iron oxide waste form for stabilizing ${ }^{99}$ Tc." Journal of Nuclear Materials 429:201-209. 


\section{Distribution*}

No. of

$\underline{\text { Copies }}$

OFFSITE

6 Savannah River National Laboratory

AD Cozzi

GP Flach

KM Fox

CM Jantzen

DI Kaplan

CA Langton

1 Oak Ridge National Laboratory

EM Pierce
No. of

Copies

ONSITE

2 U.S. Department of Energy Richland Operations Office

RD Hildebrand

JG Morse

4 U.S. Department of Energy Office of River Protection

JA Diediker

BJ Harp

BM Mauss

SH Pfaff

5 Washington River Protection Solutions

KA Colosi

TH May

MA Melvin

KE Smith

DJ Swanberg

8 Pacific Northwest National Laboratory PR Bredt

HB Jung

RA Peterson

LM Peurrung

RJ Serne

W Um

G Wang

JH Westsik, Jr.

*All distribution will be made electronically. 


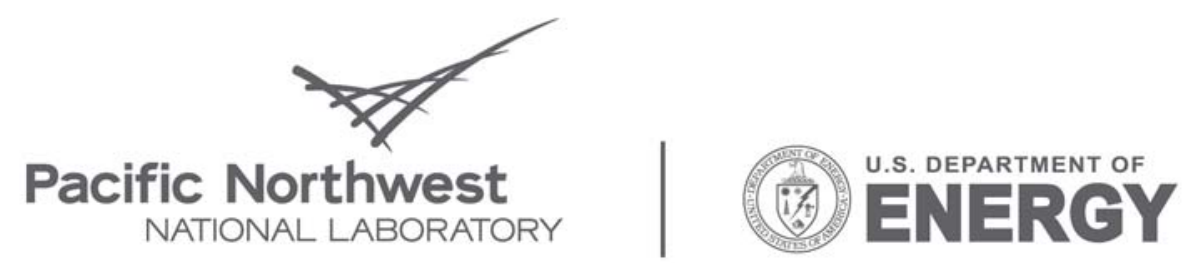

Proudly Operated by Battelle Since 1965

902 Battelle Boulevard

P.O. Box 999

Richland, WA 99352

1-888-375-PNNL (7665)

www.pnl.gov 